The Ethics of Biomedical Enhancement Research

by

\author{
Ben Trainor
}

A thesis submitted to the Faculty of Graduate and Postdoctoral Affairs in partial fulfillment of the requirements

for the degree of

Master of Arts

in

Philosophy

Carleton University

Ottawa, Ontario

(C)2014

Ben Trainor 


\title{
The Ethics of Biomedical Enhancement Research
}

\author{
Ben M. Trainor
}

Abstract

Biomedical enhancement interventions require a departure from the justificatory routes typically available to biomedical research, focusing on making individuals "better than normal" instead of treating those who are impacted by illness and disease. Discussion of the ethical implications of such interventions has primarily been done in bioethics and political philosophy, but the questions concerning the ethical practice of enhancement are substantially different than those concerning the research. This thesis will focus on the ethical questions pertinent to biomedical enhancement research, including an examination of the arguments from enhancement opponents as applied to research ethics and an assessment of the values promoted through such research. Furthermore, it shall attempt to elucidate the values motivating biomedical enhancement research so as to better recognize the justifications behind exposing trial participants to health risks and to develop a strategy for mitigating practical problems linked to prioritization in enhancement and treatment research. 


\section{Table of Contents}

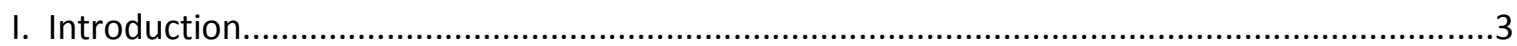

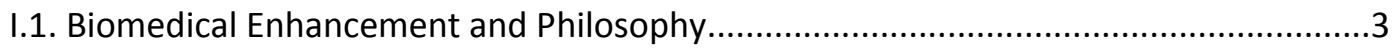

I.2. Initial Reactions Concerning Biomedical Enhancement...............................................

I.3. Eugenics and Biomedical Enhancement Research..................................................

I.4. The Role of Research Ethics and Biomedical Enhancement.........................................13

II. Research Ethics and Human Enhancement: A Taxonomy of Concerns.....................................17

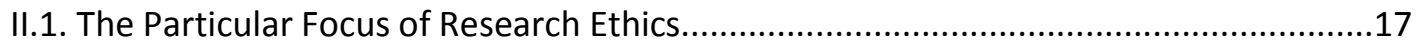

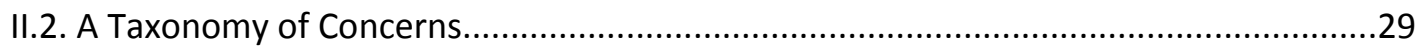

III. Research Ethics-Related Concerns and Biomedical Enhancement Research...............................33

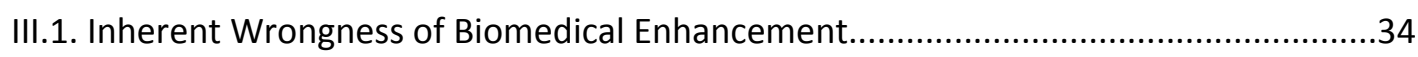

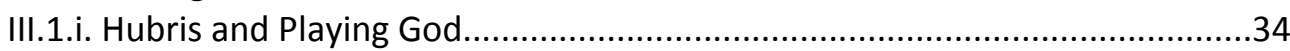

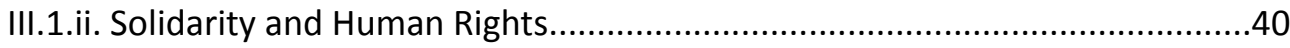

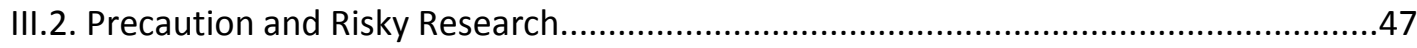

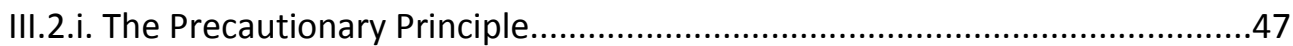

III.2.ii. Concerns with the Precautionary Principle................................................54

III.2.iii. An Alternative to the Precautionary Principle.............................................59

III.2.iv. Weakening the Proactionary Principle..................................................63

III.3. Trial Participants and Enhancement Research..........................................................66

III.3.i. Challenges from the Risk-Benefit Criterion................................................67

III.3.ii. Exploitation of the Developing World........................................................

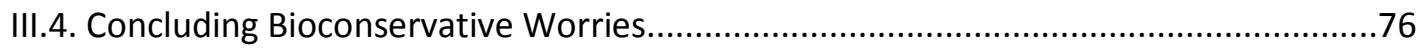

IV. The Positive Case for Enhancement Research and Development...........................................77

IV.1. The Permissibility of Enhancement Research and the Risk/Benefit Criterion...............79

IV.1.i. Health Risks and Enhancement-Related Benefits......................................79

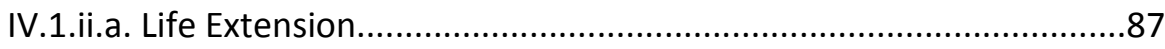

IV.1.ii.b. Cognitive Enhancement......................................................93

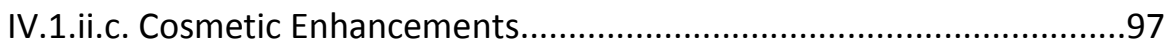

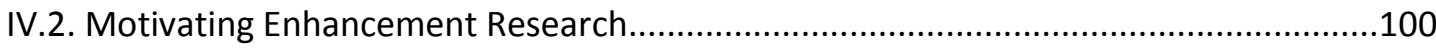

IV.2.i. Adaptability and Meeting the Competing Claims of Justice...........................100

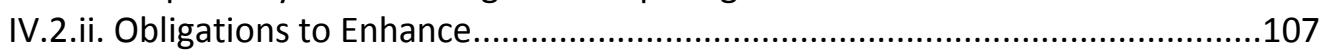

IV.2.iii. Improving on the Human Condition........................................................110

IV.3. Priority, Proaction and State Responsibilities in Enhancement Research.....................116

IV.3.i. The Prioritization Problem and Treatment Research...................................116

IV.3.ii. State Responsibilities and the Promotion of Enhancement Research..........121

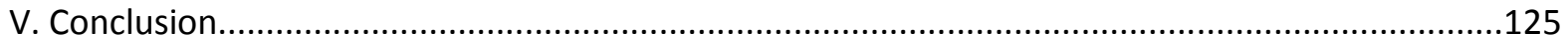




\section{Introduction}

\section{I.1. Biomedical Enhancement and Philosophy}

While the prospect of using technological innovations to improve the human condition is far from new, recent advances in medicine have raised concerns with respect to the intentional intervention and modification of important features of the human species. As the so-called "identity constituting characteristics" (Buchanan, et al. 2000, 85) of humanity increasingly become the target of biomedical intervention, the adequacy of the moral and legal frameworks meant to protect individuals and promote values of social importance will be tested and any shortcomings are likely to be highlighted in the light of failures to carry out that mandate. Unfortunately, many of the worthwhile developments in bioethics and research ethics have been motivated primarily by such past failures. From Tuskegee to the atrocious research done by the Nazis and Japanese of the $20^{\text {th }}$ Century to the oftentimes problematic relationships between first world research institutions and vulnerable test participants in the developing world, ethicists and policymakers seem to be playing catch-up all too often. Whereas many of these inadequacies might be explicable given the challenges in anticipating the particular moral problems that might arise in such complex areas as research involving human subjects, they also, I think, serve as a strong reason for improving foresight and expanding the role of futures research in anticipation of such impending challenges.

Many of the ethical issues in human enhancement research recognized in contemporary bioethics were, in part, foreshadowed by the debates that arose in the 1980 s and 90 s concerning the Human Genome Project (Buchanan, et al. 2000, 5). A massive undertaking at the time, the project brought many relatively new ethical issues to the fore including the patenting of genes, the relationship between gene sequencing, protecting individual privacy and control of genetic information (Wiesenthal and Wiener 1996), the extent to which insurance risk pools can be sensitive to genetic preconditions, and the role that genetic heritage plays in the personal identity and self-perception of individuals 
(Juengst 1992). While such questions share some characteristics with more traditional questions about privacy, individuality and discrimination, the rather unclear relationship between an individual and their genetic information and the extent to which the use of such information by a third party encroaches on individual rights make the answers to these moral challenges all the more difficult to ascertain.

All that being said, the unprecedented capacity to make substantial modifications to the human condition presents new challenges for the regulatory and ethical frameworks that are meant to keep technological advancements in check. The moral concerns with respect to enhancement that are likely to arise within the coming decades are no longer primarily about the control and use of genetic information, but rather are about the employment of modern medicine for the purposes of intentionally modifying individuals with a particular end in mind. Any mishandling of genetic information and violations of privacy rights are certainly grievous, but the potential for violating the bodily integrity and autonomy of individuals through biomedical enhancement interventions is all the more daunting and deserving of informed, careful analysis before the proliferation of these technologies results in a situation in which those in the ethics community are left scratching their heads and wondering where things went wrong. Working with the benefit of hindsight might offer additional clarity in these murky issues, but such work begins with the acknowledgement that something has already gone deeply wrong, and such failures are unacceptable when we're discussing such serious moral hazards as intentional biomedical interventions for the purposes of modifying individuals' identity constituting characteristics. It is imperative, then, that we proceed with careful attention to any foreseeable, potential hazards and resist the temptation to leave such questions on the sideline and wait for certainty as to precisely what the technology is capable of before making strides in our ethical analysis.

A further temptation is worth dissuading; namely, the relegation of some of these advancements to the realm of science fiction (even if this designation is appropriate in some cases). It is 
becoming increasingly difficult to deny the array of enhancements on the horizon. A few examples of biomedical enhancements currently in development are:

\section{Life Extension}

- The pursuit of negligible senescence to radically extend the human lifespan (de Grey and Rae 2007).

- The use of infusions of younger blood and the protein GDF11 to mitigate the effects of aging (Frazer 2014).

- Cryonics research for suspending individuals in biostasis after they have undergone personal and biological death with intension of reanimating them in the future (Alcor Life Extension Foundation 2014).

\section{Cognitive Enhancements}

- DARPA is spending $\$ 100$ million per year on enhancing human resilience against sleep deprivation (Mehlman, et al. 2011, 30).

- Interventions directed toward the 779A allele for the TPH gene for the purposes of improving impulse control (Lev, Miller and Emanuel 2010, 109).

- The use of dopamine, cholinergic drugs, and noradrenergic agonists to improve human memory, spatial planning, and "reaction time/latency on different working memory tasks." (Bostrom and Sandberg, Brain Boosters 2009, 132).

- Attention and cognition-boosting pharmaceuticals such as Adderall and Modafinil typically prescribed to those who suffer from attention-deficit disorders are becoming increasingly prevalent on college and university campuses as students make use of them for cognitive enhancement purposes (Gould 2009).

Far from science fiction, these enhancements are being actively pursued as their development is being strongly incentivised by both military and private interests and the examples above represent an extremely limited sample of the innovations that are likely to become available to this generation. To brush them aside as science fiction is worse than unhelpful, as it risks also blinding oneself to the real concerns that come with these technologies. Some of these concerns were first brought to light in the initial reaction of different communities over the past few decades to the prospect of human enhancement becoming a real possibility, and are, I think, worth introducing here not only because of the legitimacy of some of the concerns expressed, but also because this initial reaction has done much in establishing the context in which the current debate over enhancement technology is taking place. 
With this in mind, this thesis will be examining the arguments that have been forwarded in the ongoing debate between Bioconservatives and Transhumanists concerning the justifiability of human enhancement research in an attempt to anticipate possible concerns that may arise in its development as well as identify the role that it plays in promoting key values in modern society. To do this, Section II will propose a taxonomy of enhancement research-related concerns that distinguishes them from proliferation concerns while also noting important differences between arguments that target enhancement research as a general activity and arguments that highlight concerns that might arise within enhancement-related research trials themselves. Section III.1 will exposit and assess the former of these arguments concerning enhancement research, specifically those that attempt to make the case that human enhancement research represents the kind of activity in which society ought not to engage for reasons related to its inherent wrongness, undermining of human rights, and the undermining of what is naturally "given". Section III.2. will examine the role that the precautionary principle and the proactionary principle might play in this discussion, as they represent a more general approach to policymaking in the face of uncertainty and risk that will be relevant to the permissibility and motivation of enhancement research. The precautionary principle has been employed by a number of bioconservatives to object to certain kinds of enhancement interventions and research, attempting to "bridge the gap" between proliferation and research-based concerns, but it is not without problems of its own, and I will suggest that a proactionary approach might be better suited to the assessment of enhancement-related research.

Section III.3. will be focused on the concerns that arise within enhancement-related research trials, specifically the problems with justifying the imposition of health risks on healthy trial participants and the prospect of exploitation of the developing world in the context of globalized biomedical research. The problems raised with respect to the conduct of research trials are certainly cause for concern, but I do not believe them to be insurmountable nor sufficient reason to restrict enhancement 
research, insofar as they are appropriately recognized and the value of enhancement research more formally understood. The latter of these requirements will be my focus in Section IV., where I will endeavour to make a case for enhancement research that does not rely on the purely proliferationbased benefits that are often highlighted in pro-enhancement arguments or on the ancillary benefits that might be realized as side-effects of enhancement research, first by looking at its permissibility given the risks involved, the motivations given the values of adaptability and expanding the domain of justice promoted through enhancement research, and finally by briefly considering the justifiability of state contributions to the enhancement project. This final section will also examine problems related to the automatic prioritization of treatment research over enhancement, which threaten, in part, to incentivize researchers to deceive REBs for the sake of their enhancement research. Ultimately, despite the concerns of numerous bioconservative commentators, the intuitive appeal of prioritizing treatment research, and the substantial risks involved in developing enhancements, I do believe certain kinds of enhancement research to be justified, worth pursing, and, in some cases, worthy of state funding.

\section{I.2. Initial Reactions Concerning Biomedical Enhancement}

The technological optimism of the $20^{\text {th }}$ Century heralded human enhancement as a possible solution to all sorts of social ills and personal limitations. While science fiction writers dreamed of technological utopias and dystopias, commentators began examining the prospect of human enhancement in a more down-to-earth, critical light. Anticipating some of the discussion still going on today, British biochemist J. B. S. Haldane wrote in 1923 about the possibility of ectogenesis and using genetic technology to improve on human health and cognition and J. D. Bernal reflected on bionic implants in 1929 (Bostrom 2005, 5). This optimism eventually became manifested explicitly in the Transhumanist movement of the late 1980s to the present, as their so-called "Extropian"1 forbearers

\footnotetext{
${ }^{1}$ The Extropians were a hyper-optimistic group of commentators who, in the early 1990's took advantage of the ease of collaboration offered by the new Internet to discuss a host of issues related to human enhancement and
} 
lauded "dynamic optimism" in the effort to radically improve the human condition and unlock what they regard as humanity's potential that heretofore has gone unrealized (Bostrom 2005, 15, 26).

Contemporarily, philosophers such as Nick Bostrom, David Pearce, Julian Savulescu, Nicholas Agar, and James Hughes have argued vigorously for the development of these technologies, emphasizing the significant benefits that would likely come with a greater mastery of the biology that is so constitutive of the human condition.

The other end of the spectrum, the bioconservative reaction has resisted the potential solutions offered by human enhancement, highlighting instead the perils that await those who meddle in such fundamental aspects of humanity and working to demonstrate the problems that come with such bruteforce methods of attending to social problems. As this banner was taken up by bioconservative groups that had been active in the biopolitical arena for some time, it's hard to disagree that the bioconservative reaction to the prospect of human enhancement has been more organized and wellfunded than the advocacy of enhancement proponents (Hinsch 2010,68). Their verdict has been largely in opposition to the development of these technologies that they view as a threat to human dignity and the functioning of a good society. Among the interest groups leading the charge, the National Catholic Bioethics Center (NCBC), the Center for Bioethics and Culture ( $C B C)$, the Bioethics Defense Fund (BDF), and the Center for Bioethics and Human Dignity (CBHD) have all released numerous documents arguing against everything from human cloning and ectogenesis to stem cell research and physician-assisted death (Hinsch 2010, 71). In 2001, the criticisms mounted against the human enhancement project were given prominent light as then-president George W. Bush Jr. assembled a council on bioethics that was to be headed by the prominent bioconservative Leon Kass for the purposes of analysing enhancement technology as an enterprise and advising policy. Their report was, predictably, strongly against the 
development of biomedical interventions for the purposes of enhancing certain human capacities in large part because of the perceived threat to human dignity, our collective "appreciation of and respect for the 'naturally given'", and the likelihood that human enhancement would undermine the concept of human achievement (The President's Council on Bioethics 2003). Since this report, the analysis of the ethical problems in human enhancement has become more broadly regarded as something for which philosophers' expertise is relevant and needed.

\section{I.3. Eugenics and Biomedical Enhancement Research}

Eugenics-related concerns are most relevant to the practice of human enhancement as the biomedical advancements made during the late $19^{\text {th }}$ and early $20^{\text {th }}$ Centuries were coupled with the "ethnocentrism and blindness to class interests" that led to eugenic policies that violated individual liberties in a profound fashion (Peters 1995, 371). The eugenics movement sought the "betterment of society" by taking a particular conception of the human good and aimed to make use of biomedical interventions to ensure that individuals conform to that particular image. This kind of perfectionist project is precisely the kind of imposition by society ${ }^{2}$ that the more individualistic, rights-based approaches to medical and research ethics seeks to counter - individuals differ in their conceptions of the good and medical decisions are subject to this subjective evaluation. So, even if some argument could be mounted in favour of a particular conception of the good over others, it is unlikely that a case could be made in favour of imposing that conception of the good, especially if the means involves the violation of the individual's bodily integrity or autonomy through biomedical intervention.

With respect to the proliferation problems of which the eugenics movement was clearly guilty, Buchanan et. al offer five theses as explanations for its unacceptability: (a) replacement not therapy, (b)

\footnotetext{
${ }^{2}$ I say this in recognition of the fact that eugenic concerns are not necessarily tied to state action. "Backdoor eugenics", as described by Duster (1990), refers to eugenic practices motivated largely by social movements made up of individual medical decisions that, collectively, have eugenic consequences (Buchanan, et al. 2000, 51).
} 
value pluralism, (c) violations of reproductive freedoms, (d) statism and (e) justice. Of these, (b), (c), and

(e) appear to be the most plausible and the moral wrongness of eugenics likely has something to do with some combination of the three. (a) Proposes that the real problem of eugenics is that it seeks the betterment of future generations exclusively, that is, the eugenicist's goal of "improving the human race" seeks only to "cause better people to be conceived and born" but does very little to improve conditions for those already alive (Buchanan, et al. 2000, 46). I find it hard to believe both that this could be the motivation behind the moral outrage that people express when talking about eugenics and that this could plausibly be at the core of what is wrong with eugenic practices. Plenty of policies are primarily directed toward improving conditions for those who do not yet exist (climate change mitigation policies, for example), and the fact that the benefits that they offer to those currently alive are indirect at best seems nowhere near sufficient to capture the moral wrongness of eugenics (Buchanan, et al. 2000, 46).

More plausibly, (b) proposes that the moral issue with eugenics is its imposition of a particular conception of the good on those who might reasonably disagree with that conception in favour of some other view. I largely expressed this worry above, describing it as a perfectionist project that does not properly take into account the legitimate differences in personal preference and selection of life paths. Value pluralism in the realm of subjective preference with respect to life paths is a central feature of liberal political theory and it is clear that eugenics programs violate this in a profound fashion. This view of value pluralism will be important again in Section III.1.iii. in our discussion of solidarity and diverging life paths, but the point here is that a just society ought to be tolerant ${ }^{3}$ of differences in personal preference, and many of the eugenic practices of the $20^{\text {th }}$ Century were clearly anything but.

\footnotetext{
${ }^{3}$ Of course, that is not to say that there are no limits to toleration. The literature on the legitimate limits of toleration with respect to individual preferences is extensive, but at the very least some line can plausibly be drawn where the liberties of other rights-bearing individuals begin.
} 
Instead of basing its claim on the way in which society ought to treat differences in subjective preference, (c) takes a more deontological approach to describing the moral wrong of eugenics by appealing to the rights that individuals bear with respect to reproduction. As eugenicists attempted to "breed" what they believed to be a superior race of human, coercive sterilization violated the bodily integrity of thousands of rights-bearing individuals and forcibly restricted them from life paths involving reproduction (Buchanan, et al. 2000,50). Such an approach to the "betterment" of human society runs contrary to nearly all of the modern developments in research ethics, as the individual rights-bearing agent became the atom of ethical analysis and limitations on state action were developed to ensure that policies that are purportedly in the interest of society do not automatically trump the rights of particular members.

The statist thesis, (d), was initially argued for by James Watson, claiming that the real problem with eugenics practices is the involvement of the state. He argues that the most serious wrongs associated with eugenics would not have been possible without the state, as "institutionalization, sexual segregation, sterilization, and, in Germany, murder on a mass scale" all require state mechanisms and state action if they are to be effective in the violation of individual rights for the "betterment" of the human race (Buchanan, et al. 2000, 51). In his view, the key to permissible eugenics is to prohibit state involvement, presumably in favour of a more "grass roots" approach to genetic improvement (ibid.). That said, it is difficult to see exactly why state involvement is necessary for eugenics to be morally wrong, as individuals violate other individuals' rights and make unacceptable impositions on others' autonomy all the time. If we hope to ensure that individuals are self-determining in the sense that they can freely choose the life paths that interest them, then the prospect of "grass roots" eugenics should be equally worrying as it certainly undermines this value. Eugenics that stems from coercion by social groups is just as worrying as eugenic state practices, and so the state's responsibilities with respect to preventing the rise of eugenics would surely extend beyond careful policymaking and into the 
protection of individuals from eugenics more broadly ${ }^{4}$. As such, it seems doubtful that the moral wrong of eugenics is to be found merely in the state's contributions; eugenics done by the state or by social groups is to be condemned and the state's responsibilities to the protection of its citizens should recognize this.

Finally, thesis (e) bases its claim on the unequal and unjust distribution of the benefits and burdens entailed by eugenic practices. Eugenicists tend to target particular groups of individuals for segregation and stigmatization, categorizing them as a kind of "underclass" that purportedly ought to make personal sacrifices so as to benefit the social groups favoured by the eugenicists (Buchanan, et al. 2000,52 ). Furthermore, this unjust stigmatization and imposition of burdens tended to be motivated by misguided beliefs about the relationship between heredity, socioeconomic class, and social ills such as crime, unemployment and disease (ibid.). Nowadays it is generally (if not almost universally) understood that heredity and race are not the underlying cause of such social ills, but rather the fault lies with the systemic injustices and social practices that take disadvantage of particular social groups on the basis of arbitrary human characteristics. Eugenic practices meant to forcibly undermine and breed out arbitrary characteristics such as race and heredity impose burdens on the stigmatized social group for no good reason, as they do little to combat the social ills that purportedly motivate such practices.

Importantly, none of these arguments target biomedical research, but rather point out serious concerns that arise when it comes to the proliferation of technologies that seek to improve on certain human characteristics. Whether the real concern is rooted in the undermining of value pluralism, the rights of individuals or the unjust allocation of benefits and burdens, the real eugenics concerns come about when the newly developed intervention is imposed on individuals for the sake of advancing the interests of society or the state. None of these arguments make the case that the problem has to do

\footnotetext{
${ }^{4}$ As Buchanan et al. rightly point out, lack of state involvement might even be worse as the state ends up prohibited from intervening and protecting those made vulnerable by eugenic social movements (Buchanan, et al. 2000, 51).
} 
with the concept of betterment ${ }^{5}$, as the thought behind making use of medical advancements for improving on particular aspects of the human condition might be laudable when those interventions are distributed in a just fashion. While it might perhaps be argued that the state shouldn't be developing capacities that might conceivably allow it to engage in eugenics ${ }^{6}$, this would be a problematic route in large part due to the fact that both treatment and enhancement interventions can be imposed through eugenic practices. Indeed, it might be said that the central goal of biomedical research involves attempts at betterment so defined, so I think it clear that the unacceptability of eugenics is found in the manner in which such interventions are distributed forcefully through coercive practices.

\section{I.4. The Role of Research Ethics and Biomedical Enhancement}

While many bioethicists and political philosophers have taken up the charge of having to grapple with some of the anticipated moral problems with human enhancement technologies, research ethicists (with some notable exceptions) have been relatively quiet on the matter (Mehlman, et al. 2011, 30). If this is due to the "science fiction" feel of the proposed enhancement technologies, then, as I said above, I believe this to be a dangerous error that risks underestimating the pace of technological development in the $21^{\text {st }}$ Century and fails to appreciate the seriousness of the moral hazards posed by these technologies. If, however, the explanation is that the moral problems posed by enhancement technology are not new and can be met using the same policies and methods currently used for dealing with moral hazards in the researching of biomedical treatment interventions, then work needs to be done in showing how these are relatively novel problems whose solutions are not so easily found in the existing literature. Section II.2 of this thesis will endeavour not only to provide a taxonomy of different moral and political views regarding human enhancement, but also to demonstrate the difficulties found

\footnotetext{
${ }^{5}$ That said, we will be examining arguments in Section III.1.ii and III.1.iii that make a case like this, but these arguments are not necessarily committed to making a eugenics-style argument.

${ }^{6}$ Somerville seems to want to make a case similar to this in her objections to therapeutic cloning when she expresses concerns surrounding the capacity for the state to "disenhance" certain individuals for the benefit of society at large (Somerville 2004, 79).
} 
in attempts to answer these enhancement issues without further developing the moral and legal frameworks that are used to address problems in treatment research. Simply, this is a claim that I will emphasize throughout this thesis, namely, that theories designed to deal with treatment research are going to be insufficient for dealing with the unique questions and concerns that arise in enhancement research.

Still, as the debate over the ethics of biomedical enhancement trudges forward, different enhancement interventions are being developed and driven onward by significant pressure from private interest and market forces. While the enhancement research of today is relatively modest in nature, these enhancement interventions are undoubtedly a sign of things to come for as the science of enhancement becomes better understood and the tools more precise, research into more radical forms of enhancement are not far behind ${ }^{7}$. Most of the work done assessing the risks that come with human enhancement has focused on the impact that the proliferation of this technology may have on human society, arguing over the benefits and perils that we may expect to see as individuals take advantage of these novel interventions. At the same time, federal regulations in the United States state that research ethics boards should refrain from including the "possible long-range effects of applying knowledge gained in the research" in their analyses, as it lies beyond the scope of their ethical analysis of the research in specific ${ }^{8}$ (Mehlman, et al. 2011, 34). Section II.1 of this thesis will examine some of the reasons why REBs and research ethics in general should not take on the responsibility of accounting for each of the possible consequences of the development of enhancement technology.

\footnotetext{
${ }^{7}$ Further, it might be worrying to note that the fact that today's enhancement research seems so modest in nature indicates that the more radical forms that are coming will, in their time, be regarded as modest as well. These technologies have the potential to sneak up on those who are accustomed to the technology of their day. ${ }^{8}$ See the American Federal Regulations 45 CFR 46.111 (a).2. It is worth noting that Mehlman considers this policy problematic and that REBs should have the responsibility for engaging in this kind of practice-based analysis. I have my reservations about Mehlman's view here, which will be expressed in Section II.1.
} 
Even still, there is an abundance of challenges that the enterprise of human enhancement poses to the ethical frameworks from which individuals make their moral assessments and the social meaning of some of the human features and aspects of the human condition that are to become the objects of intervention and modification ${ }^{9}$. From the perspective of research ethics in particular, many of these concerns are captured by the benchmark for ethically sound biomedical research referred to as "social value" (E. J. Emanuel, et al. 2008, 126), a rather broad criterion meant to solidify the relevancy of certain bioethical concerns to the initial ethical evaluation of biomedical research trials. According to this benchmark, if the risks that biomedical research brings to bear on research participants are to be justified, then this benchmark asserts that such research ought to have some kind of value for the betterment of health or health care generally (E. J. Emanuel, et al. 2008, 127). The full suite of benchmarks typically regarded as necessary for the moral acceptability of biomedical research are:

1. Collaborative Partnership

2. Social Value

3. Scientific Validity

4. Fair Participant Selection

5. Favourable Risk-Benefit Ratio

6. Independent Review

7. Informed Consent

8. Respect for Participants (E. J. Emanuel, et al. 2008, 126).

We will delve into these benchmarks' relevance to biomedical enhancement research more specifically in the coming chapters, but for now it suffices to say that these benchmarks are central to the analysis of research trials' ethical soundness. Insofar as we are analysing the research into biomedical enhancements, these benchmarks will be applicable and a trial's failure to meet any of them will call that trial's ethical soundness into question. When it comes to the development of enhancement technology and the role of research ethics with respect to the proliferation concerns, the scope of the social value criterion is difficult to assess. I think this is in large part due to the difficult distinction

\footnotetext{
${ }^{9}$ The abundance of these concerns does not, of course, give any indication of the legitimacy of these concerns, although it isn't an outlandish assumption that some of the concerns will be legitimate and deserving of attention.
} 
between assessments of a research trial's social value and the risks posed to particular social values by the proliferation of enhancement technology. This distinction will, I hope, be made clearer in Section II.1. where we will be distinguishing research ethics from other ethics subfields, which will require a more thorough examination of the distinction.

More importantly for our purposes, given the nature of some of the bioconservative objections to human enhancement, it could be the case that enhancement research simply cannot meet all of these benchmarks since a failure to meet a particular benchmark is entailed by enhancement research. For this reason, we must distinguish which objections, if successful, would be sufficient to make such a case and examine both their plausibility and their relationship to these eight ethical benchmarks. Given the important similarities between many of these bioethical objections, I think a careful categorization of the objections based on their important features would be fruitful, not only to clarify what is a challenging and often confused discussion but also to clarify what their implications for the research into biomedical enhancements in particular ${ }^{10}$. This taxonomy will be our central concern in Section II of this thesis and, once the objections are properly identified and categorized, they will be addressed and assessed in Sections III and IV.

First though, a final point deserves mention concerning a very serious worry that faces biomedical enhancement research should its proponents fail to provide an adequate positive case for this kind of research. If the positive case for enhancement research is lacking or unconvincing and treatment research is given priority automatically, then there is good reason to worry about biomedical enhancement research masquerading as treatment research (Mehlman, et al. 2011, 32). This concern problematizes the structure that would follow from giving automatic priority to treatment research and

\footnotetext{
${ }^{10}$ As we will see, I think that distinguishing between the ethics of research into biomedical enhancements and the practice or proliferation of biomedical enhancements is fruitful not only for division of labour and clarificatory purposes, but also because there is a substantive difference between the kinds of justificatory routes available to the debate over the research as opposed to the practice.
} 
the often dual-use nature of enhancement research - many enhancement research projects can be described in terms of the benefits they could have for treatment interventions and describing them as enhancement research, if treatment research is given automatic priority, would disadvantage the trial from the outset. Such a scenario would incentivise researchers to characterize their enhancement research in treatment terms so as to pass independent review or secure funding, and make for a dangerous set of conditions in which enhancement research must be done through the evasion of the careful oversight of independent review panels. I think we ought to be honest in our enhancement research, especially if the above scenario is wholly unnecessary as a legitimate positive case can be made for enhancement research that doesn't rely on treatment-based social benefits or the proliferation of enhancement technology for its justification. Section $\mathrm{V}$ of this thesis will attempt to motivate certain kinds of enhancement research by identifying and justifying particular criteria for the development of ethically sound and motivated enhancements.

\section{Research Ethics and Human Enhancement: A Taxonomy of Concerns II.1. The Particular Focus of Research Ethics}

To isolate the concerns that are relevant to research ethics in particular, we must first look at the mandate of research ethics and how it differs from bioethics and political philosophy and why it should differ as a field within practical ethics with particular concerns and justificatory methods. This is, then, not only a descriptive project - describing the origins of research ethics and pointing out how it has manifested itself as a field in its own right - but also a normative one as certain justifications might be more acceptable in research ethics than in political philosophy or bioethics more generally. Some of the reasons for this difference in acceptable justificatory routes is, at least in part, a consequence of the complex relationship that exists within biomedical research between the protection of research trial participants as autonomous, rights-bearing agents, the role-specific obligations of researchers and other involved medical professionals, the experimental, risky and uncertain nature of research trials and the 
interests of the state and society as a whole. This section will focus on distinguishing research ethics from its neighbouring subfields in ethics and, once the distinction is made clear, we may begin to examine what properties an argument must have to be properly an argument that concerns research ethics in particular.

Firstly, I want to distinguish three broad reasons why research ethics ought to be treated as its own distinct field that handles specific concerns that fall within a well-defined mandate, and once we have adequately isolated research ethics for analysis, we may look at the different kinds of concerns expressed regarding enhancement technology and their relationship to research ethics.

Social Benefit-Oriented Justification of Research Trials: The first broad reason for distinguishing the concerns of research ethics from those of other practical ethics subfields is the socially-oriented or collective nature of the ultimate justification of biomedical research trials' imposition of risk onto participating subjects. Trial participants consent to a degree of risk when undergoing a scientific trial, and the determination of REBs concerning whether the risk is adequately justified will hinge largely on the kind of generalizable knowledge that the trial can be reasonably expected to produce (King and Churchill 2008, 514). Trial participants can be deceived, given substandard care, exposed to substantial health risks, and incentivized to consent to such risks, all insofar as those risks were minimized as much as possible and there is a potential for sufficient social value being gleaned from the research ${ }^{11}$. This broad collectivist justificatory route takes us away from the more common individualistic justifications normally seen in liberal approaches to analysing the normative grounds of state activities. Still, however, the $20^{\text {th }}$ Century saw substantial changes to the way in which research is justified that ensured that the individual's self-determination remains an important factor in the considerations of REBs. This

\footnotetext{
${ }^{11}$ I do not mean to imply here that these practices are uncontroversial, but rather that they are generally regarded as being acceptable under certain, specific circumstances.
} 
tension is especially prevalent in research ethics, and to understand it requires an understanding of the role that research participants play in scientific research.

The individual-centric route of attempting to justify a research trial by appeal to the direct benefits that a trial participant might accrue from experimental and unproven interventions risks running afoul of the therapeutic misconception and mischaracterizing the goals and intentions of the research trial (E. J. Emanuel, et al. 2008, 634). The therapeutic misconception is a well-documented phenomenon ${ }^{12}$ occurring within research trials, describing trial participants' predisposition toward the mistaken belief that the trial design and decisions about their treatment within the trial will be made within the context of their personal condition and needs and the trial's success will be assessed on those grounds (Appelbaum and Lidz 2008,633). Such a view might be appropriate in clinical medicine where the physician is committed to the "principle of personal care" ${ }^{13}$ which ensures that the physician's deliberations are informed and motivated by the patient's interests, but research trials are designed to produce specific data without overstepping the ethical benchmarks that are in place to protect those trial participants. For this reason, the benefits that might accrue to a trial participant are not good grounds for justifying the research trial - trials are carried out with the general public good in mind and our justifications should reflect that fact.

A more plausible route for justifying a research trial by appeal to the benefits that might accrue to the participants is to rely on the benefits those individuals might accrue as members of a society enriched by the results of the research trial. While this preserves the individual-centric nature of most ethical analysis, it still misidentifies the actual goals of the research and produces counterintuitive results in particular cases. If we relied on the benefits individual trial participants might accrue as

\footnotetext{
${ }^{12}$ See also: Appelbaum (2004) and Miller (2006) for more on the frequency and prevalence of the therapeutic misconception.

${ }^{13}$ This principle gets its name from legal philosopher Charles Fried and serves to solidify the primacy of the patient's interests when it comes to decision-making in medical care (Appelbaum and Lidz 2008).
} 
members of a society enriched by the research trial, then certain trials would have to be precluded if the individuals taking the risks as trial participants will not be privy to the benefits. For example, trials that involve terminal patients that might not have the prospect of them benefiting from the knowledge produced by the research would have to be seen as exploitative as the risks taken by the participants cannot be justified by appeal to the benefits they would accrue. The risks individuals take as trial participants are for the social good; they aim to help produce information that would add to the set of capacities available to the society to deal with particular health problems.

One must be careful not to go too far in the privileging of social benefits, however, as developments in the $20^{\text {th }}$ Century in research ethics (and, indeed, medical ethics as a whole) steered us away from the more collectivist and utilitarian views and toward a deontological foundation that highlighted the importance of individual self-determination and autonomy. Whereas doctors once were thought to know what is best for individual patients and researchers were given the power to pursue social goals with relatively little consideration for their trial subjects, more recent work has shown the importance of protecting the interests of the trial participant ${ }^{14}$. The utilitarian nature of early $20^{\text {th }}$ Century research trials brought about a situation in which individual rights could be overridden in the name of some particular social benefit, which not only provided a rather specious justification for the Tuskegee Syphilis Trials, but also for the eugenic programs from which we seek to distance modern research (Jones 2008,86 ). Similarly, the idea that the patient ought to passively accept the dictates of their physician has largely fallen out of favour both in the public and in the philosophical analysis of the doctor-patient relationship - the physician is thought to play an important role in ensuring that the patient has all of the information necessary to make an informed personal decision with respect to medical treatment, but ultimately it is the patient's decision that is to be respected.

\footnotetext{
${ }^{14}$ This is, in part, the motivation for referring to these individuals as trial participants, rather than subjects that play a more passive role in the research being done to them (Levine 2008, 219).
} 
Even if the ultimate justification of research trials will end up being grounded in the social benefit brought about by their product, upholding the rights of the individual trial participant remains necessary, especially their rights regarding self-determination ${ }^{15}$. The individual's rights and decisions serve as a strong limitation on the kinds of activities in which researchers may engage, but over and above that there remains a need for a broader social justification that can be weighed against the risks undertaken by trial participants. This is not merely an attempt to ensure that resources are used efficiently, but also a recognition that individuals should not be exposed to health risks for frivolous purposes.

This contrasts with developments in political philosophy and other applied ethics subfields rather substantially. Liberal theories in political philosophy, for example, prioritize the individual and justify social programs and state activities by appeal to the benefits to the positive effects that they will bring to the individuals within a given society. The focus on individuals over collective good is built into liberal frameworks, regarding the role of the state as an entity that promotes individuals with respect to their ability to choose between and pursue different life paths depending on that individual's conception of the good, remaining neutral on the different competing (and sometimes conflicting) conceptions of the good adopted by different individuals within the society. Competing liberal frameworks preserve this focus (albeit, at times, to varying degrees of commitment) as public education, healthcare, social welfare programs, affirmative action programs, and other programs aimed at the construction of a just society are justified by appeal to the benefits that they promise for individuals within the society. These programs, the liberal theorist would argue, are about promoting ${ }^{16}$ : equality of opportunity, welfare, resources, luck, individual interests, preferences, autonomy, etc., all of which are assessed by their

\footnotetext{
${ }^{15}$ More conservatively or collectivist-minded critics might criticize this emphasis on the individual for the purposes of deliberating about social policy with the thought that the social good is being neglected.

${ }^{16}$ This promotion would naturally be constrained by resource limitations, which will change how these different values are promoted. It might, for example, justify prioritizing certain individuals over others in the interest of fairness.
} 
impact for individual citizens. Of course, one would be ill-advised to neglect the effects that such policies have on the society as a whole, but the justification of these programs focuses far more heavily on the promotion of individuals within the society rather than the interests of the society itself.

Of course, commentators that do not share in these liberal intuitions about justice would bemoan this situation in political philosophy and claim that the prioritization of individuals has neglected important elements of justice by shifting focus away from the "greater good" (Somerville $2004,6)$. Through research trials, individuals are exposed to health risks for the production of scientific knowledge, which in turn is used to improve the society's capacity to respond to certain health issues and better care for its citizens as a whole. This does not mean that research ethics represents an inconsistency in our ethical frameworks but rather serves to indicate that biomedical research involving human subjects is a particularly special kind of activity in which governments, academics, and private companies can engage.

Research/Practice Distinction. The second reason why distinguishing research ethics from other practical ethics subfields is good practice when one intends to engage with a particular biomedical research avenue for ethical analysis is the salient distinction between the research into a particular technology or intervention and the practice or proliferation of the fruits of that research. This point is, I think, well-argued by Lev, Miller, and Emanuel in their paper "The Ethics of Research on Enhancement Interventions" which argues, in part, that research and practice come apart in such a way that some objections to the practice of human enhancement are insufficiently suited for objecting to the human enhancement research (Lev, Miller and Emanuel 2010, 101-2). Indeed, if the distinction is both sound and salient, it would be perfectly plausible for one to object to the proliferation of human enhancement technology for all kinds of bioethical or political reasons while maintaining wholehearted support for the research into enhancement interventions. 
The principal reason why such a position can be maintained is that the goal of research is not necessarily to bring about the widespread proliferation of that which is being researched, but rather the generation of useful and valuable scientific data and interventions which can be used for a multitude of purposes. The practice of a biomedical intervention is not entailed by its research, but is rather taken up separately and implemented once compared to other competing researched interventions - the research expands the range of viable practices and deepens our understanding of both the interventions themselves and that which they target. As such, Lev, Miller and Emanuel mount their argument by providing justification for four distinct types of enhancement research, namely: (1) Health-Related Enhancement Research, (2) Safety Studies, (3) Dual-Use Interventions, and (4) Enhancements to Promote Healthier Lifestyles (Lev, Miller and Emanuel 2010, 106). Arguments (2) and (3) interest us here $^{17}$, as they work without appealing to the practice side of the equation and therefore provide a justification of the research into enhancement without overstepping the research/practice distinction.

Lev's argument from Safety Studies notes that even if there were a complete ban on enhancement technology, this would not prevent all biomedical enhancement as some individuals are likely to pursue enhancement whatever legal restrictions are imposed. The probable emergence of this black market of sorts poses a health risk to the citizens who partake in its products and such public health issues fall under the purview of the state, whatever the state's position on the proliferation of enhancement technology happens to be. Just as "the ethical justification of research on needle exchange programs does not implicitly endorse heroin use" (Lev, Miller and Emanuel 2010, 107), the pursuit of a better understanding of the safety of different enhancement interventions does not implicitly endorse the use of these enhancements. Furthermore, a better understanding of the safety of these interventions would only improve the state's capacity to make policy decisions regarding such

${ }^{17}$ (1) and (4) will be of interest in a later section when dealing with the very specific bioconservative objection to research into human enhancement interventions that hinges on the health-related social value of such interventions. Here, however, our primary concern is with the arguments that do not rely on the proliferation of a researched intervention to make their case, so as to highlight the importance of the distinction. 
enhancements, which is good news for both bioprogressives and bioconservatives alike (insofar as they appreciate the role of evidence-based decision-making in government policy, of course). Therefore, Lev argues, there is at least one kind of enhancement research that ought to be wholeheartedly endorsed by even the staunchest bioconservatives.

The second argument concerning dual-use interventions notes the applicability of data produced by enhancement-oriented studies to different treatment interventions. Enhancement and treatment research, although perhaps normatively quite distinct, are not so distinct in their aims that they cannot be mutually beneficial - research on, say, cognitive enhancement interventions would likely be useful to many different treatment interventions that are concerned with the human brain, such as those targeting dementia or epilepsy (Lev, Miller and Emanuel 2010, 109). So, says Lev et al., any bioconservatives who seek to oppose enhancement research on the grounds that it isn't strictly speaking treatment-related ${ }^{18}$ will find it difficult to oppose this kind of research. Like argument (2) above, this opens up a modest set of enhancement interventions for research without appealing to the proliferation of the enhancement being researched.

While these arguments are meant to identify the distinction between the research into an enhancement intervention and its proliferation, the social value criterion for ethically sound biomedical research emphasizes that some assessment must still be made about the potential consequences of a particular line of research because exposing trial participants to health risks without prospects for something of value to be gleaned from the research is morally unacceptable (King and Churchill 2008, 514). There is a difference, however, between an assessment of the consequences of the proliferation of enhancement technology and an assessment of the social value of certain kinds of research, since, once a new intervention is developed, policymakers have further tools available to them to determine how it will be proliferated, if at all. These tools include an assessment of where the responsibility for

\footnotetext{
${ }^{18}$ We will examine arguments that take this route in Section III.
} 
taking up a developed intervention falls ${ }^{19}$, the use of regulations for the successful implementation of the intervention, the relocation of dangerous aspects of the product ${ }^{20}$ and the modification of existing policies and institutions to make use of the intervention, among others.

To motivate restrictions on research based on the possible long-term consequences of the impact the development may have on a society requires: (a) a strong entailment relationship between the research and the emergence of the unacceptable consequences, (b) an expansion of the role of research ethics to take responsibility for considerations that are not currently regarded as being part of their purview, or (c) some precautionary stance on how such risks ought to be managed at the research stage. Arguments that take route (a) attempt to establish some wrongness inherent to enhancement technology such that it necessarily entails an undermining of particular values, and as we shall see in Section II.2., some will "bridge the gap" between research and practice, thereby making a case for restrictions on both. Route (c) is far from uncommon as well, as the Precautionary Principle has solidified itself in the realm of environmental ethics as a way to explicitly constrain certain kinds of research on the basis of the possible future consequences of a technology's proliferation. I have my doubts about the advisability of such a principle for methodological and normative reasons which shall be addressed in Section III.

Mehlman argues along the lines of route (b), making the case that the American federal regulations that advise research ethicists to abstain from making their judgments based on the possible future consequences of a technology's proliferation ought to be changed to expand the scope of analyses in research ethics (Mehlman, et al. 2011, 42). Mehlman argues that these proliferation

\footnotetext{
${ }^{19}$ The appropriate institution will vary depending on the developed capacity - the capacity for the society to make use of, say, a new method of carbon capture for reducing greenhouse gases will be the responsibility of those institutions that have environmental protection and stewardship as their mandate, as well as federal regulators, etc. whose role is to ensure that the methods used by different institutions within the society are sound, welladvised and in the interest of the public.

${ }^{20} \mathrm{An}$ example of the relocation of dangerous technology to a less-dangerous field is the use of knowledge gained through the development of nuclear weaponry for the development of nuclear energy (Kelly 2009).
} 
concerns are relevant to research ethics, presumably making research ethicists the first line of defense when it comes to preventing the proliferation problems from coming about once the risky technology is developed. Again, however, the research itself does not implicitly endorse the proliferation of the technology. Once the society, through research, develops the capacity to intervene in certain issues, it falls on the appropriate institutions to decide the way in which this capacity will be manifested in practice. When assessing the social value of a research trial, the question is whether the trial will produce valuable information or a valuable technology that, if properly implemented, would enable certain institutions to carry out their mandate in a more effective manner. As such, the expected social value of research into a novel intervention does not hinge on the anticipated consequences of its proliferation, but whether or not it is a positive and valuable contribution to the set of interventions available to society for combating different problems - questions about its proliferation fall under a different category and is subject to the distinct set of moral considerations found in bioethics and political philosophy as well as considerations that are not principally philosophical ${ }^{21}$.

Uncertainty in Practice/Uncertainty in Research. The third reason why distinguishing the concerns specific to the research into enhancement and the proliferation of enhancement technology is important is the radically uncertain consequences of the proliferation. While some bioprogressive commentators propose a picture of the future in which human enhancements bring about a veritable utopia in which biologically immortal posthumans wander the stars having left such mortal afflictions as aging, disease, suffering and ignorance behind, bioconservatives paint a dystopic picture in which a kind of Brave New World oppression or posthuman/human war undermines all the progress humanity has made over the millennia. As with most new technologies, the promises and perils are often greatly exaggerated and unsupported by concrete evidence, allowing the commentators' (often under-justified)

\footnotetext{
${ }^{21}$ I would include here cost-effectiveness, the necessity of proliferation (in cases of emergency, for example), and (perhaps) the mandate of democratically elected representatives.
} 
presuppositions about technology and human nature to, in part, determine the conclusions of their analyses. In reality, the consequences of the proliferation of enhancement technology are likely to lie somewhere in between as society struggles to cope with its new capacities and limit those that would bring about significant harm ${ }^{22}$. There are at least two important consequences of this uncertainty; firstly, any argument that relies strictly on the benefits or detriments of widespread proliferation will be at best contentious and at worst methodologically flawed as they are coloured by implicit assumptions that are difficult to assess, and, secondly, some sound method is required for making assessments about the permissibility of certain kinds of research in the face of this uncertainty.

When it comes to the first of these important consequences, it is clear that the projections of the bioconservatives and bioprogressives diverge drastically on the benefits and detriments likely to come about from the proliferation of human enhancement technology. While both seek to ground their analyses in empirical evidence, both (with some notable exceptions) also tend to argue that enhancement is a particularly new kind of human activity that is largely without precedent (Annas, Andrews and Isasi 2002, 159). Naturally, one must wonder about the suitability of evidence gathered today for assessing the plausibility of different future scenarios that result from a uniquely different kind of human activity that is not yet in widespread practice and whether the commentators' presuppositions are inappropriately clouding the objectivity of the analysis ${ }^{23}$.

With regards to the second consequence of this uncertainty, it is clear that assessments must still be made about different investigative routes despite the difficulties found in making accurate

\footnotetext{
${ }^{22}$ Garreau (2009) appropriately calls this scenario "Prevail", contrasting it with the "Heaven" and "Hell" scenarios often put forward by commentators. (Garreau 2009)

${ }^{23}$ While this claim seems harsh, I believe it is well-motivated. It is altogether unsurprising that certain commentators are so consistent in their optimism or pessimism, even across very different activities. Dr. Ray Kurzweil, for example, argues consistently that we will see "Heaven" scenarios arising from: nanotechnology, artificial intelligence, genetic manipulation, robotics, etc. At the same time, commentators such as Leon Kass and Francis Fukuyama end up projecting "Hell" scenarios arising from the very same activities. It is unlikely, I think, that either side will be shown to be perfectly correct on all counts, but the consistency of their optimism and pessimism on these matters is striking.
} 
predictions about how things will unfold in reality. The uncertainty has two main sources, namely, the difficulties in predicting human behaviour (especially in large groups and when encountering novel circumstances) and the nature of scientific research which attempts to make progress in many directions at once and ultimately succeeds in only a few, if any. While it may be possible to predict certain kinds of technological progress through the analysis of trends (Moore's Law ${ }^{24}$ comes to mind here), developments that rely on breakthroughs or require changes to existing systems (whether regulatory or systemic) are next to impossible to anticipate effectively. At the same time, the points above demonstrate that ethical analysis of research trials into enhancement interventions is not committed to such predictions, but rather focuses on the value of the capacities that the research looks to develop as well as the benchmarks for ethical research.

These three reasons for distinguishing research ethics from the other ethics subfields when approaching the research into human enhancement technology have two main implications for our analysis going forward. Firstly, one should not approach the justification of enhancement research by appeal to the possible benefits that might arise from the proliferation of enhancement technology they are too uncertain and, if the grand benefits predicted by Transhumanists do come about as a result of the proliferation of enhancement interventions, they are as much a product of proper implementation of the researched interventions as the initial research itself. I think, then, the justification should instead be found in the promotion of certain capacities for meeting the challenges that humans face - further argumentation is required over which capacities ought to be put into practice and it is this further argumentation that will highlight the potential consequences of proliferation. Secondly, the distinction between evaluating the likely consequences of an enhancement intervention's proliferation and the social value of enhancement research carves out a set of concerns

\footnotetext{
${ }^{24}$ Moore's Law, observed by Gordon Moore in the mid-1970s, describes the doubling of transistors that can be fit onto an integrated circuit every twenty-four months (Kurzweil, The Singularity is Near 2006, 57).
} 
that are specific to research ethics in particular. We will have to assess which bioconservative and bioprogressive arguments in bioethics and political philosophy "bridge the gap" such that they remain salient even when research ethics is isolated for analysis. Some arguments will be committed to focusing on the practice of enhancement interventions once they have been successfully developed and will therefore be largely unhelpful in our assessments of the initial research phases ${ }^{25}$. At the same time, there are arguments available that will have implications for the research specifically, so distinguishing precisely which arguments fall where in this debate is an essential first step in constructing a comprehensive analysis of the research ethics of enhancement technologies. As such, the kind of taxonomy of concerns required here will be the subject of the following subsection.

\section{II.2. A Taxonomy of Concerns}

The reasons above provide what I think are good reasons for approaching the enhancement debate in a way that distinguishes the research into enhancement from the practice - such an approach serves to clarify this often messy and complicated debate by distinguishing the two due to the differences in their aims, justificatory approaches and sources of complication. At this stage, we may go on to identify different categories in which the different arguments found in the literature may fall, such that we may appropriately focus on those that are relevant specifically to the research into enhancement interventions. Once we have distinguished the different categories in which the different concerns fall, we may look at what makes enhancement research unique - why it is distinguishable from research into biomedical treatment interventions.

Broadly speaking, I propose that we classify the competing concerns with enhancement research with the following four categories: (1) Social harms, (2) Third-party harms, (3) Inherent wrongness-related concerns, and (4) Concerns for human trial participants and trial design. These four

\footnotetext{
${ }^{25}$ It is worth repeating that this does not in any way imply that these concerns are unimportant, just that they are
} important at a later stage when dealing with the ethics of a technology's practice. 
categories are meant to be exhaustive; if it is an objection to human enhancement, then it falls within at least one of these broad categories. Most objections to human enhancement that one sees coming out of the bioconservative camp are most strongly identifiable as belonging to categories (1) and (3), as perhaps the most common approach to contesting the ethical viability of the human enhancement is to argue for a particular social value's importance and go on to make the claim that human enhancement technology threatens that important value in some unacceptable way. There are a number of plausible social values that are suited to this role, from human dignity, to solidarity, humility (Sandel 2007), commitments to human heritage (Somerville 2004), equality and even some value tied to social coexistence (Annas, Andrews and Isasi 2002, 162).

Third-party harms, (2), should they come about, would be the result of the proliferation of enhancement technology. These arguments are specifically directed at identifying the various social groups that would incur harms from the proliferation of enhancement technology. This would include the less developed nations whose citizens would not have comparable access to enhancement technology as the wealthier nations and the creation of new vulnerable groups as a result of the new technology (Agar 2010). While some approaches to the distribution of enhancement technology have the potential to mitigate the more worrisome kinds of social stratification that might result from the proliferation of enhancements, it is far from clear how to extend its benefits to citizens of other nations. Market solutions are likely to further accentuate this problem and more cosmopolitan approaches to resource distribution are unlikely to be adopted for a number of reasons including: the anticipated cost of enhancement interventions, the reluctance of states to agree to the redistribution of such interventions ${ }^{26}$ (especially given their reluctance to redistribute even most treatment interventions), and the doubts surrounding whether states are even responsible for such significant redistributive efforts. When it comes to the creation of new vulnerable groups, Sandel notes that when enhancement

\footnotetext{
${ }^{26}$ This problem will be relevant to the concerns we will examine in Sections III.3.ii. and IV.2.i.
} 
interventions become widely available, there is good reason to worry that those who choose to abstain from these interventions (or decline such interventions for their children) will incur blame and social stigma for their choice (Sandel 2007). The likelihood of this consequence coming about and whether there is a way to avoid it remains to be seen, but such solutions would have to be sought among the tools that are meant to mitigate the negative consequences of a technology's proliferation.

Whether the argument in question belongs to (1) or (3) will ultimately depend not on what social value is being threatened, but how it is threatened by human enhancement interventions. If the concern is rooted in the impact that widespread proliferation of enhancement technology might conceivably have on the social values of a given society, then it would belong to category (1) concerning the practice-based concerns about human enhancement. So, Annas presents the argument that human enhancement technology could eventually lead to war between the enhanced and unenhanced presumably due to some combination of human foibles (jealousy, greed, lust for power, propensity for violence, etc.), social stratification, poor governance, etc. (Annas, Andrews and Isasi 2002, 162). Such an argument hinges entirely on speculation about the eventual impact of the proliferation of enhancement technology, establishing it as an instance of (1).

At the same time, however, many arguments designed to identify particular threats to social values are not dependent on the widespread proliferation of the technology - these arguments are concerned with a society developing the capacity to engage in activities that are, in some way, fundamentally or intrinsically wrong. Just as many would argue that governments should not be in the business of developing, say, certain kinds of biological weaponry because certain biological weapons are not the kind of thing that governments ought to possess ${ }^{27}$, arguments have been made that human enhancement constitutes the kind of technology that simply should not be developed. These arguments would, then, "bridge the gap" between the practice and research of human enhancement and, if

\footnotetext{
${ }^{27}$ Importantly, such an objection is viable even if the state never makes use of the weapon.
} 
successful, would be sufficient for justifying restrictions on both. Arguments of this kind highlight the apparent wrongness of the capacity to engage in enhancement, ranging from concerns about the creation of different branches of "posthuman", the undermining of certain obligations to human heritage or maintaining a necessary connection between the research into enhancement interventions and the undermining of particular social values.

The last of these categories, (4), is made up of the concerns that come directly from research ethics. This includes objections that point out unacceptable moral hazards relevant to trial participants especially, including the dangers they bear within the trial and the typically treatment-oriented justification that normally grounds such risk, their incentivization and consent, the vulnerability of certain groups to exploitation due in part to the therapeutic misconception, and maintaining the independence of research ethics boards when the institutions that employ them might have particular interests in the potential benefits of enhancement (Mehlman, et al. 2011, 43). Furthermore, concerns that fall within this category would include the worry expressed in Section III.3.i., namely, that a justification of enhancement research that relies too heavily on the treatment side of the equation risks creating a scenario in which clear advantages are given to enhancement research that masquerades as treatment research for the purposes of satisfying REBs and securing funding (Mehlman, et al. 2011, 32). These concerns will be the subject of Section III.3, at which point we will examine them in more detail.

Now that we have a clearer picture of the different ways in which objections to human enhancement target the research and practice of human enhancement interventions, we may proceed with a thorough look at the ethics of research into these interventions. Going forward, we will be examining the arguments that seek to show that human enhancement is impermissible because of some inherent wrongness that lies in enhancement itself or the nature of enhancement research. I will suggest that these arguments are not sufficient for banning enhancement research in its entirety, 
leading to questions regarding how we might proceed in conditions of uncertainty and risk when the goal is not the treatment of some health need but the development of an enhancement intervention. Such uncertainty and risk concern research participants as well as society as a whole, so specific attention will be paid to both, first looking more closely at the Precautionary Principle that informs so much environmental policy and that some commentators suggest could be used to keep enhancement research in check, and secondly examining concerns surrounding trial design and the protection of research participants. Finally, as I said above, a positive case should be made for certain kinds of enhancement research since there are plausible options for such a case and automatic preference for treatment research may bring about problematic incentive structures. This positive case will have to do with the strong reasons for promoting certain kinds of enhancement that enable the society to bring about practices that confront certain social problems while avoiding some of the perils that lie in the promotion of enhancement technology. This positive case will be our primary concern in the final section of this thesis.

\section{Research Ethics-Related Concerns and Biomedical Enhancement Research}

As I claimed above, some commentators argue that human enhancement, as a human activity, is inherently morally unacceptable, either because it is simply not the kind of activity in which human societies ought to engage or because it necessarily undermines some important social value. Arguments that do not commit to some necessary connection between human enhancement and the undermining of particular social values will not concern us here, as they fall within what I called category (1) above and I maintain that they are not the concern of research ethics, as they hinge on contingencies that can presumably be met or mitigated through the good policy, moratoria, or relocation that is the mandate of bioethics, political philosophy as well as fields outside of philosophy. 
As such, in this section we will be dealing with claims that, while primarily directed toward the practice of human enhancement, would bridge the gap between practice and research and, if successful, would be sufficient to motivate bans on enhancement research as well as the practice. In this section, we will first examine arguments from the prominent bioconservatives Leon Kass, Margaret Somerville, Francis Fukuyama, and George Annas; showing how these related but nuanced arguments apply to human enhancement research and examine the conclusions that such research projects are necessarily unethical because they necessarily undermine an important value or represent the kind of technology that states should not possess. This section will then go on to look at the so-called Precautionary Principle which is used by many bioconservative commentators to claim that the risks involved in enhancement research are sufficient to prevent the research from being done. Finally, we shall examine arguments that target the research specifically, appealing to the criteria that aim to protect research trial participants and ensure ethically sound research trials. Some of these arguments from the principles of research ethics conclude that enhancement research will end up being necessarily unethical due to the moral hazards such research poses.

\section{III.1. Inherent Wrongness of Biomedical Enhancement III.1.i. Hubris and Playing God}

The first arguments we will be considering are those that claim that there is some social value that would be violated by the research and proliferation of human enhancement technology. The wellknown report by former President George W. Bush Jr.'s council on bioethics famously made its case against the practice of human enhancement based, in part, on an admonishment of artificial "shortcuts" to human achievement ${ }^{28}$, human hubris and the purported assault on the dignity of human activity that human enhancement represents (President's Council 322).

\footnotetext{
${ }^{28}$ They were careful here, however, to emphasize that it isn't really the artificiality of these shortcuts that is at issue but rather that something is lost in achievement that does not struggle through the "natural" challenges facing achievement (i.e. practice, training, study, etc.) (President's Council 329).
} 
The argument from hubris is a strong example of the kind of argument that, while it is directed primarily at the practice of human enhancement, is capable of making a case against its research as well. The central claim of the argument is that some respect is owed to the "giftedness" of nature and that the will to modify nature so as to better suit humanity's desires and ambitions is in some way a violation of this respect (The President's Council on Bioethics 2003, 323). This “Promethean Inclination" or socalled "hyper-agency" that would result can certainly be applied to the consequences of proliferation as individuals make use of enhancements to pursue different life paths through allegedly objectionable means, but insofar as we are talking about developing state capacities through research, we can see that such objections would apply to research as well. Straightforwardly, if intervening in nature for the purposes of satisfying some aspiration to become "better than well" requires the violation of some obligations we have toward nature itself, then the research into activities that necessarily violate those obligations would be objectionable on those grounds ${ }^{29}$. Individuals can violate these obligations by making use of these technologies and states can violate these obligations through the research and practice of human enhancement, so the problem of hubris can be applied to the actions of individuals and societies alike.

The argument from hubris is committed to this concept of the giftedness of nature, that nature is in some way given to us as something to be treasured and treated with the utmost respect and admiration (The President's Council on Bioethics 2003, 325). It is relatively clear how this respect and admiration might be used to prevent certain kinds of human activity such as animal cruelty, unsustainable industrial practices, the destruction of habitats, etc. Each represents an activity in which humans, presumably in pursuit of some ambition, bring about some harms to the natural world. While these harms might have some negative consequences for humanity (or the humans involved), these

\footnotetext{
${ }^{29}$ Similarly, for example, if biological weaponry is unacceptable due to some commitments we have toward humanity, then researching biological weaponry is similarly unacceptable as it develops the capacity to breach these commitments.
} 
negative consequences are not the main moral wrongdoing that is being argued for here - the primary harm is said to be done to our attitudes toward nature itself (ibid.). This feature distinguishes these arguments from those that start from some conception of human dignity ${ }^{30}$ or human nature, as it involves proposed legitimate external constraints on human action whereas those that derive their objections from human dignity argue that biomedical enhancement poses a threat to some important feature of individuals.

Further, this argument shares significant features with what is commonly referred to as the "playing God" argument, which deserves some acknowledgment as it rears its head in a wide range of debates over everything from GMOs and stem cell research to brain death diagnosis and physicianassisted death (Dabrock 2009, 47). Essentially, the "playing God" argument asserts that there exists some limit to legitimate human action, that the technology in question risks overstepping that limit (or, indeed, necessarily oversteps that limit) and to overstep this limit is to venture into activity that is reserved for some conception of the divine, which is supposed to be inherently objectionable. Just as the argument from hubris would apply to the research of a new intervention insofar as that intervention is itself a violation of the legitimate limits placed on humanity by nature, this argument attempts to make the remarkably similar case that humanity is legitimately restricted from those activities reserved for the divine - and so I believe it fruitful to address them together, if only briefly.

There are three main questions we must ask with respect to the "playing God" and hubris arguments, namely, (1) whether the limitations set by nature are really so deserving of our respect and admiration, (2) whether the legitimacy of the restrictions that nature places on human ambition is in some way entailed by these obligations toward nature, and (3) whether biomedical enhancement is the kind of activity that would violate these obligations. If these two arguments are to make the case that

\footnotetext{
${ }^{30}$ Which is, in part, why we will be looking at Annas' argument that relies heavily on a particular conception of dignity and the President's Council's "dignity of human action" arguments in the following subsection.
} 
biomedical enhancement exemplifies the kind of hubris or overreach that is morally unacceptable, then they would require a positive answer to each of these questions. They are committed to holding the view that nature comes with a set of legitimate limitations on human ambition that serve as the boundary of morally acceptable human action.

It is no insignificant fact that this argument comes up so often in the debates surrounding new technologies and policies, as it is particularly difficult to pin down precisely what the legitimate limitations on human action are. There was a time when even the use of anaesthesia was seen as being this kind of excessive overreach, but the boundaries, clearly, have since shifted (Dabrock 2009, 47). The problem really lies with the indeterminacy of the concrete implications that come from the values of "respect and admiration" for the giftedness of nature, even if we agree that those are values worth promoting. Dworkin (2000) rejects these "playing God" arguments for this reason - they end up being more of an expression of the individual's discomfort and, as such, resemble the so-called "Yuck Factor"31 rather than a robust philosophical argument ${ }^{32}$ (ibid.). This is further supported by the observation that these boundaries tend to shift as the contested technology becomes more commonplace and individuals become more accepting of its proliferation. As such, we may answer the above questions (1) and (2) affirmatively ${ }^{33}$, but (3) will depend on this indeterminate, shifting boundary that determines whether the activity is acceptable or not. Bioconservative commentators might decry this gradual acceptance of new technologies, but the gradual acceptance and resulting moving boundary shows that it alone cannot be relied upon for making a case against human enhancement; something more is

\footnotetext{
${ }^{31}$ We will be touching on the "Yuck Factor" in somewhat more detail in Section III.1.iii.

32 Indeed, Dworkin goes so far as to say that those who employ these arguments are being "intellectually and morally dishonest"

${ }^{33}$ Although we certainly don't have to, as Nick Bostrom, for example, appears to contest the legitimacy of the supposed limitations on human ambition that follow from an obligation to respect and admire nature when he quips: "Had Mother Nature been a real parent, she would have been in jail for child abuse and murder" (Bostrom, In Defense of Posthuman Dignity 2005, 211). This negative sentiment about the role nature plays in determining the limits of legitimate human action is common in the Transhumanist movement, being echoed by Transhumanists such as Pearce (1995) and Kurzweil (2005). This is a point we will return to in Section IV.1.iii.
} 
needed - namely, an explanation of why the boundary ought not to shift. It is in this additional explanation that we might find a persuasive case, rendering the hubris and "Playing God" arguments rather ineffectual unless supported by or combined with a more potent argument.

Two prominent examples of commentators attempting to supplement the unease expressed in the hubris and "Playing God" arguments are Somerville and Fukuyama. Margaret Somerville takes an approach that she calls the "Science-Spirit View", defined as the: "essential, intangible, invisible, unmeasurable reality we need to live fully human lives..." (Somerville 2004, 62). The Science-Spirit View is meant to offer an additional explanation for the discomfort expressed in the hubris and playing God arguments by reaffirming the importance of going beyond pure scientific reasoning and appreciating the role of cultural beliefs and values (including, and perhaps especially, religious values) in debates surrounding different bioethical issues. Furthermore, it seeks to emphasize the role of collective good in debates around public policy and, specifically when it comes to genetic interventions, it argues for restraint based on the "common heritage of humankind handed to us by our ancestors and that we hold in trust for future generations" (Somerville 2004, 80). When it comes to arguments that begin from an affirmation of particular cultural values for the purposes of limiting the life paths available to citizens, however, one must ask whether the value in question actually entails the restrictive policies being sought after and whether it represents an overstepping of the authority of the state in the limiting of individual autonomy. Insofar as we seek to avoid policies that impose illegitimate restrictions on the freedom of individuals to make decisions about their own life paths except in cases where the life path brings about some illegitimate harm ${ }^{34}$, this Science-Spirit View would have to make the case that the

\footnotetext{
${ }^{34}$ It could be said that the use of illegitimate harm here risks a kind of circularity; however it could be the case that harms done to oneself are "legitimate" in the sense that the state should not have the authority to take measures to prevent them. For example, a case could be made that self-harm brought about through the use of drugs or physician-assisted death should be permitted lest the state adopt an overly paternalistic stance, while otherdirected harms such as life paths that include murder or other such impositions on others' life paths would fall under the legitimate authority of the state as it carries out its obligations to protect the security of its members.
} 
research and development of biomedical enhancement technologies opens up life paths that would necessarily bring about such illegitimate harms.

I have my doubts that this potential for undermining some cultural or social values of particular social groups could be sufficient for motivating restrictions on the research (or even practice) of biomedical enhancement. Those who have chosen to become a member of these cultural groups (or chosen to remain a member of their particular cultural group) thereby commit themselves, at least to some extent, to the values of that cultural group and it is difficult to see how their commitment to those values should be sufficient for limiting the choice of life paths available to others. Without some kind of perfectionism by which the state is granted the authority to impose upon life paths that do not emulate the values of a particular social group, the most one can get out of this kind of argument is a claim something like: if one aspires to be a member of social group $x$, then they should not pursue life path $P$ where $P$ is a life path that undermines values that are important to that social group ${ }^{35}$. Additional argument is required to make the case that the values of that particular social group are of the kind that society should restrict any and all life paths that threaten to undermine them.

Without this additional argument, the state's imposition of values that are important to particular social or cultural groups onto citizens that belong to other social groups that do not share those values runs the risk of undermining the value pluralism that is so central to liberal democratic society. This is not entirely unlike the undermining of value pluralism that we identified as being such a problematic aspect of eugenic policies, only in this case the imposition is on the life paths that individuals might choose without the violations of bodily integrity that one sees in eugenics. The point is that arguments that seek to restrict research into enhancement interventions on the basis of the values of a particular social group ultimately must rely on the state to enforce adherence to the values

\footnotetext{
${ }^{35}$ Some arguments concerning abortion are a good example of this kind of claim masquerading as a broader claim that aims to restrict the choices of individuals. This is, I think, part of the reason one encounters the response: "If you don't like abortion, don't have one" with such frequency.
} 
of a particular social group, and yet as soon as the state begins imposing the values of a particular social group, it risks venturing into the very eugenic practices that we seek to prevent. It does not need to forcibly undermine the bodily integrity of individuals to accomplish such egregious goals - restricting certain kinds of research due to the grievances of particular life paths ultimately limits the life path options available to individuals for the sake of the values espoused by particular social groups.

\section{III.1.ii. Solidarity and Human Rights}

Francis Fukuyama attempts to further justify the unease expressed in the above hubris and "Playing God" arguments with an appeal to something he calls "Factor X". According to this argument, there exists some important feature of humanity, dubbed Factor X, which prohibits those technologies that necessarily threaten it (Fukuyama 2002). Fukuyama does not believe it necessary to actually go about defining Factor $\mathrm{X}$ (thus the choice of nomenclature), as it is meant to denote that which serves as the foundation of human unity and solidarity, whatever that foundation happens to be. Of course, it is a matter of some debate whether an undefined feature such as Factor $\mathrm{X}$ can generate the more specific policy recommendations that bioconservatives seek here, especially if it is meant to further clarify their unease toward biomedical enhancement. That being said, the important claim here is that biomedical enhancement threatens to undermine human solidarity by undermining that which unifies us.

This value of solidarity is echoed in Annas, Andrews and Isasi (2002), who take a similar approach to the Factor $\mathrm{X}$ argument in their case against reproductive and therapeutic cloning, but they do so without leaving the unifying foundation quite so undefined. According to their argument, biomedical enhancement, especially done through genetic interventions (although, as we shall see, the argument could certainly extend to other kinds of enhancement):

“...can be seen as crimes against humanity of a unique sort: they are technologies that can alter the essence of humanity itself (and thus threaten to change the foundation of human rights) by taking evolution into our own 
hands and directing it toward the development of a new species, sometimes termed the 'posthuman'." (Annas, Andrews and Isasi 2002, 153).

The central claim here is that genetic interventions (and those aimed at enhancement particularly) threaten the foundation of human rights by enabling individuals to pursue life paths that ultimately lead to membership in a non-human species. Insofar as these enhancements would be used to bring about persons who will not share in this "fundamental commonality", their claim to human rights is thrown into question (ibid.). To bring about persons without such a claim to human rights is, in their view, a crime against both that individual and humanity itself as the protections that human rights theorists have established are rendered insufficient. Their conclusion, then, is that such experimental biomedical interventions are intrinsically objectionable and that procedures that involve "intentional, inheritable genetic modification" of embryos should be criminalized through international law (Annas, Andrews and Isasi 2002, 154).

Even if we distinguish between the research into enhancement interventions and the practice of enhancement, it must be admitted that the above argument would be sufficient for motivating the prohibition of both. In Section II.2. I count it as falling within (3) arguments from inherent wrongness as opposed to (1) arguments from social value because the issue is with the interventions themselves as opposed to ancillary and contingent consequences that may or may not follow from their use as it purportedly threatens the basis of human rights which results in the "crime against humanity" classification. If biomedical enhancement is as grave a threat to human dignity and rights as the above authors suggest, then the research trials that undermine that dignity would be unacceptable on those grounds. 
Questions of whether the violation of individual dignity truly entails a crime against the entirety of humanity aside ${ }^{36}$, there is good reason to doubt the claim that enhancement interventions are the kind of activity that would undermine human rights and thereby bring about harm to humanity as a whole. In his In Defense of Posthuman Dignity (2005), Nick Bostrom argues against the view espoused by Fukuyama and Annas by looking biomedical enhancement interventions mean for human dignity and, thus, human rights from the perspective of the Transhumanist position. In his argument, Bostrom highlights a key difference between the conception of the foundation of human rights being used by the bioconservative and the conception more commonly found among transhumanists; namely, that the claim to human rights is simply not premised on the "pedigree" or "causal origin" of individuals but rather it at least includes what they have the potential to become (Bostrom 2005, 213). For Bostrom, the emergence of novel life paths that might take individuals away from membership in the human biological species calls for an "expanding moral circle" that includes posthumans, rather than an attitude that limits their claims to human rights (ibid.). Even if posthumans represent a new species, it seems to be a hasty assertion that their enhanced characteristics are in some way sufficient to strip them of their moral status as autonomous agents, especially insofar as the characteristics typically deemed important for claiming moral status remain unhindered.

So why do bioconservatives maintain the importance of membership in the biological species as a foundation of human rights? The answer, I suspect, lies in the aforementioned value of solidarity (a point that Bostrom does not address directly). It is either thought that exclusionary tendencies among humans would bring about a rift between the human and posthuman such that the sought-after unity that grounds human rights theory would be rendered unachievable, or that dignity and human rights

\footnotetext{
${ }^{36}$ While potentially assailable (See Daniels 2010), this foundational principle of human rights theory has enjoyed enormous success (both in its consequences for policy and for its laudable contributions to the protections offered to individuals) and one should be wary of working to undermine it without a plausible alternative. I have my doubts about such a project and positing such an alternative would take us far beyond the scope of this thesis, so I will not be problematizing it for this discussion.
} 
necessarily require a unified biological species to preserve that solidarity. Annas expresses a not-

uncommon sentiment along these lines when he says:

"The new species... will likely view the old 'normal' humans as inferior, even savages, and fit for slavery or slaughter. The normal, on the other hand, may see the posthumans as a threat and, if they can, may engage in a preemptive strike by killing the posthumans before they themselves are killed or enslaved by them"

(Annas, Andrews and Isasi 2002, 162).

This is, I think, an unduly pessimistic vision of the likely consequences of the proliferation of enhancement technology, but it has implications for enhancement research as well. It is the division of human and posthuman that is at issue here, and insofar as one accepts the claim that certain capacities can be enhanced such that the enhanced individual is no longer truly human ${ }^{37}$, then enhancement research pursues this division in a very meaningful sense. A further point of agreement here is that solidarity is something worth striving for - human rights theory has plausibly made the case for its importance in the promotion of a number of pro-social behaviours including tolerance and compassion while maintaining its usefulness in grounding the powerful notions of human rights.

The basis of the claim that solidarity is threatened by the emergence of life paths that allow for divergence between human and posthuman must be either: (a) humans generally would reject solidarity due to the divergence of certain individuals from membership in the biological species or (b) that human rights theory needs this biological foundation to preserve its "meaning and enforcement" (Annas, Andrews and Isasi 2002, 153).

If enhancement research is to be prohibited on the basis of (a), then it must be shown that the emergence of new bases of discrimination is a threat to solidarity and that the conclusion to be drawn

\footnotetext{
${ }^{37}$ I do not mean to imply that there are no problems with this claim, as transhumanists Ray Kurzweil and Nick Bostrom have both been known to question the apparent failure to appreciate the "dynamic, partially humanmade, and improvable" features of humanity that blurs the boundaries of the category (Bostrom, In Defense of Posthuman Dignity 2005, 213). That said, Transhumanists and bioconservatives generally agree (if at least for the sake of argument) that this separation is at least possible, if not the likely outcome of enhancement technology.
} 
from this is that activities that bring about new bases of discrimination ought to be prohibited. I find both of these claims to be questionable at best, as the new bases of discrimination aren't objectionable in themselves, but rather once they are actually employed for unjust discrimination, the discrimination becomes objectionable. Bringing an individual into the world (whether intentionally or unintentionally) who has characteristics that certain members of society might target for such unjust discrimination is not the moral wrong here; it is the discrimination based on arbitrary characteristics that are beyond the victim's control that should draw the most concern and motivate social policies to combat such moral wrongdoings. As Nick Bostrom puts it: "human society is always at risk of some group deciding to view another group of humans fit for slavery..." or discriminatory practices, and this ever-changing landscape of moral wrongdoing is almost impossible to predict as the unjustified discrimination tends to be based on cultural biases and prejudices that change and adapt to social pressures (Bostrom 2005, 207). Straightforwardly, if person $A$ is brought into the world with characteristics $x, y$, and $z$ and certain social groups decide to take issue with characteristic $y$ for the basis of discriminatory practices, the fault lies with the discrimination, not the characteristic or the act of bringing person A with characteristic y into the world.

It might be argued that the intentionality of the decision-maker makes the relevant difference here - the moral problem is with those who choose to bring about a person who has some characteristic that is objectionable to certain members of society. Such a position would be capable of objecting to interventions that determine the characteristics of individuals where those characteristics would make the individual susceptible to social pressures and discriminatory practices while allowing for carrying to term those who happen, through the chance of the natural lottery, to have those problematic characteristics. However, if we object on principle to the intentional decision to bring about individuals who have characteristics which go against the cultural zeitgeist of the time, then not only do we risk 
reinforcing such cultural biases, but we also risk limiting the reproductive rights ${ }^{38}$ of prospective parents on the basis of the personal beliefs of a particular social group. Both of these possibilities are, I think, unacceptable. There was a time in which intentionally bringing about a child of mixed race ${ }^{39}$ was to go against the cultural beliefs of a particular social group, but today we rightly place our moral admonishments on those who shared in those cultural beliefs and attempted to restrict the liberties of others on that basis.

If the concern for human solidarity is based on (b), the idea that a unified biological species is necessary for the foundation of human rights (as Annas' position appears to be), then I think we should have some serious concerns about this foundation. Human rights are designed to protect the dignity of agents by affirming the value of dignity ${ }^{40}$ and its importance to society as a whole such that violations of that dignity are to be seen as "crimes against humanity" and made subject to international justice. If we are to premise human rights (at least partially) on membership in the biological species, then dignity becomes a strictly human affair and non-human persons, should any come about, would be barred from sharing in this dignity by necessity. This seems to be at least hasty if not downright problematic, as if we were to come across a distinct species that shares in the features necessary for agency or autonomy, then on what grounds would we deny them dignity and thus the rights that follow from it? Hypothetically, if it were possible to biologically engineer a "posthuman" that does not share in this

\footnotetext{
${ }^{38}$ This is not to say that there exist no legitimate restrictions on the kinds of enhancements that prospective parents or individuals can choose, but those legitimate limitations wouldn't appeal to the cultural beliefs of particular social groups. What these legitimate restrictions might look like will be addressed Section IV. of this thesis.

39 The fact that this is presumably done through a "natural" reproductive process rather than an "artificial" one does not change the fact that the prospective parent is intentionally bringing about a child with characteristics that some individuals might, on the basis of their cultural beliefs, find objectionable. The "artificiality" of the process points to differences in the method by which such an intentional act is carried out, but not the salient features of the act. If the concern is with the artificiality of the method as opposed to "natural" reproductive methods, then a different argument would have to be made that would have to contend with less-controversial practices such as IVF (which is part of the reason why the President's Council on Bioethics avoided this line of argumentation) (The President's Council on Bioethics 2003, 327).

${ }^{40}$ Although Annas specifies human dignity here, this qualifier cannot be relied upon here without begging the question - the problem is precisely with that qualifier.
} 
species membership yet maintains those features necessary for agency or autonomy, and, say, a rogue scientist brings about such an individual, it seems simply heinous to not extend the protections of human rights to that individual due to the fact that they happened to be of a different species. We might regard that scientist's actions as criminal (insofar as his or her actions are in violation of international law), but the non-human person would be seen as the victim and deserving of protection. I suspect that further activities that undermine that novel person's dignity would be seen as no less egregious than activities that violate the dignity of humans, which indicates that the rights designed to protect individuals are meant to protect those individuals' dignity and that dignity and biological species-membership come apart.

The view I am advocating here is not unique; "personism" ${ }^{41}$ is the view that biological membership in a particular species is not what motivates moral consideration and concepts such as dignity, but rather their foundation has something to do with certain independent features that most humans happen to possess (Savulescu 2011, 220). While biological membership determines certain aspects of reproduction due to biological restrictions on inter-species breeding, advocates of personism maintain that it does not carry the normative weight that would be required for a foundation of moral consideration or dignity. It is, of course, difficult to pin down exactly what features ground moral consideration here (especially given the fact that our sample of persons is exclusively human), but it appears likely that rationality and self-consciousness have something to do with it, as the capacity to understand one's existence over time and have preferences that extend into one's future appear to be important features worthy of respect (Savulescu 2011, 221).

Finally, if we are particularly concerned with the protection of the social value of solidarity, then it hardly seems appropriate to be drawing arbitrary boundaries to limit membership in the "in-group".

\footnotetext{
${ }^{41}$ This term comes from Williams (2006) and his defense of human prejudice, but the view is clearly espoused by the likes of Tooley and Singer (Savulescu 2011, 221).
} 
As Bostrom suggests, the prospect of non-human persons indicates that some flexibility in our moral circles is called for, as there is legitimate debate over precisely what the necessary and sufficient conditions for personhood would be (Bostrom 2005, 213). Were there a non-human individual that was capable of understanding their situation, making informed decisions, etc. a case could plausibly be made in favour of their dignity. Worse still, restricting their claims to human rights based on some arbitrary biological features over which the individual has no control risks stigmatizing a particular social group for reasons related to the justice-based eugenics concerns covered in Section I.3. The autonomy of individuals matters, and the protections that human rights offer to autonomous individuals can plausibly apply to them whatever biological species they happen to $\mathrm{be}^{42}$.

\section{III.2. Precaution and Risky Research III.2.i. The Precautionary Principle}

Another route for objecting to biomedical enhancement research is to point to the risks that such innovations pose to the whole of society and, in light of these risks, argue that good scientific research would abstain from pursuing them. This precautionary principle is explicitly endorsed by a number of the commentators we have examined, including Somerville ${ }^{43}$ and Kass, both of whom go further to argue for the "wisdom of repugnance" - the claim that intuitive repugnance to certain developments can be "the emotional expression of deep wisdom, beyond reason's power fully to articulate it" (Kass 1997, 20). There is good reason to doubt its relevance, however, as such emotional expressions of repugnance have been directed at everything from interracial marriage and the civil rights movement to gay rights, and the inability of its advocates to express their grievances in rational terms protects them from rational counterargument - this is not an advantage but a serious shortcoming. While proponents of the precautionary principle are not necessarily committed to this

\footnotetext{
${ }^{42}$ In Vulnerability and Human Rights (2006), Bryan Turner points out another way in which biomedical enhancement technology may threaten solidarity and human rights that does not rely on this divergence of posthuman from human, but on the basis of existing vulnerabilities. The concern is that they might drive a wedge between rich and poor societies and further reinforce the inequalities that are already disconcerting (Turner 2006). ${ }^{43}$ See: Somerville (2004), 56.
} 
affirmation of the so-called "Yuck Factor", its influence remains important for its application, as we will see when it comes to the role that the precautionary principle plays in the influencing of public debate in Section II.2.ii.

We must be careful here to avoid venturing beyond the scope of research ethics. I claimed in Section II.2. that considerations about the possible eventual consequences of a technology's proliferation typically do not "bridge the gap" between research and practice, but the precautionary principle is somewhat of a special case. The principle seeks to undermine the salience of the gap by arguing that the possibility of negative practical consequences is sufficient to prohibit research, which distinguishes it from arguments that appeal to specific possible negative consequences. Straightforwardly, there is a difference between arguing from, say, the possibility of eventual posthuman-human war and arguing that the general possibility of negative consequences should motivate restrictions on research - the latter does not necessarily need a strong argument for the likelihood of those negative consequences, but can instead rely on their mere possibility and the purported advisability of precaution.

The precautionary principle is relevant to dangerous research and, I think, there is little argument needed for the claim that biomedical enhancement is particularly dangerous - it specifically involves the imposition of health (and social) risks in an attempt to improve on important human characteristics for non-treatment reasons. When it comes to treatment research on interventions that are designed to meet health needs, the sought-after products are designed to mitigate these negative effects of illness, and one can see rather straightforwardly why the possibility of health problems imposed on research participants (and, perhaps, society as a whole) can be justified given that they target ill health. III health is a rather obvious hindrance to individual autonomy and impairs individuals' pursuit of the good life, so risky research on treatment interventions can be justified from a range of 
moral frameworks that prioritize different values ${ }^{44}$. When it comes to enhancement research, the justification of health risks is less obvious as they impose health risks without the straightforward treatment-based justifications. If in spite of these challenges enhancement research is permissible (which I have, and will continue to argue), then special care is undoubtedly called for, but establishing a principle or set of benchmarks that offer sufficient mitigation of these dangers without stifling discovery has proven difficult - which is the challenge that the precautionary principle aims to meet (Harris and Holm 2002, 359).

Originally designed with environmental policy in mind, the precautionary principle began seeing use late in the $20^{\text {th }}$ century and its scope was broadened over time to include other public health threats and risks ${ }^{45}$ (Harris and Holm 2002, 357). Given its widespread use in different fields and different cultural and political contexts, it is altogether unsurprising that the precautionary principle comes in many forms and has resisted precise definition. Indeed, the vagueness of the precautionary principle has probably contributed to its success among activist and protest movements against certain technological developments ${ }^{46}$ and is lauded by some commentators for that very reason (Clarke 2005, 5; Jordan and O'Riordan 1999). Furthermore, the principle admits of strong and weak versions, the latter of which have been developed in large part in response to legitimate concerns and counterintuitive implications that accompany the stronger definition. In the following section I hope to explicate these two weak and strong versions of the precautionary principle and to briefly address why it has enjoyed such broad success among policymakers globally. I will then go on to examine the difficulties that the precautionary principle faces generally and finally argue that, in light of these problems, the precautionary principle is inadequate for the prohibition of enhancement research.

\footnotetext{
${ }^{44}$ So much so that a moral framework's failure to justify treatment research would, I presume, be seen as a grievous oversight.

${ }^{45}$ See also: John (2007), 221.

${ }^{46}$ Calls for categorical bans on GMOs based on this principle are, I think, a prominent example of this (Comstock 2010; Clarke 2005, 126).
} 
In its most general form, the precautionary principle advocates action ${ }^{47}$ to mitigate foreseeable and probable risks to particular values, some of which would be deemed "special" in the sense that transgressing them would be profoundly unacceptable (John 2007, 221-2). As John (2007) rightly points out, the "specialness" of a particular negative outcome can be justified in either deontological terms (that is, through claims that the harm really is special in some normatively salient way) or consequentialist terms (that the state ought to treat certain threats as special, since, in part, doing so would have prevented or mitigated some of the "worst health crises of the $20^{\text {th }}$ century") (John 2007 , 222). As such, if the research into a technology comes with serious potential threats to the society or its members, then the precautionary principle strongly motivates cost-effective measures to mitigate such potentialities, and rightly so. If the threat is known or reasonably foreseeable ${ }^{48}$, then it makes sense that they should be mitigated whenever possible to the highest degree given the budget allotted for such public safety measures ${ }^{49}$. This call to mitigate potential risks even when the empirical evidence doesn't point to them being anything more than a possible consequence is, I take it, the driving force behind the intuitive pull of the precautionary principle - when it comes to dangerous technologies, it seems straightforwardly better to err on the side of caution and protect the safety of citizens whenever possible.

As mentioned above, some of the advocates of the precautionary principle see its vagueness as an advantage due in large part to the practical utility such a vague principle has in policy discussions and for motivating governments to take more seriously the environmental and social effects some technologies may have within such discussions (Clarke 2005, 5). Further, the vagueness of the precautionary principle

\footnotetext{
${ }^{47}$ Importantly, "action" here includes moratoria and prohibitions on the research or implementation of technologies deemed overly dangerous.

${ }^{48}$ By "reasonably foreseeable" I mean only that the mechanisms that would have to be in place to make a negative consequence result from the research or practice of a particular technology are understood to the degree that it is plausible to assert that the technology will interact with them in a way that will bring about those negative consequences.

${ }^{49}$ This point about cost-effectiveness is important, as it allows us to remain cognizant of the fact that there are other important uses for taxpayer dollars that are not to be neglected.
} 
can, much like some of the human rights language, contribute to its global acceptability since it may be nuanced by different governments in different cultural and geopolitical contexts ${ }^{50}$. Nevertheless, more precision in its definition appears to be needed for it to be used effectively in policymaking while meeting criteria surrounding public justifiability. Fortunately, two proponents of the precautionary principle, Jordan and O'Riordan (1999), have identified key features of the principle that is relatively consistent across formulations and offer some clarity to the issue. These features are:
(1) proaction
(2) cost-effectiveness of action
(3) safeguarding ecological space
(4) intrinsic value and legitimate status
(5) shifting the onus of proof
(6) meso-term planning
(7) paying for ecological debt (Clarke 2005, 5).

(1) and (2) have to do with the advantages described above, namely, the proactive motivation to mitigate risk even in the absence of scientific certainty and due consideration for the resource limitations present in risk mitigation. (3) and (4) have to do specifically with the environment and the "special" bad outcomes, affirming a "wide margin of error" when environmental destruction is a legitimate worry and attributing some kind of moral status to nature (although, admittedly, the extent and force of this moral status will vary depending on exactly who is wielding the principle, which is indicative of another vagueness issue). (5) places the onus to prove the safety of a technology onto the advocate of that technology - a point to which we will be returning shortly. (6) ensures that a long-term focus is brought to bear in the risk assessments surrounding a particular technology in the hopes of reducing the likelihood that future considerations are underestimated when compared with present-day considerations and (7) holds institutions and individuals responsible for damages to the environment,

\footnotetext{
${ }^{50}$ Those who praise the utility of the principle's vagueness typically regard the vagueness of some concepts in human rights in the same light. Vagueness in international treaties can be effective, but there is good reason to wonder whether allowing such socio-political contingencies to determine the content of these agreements and principles is advisable.
} 
even those done in error or out of ignorance (ibid.). These seven features give us a set of benchmarks that can plausibly guide the formulation of a precautionary principle for use in policymaking, a guide to the way policymakers ought to view the world ${ }^{51}$, and a substantive and more manageable set of criteria that can be subjected to philosophical analysis.

As I said above, the precautionary principle can be interpreted and employed with varying degrees of conservatism and this has caused significant confusion stemming largely from vagueness in dealing with (3), (4) and (5). For example, a deep ecologist might employ (3) and (4) to motivate particularly strong non-interventionist principles and prohibit activities that would be deemed permissible were the principle wielded by another (although the divergence need not be so severe to have a profound impact on policy decisions). (5) is, perhaps, the most contentious of the precautionary principle's features - placing the burden of proof on the advocate of a particular technology will raise questions about what that burden entails and what standards we ought to employ to determine if that burden is met. Nevertheless, (5) has a significant advantage in that it specifically precludes corporate attempts to push an innovation through a regulatory body merely due to a lack of evidence pointing to its dangers. If the advocate of a particular technology must shoulder the cost and effort to prove the technology safe for research or proliferation, then the regulatory agency might focus its attention on vetting the quality of the researchers' results and proposals, rather than having to take the initiative to prove a technology unsafe before it can be proliferated due to insufficient evidence. This is, I take it, an advantage that (5) brings to the precautionary principle that is not present in alternatives and, further, is not something that should be thrown away lightly.

A strong version of the precautionary principle might be formulated as:

(Strong) Precautionary Principle: "When an activity raises threats of serious or irreversible harm to human health or the environment,

\footnotetext{
${ }^{51}$ Jordan and O'Riordan consider the precautionary principle to be more of a guide to "how policymakers ought to view the world" rather than a mere strategy for cost/benefit analysis (Clarke 5).
} 
precautionary measures which effectively prevent the possibility of harm (e.g., moratorium, prohibition, etc.) shall be taken even if the causal link between the activity and the possible harm has not been proven or the causal link is weak and the harm is unlikely to occur." (Harris and Holm 2002, Page 358).

While Harris and Holm intended this formulation to be weak in nature, I find Jonathan Hughes' critique convincing. Their formulation takes the stronger parts of the Rio and Wingspread formulations and combines them to derive a formulation that is stronger than either (Hughes 2006, 450).

Nevertheless, it is useful to show how the proactionary feature (1) of the precautionary principle can be strengthened from a motivation to mitigate risk in the case of incomplete evidence to an obligation (in Harris and Holm's formulation) to do so. Further, we can see the (5) at work in this formulation, as the obligation to engage in precautionary measures comes with the possibility of harm that has not been proven and, presumably, lifting the moratorium (or whatever restriction is imposed on the technology) would require adequate proof of the technology's safety provided by the advocate.

A weaker version of the precautionary principle would not, then, employ the obligatory language that we see in the stronger version, leaving the policymakers with more autonomy in their decisions regarding risk mitigation. Indeed, the Wingspread formulation of the precautionary principle opts instead to state that the lack of scientific certainty about the potential ill effects of a particular technology's development and proliferation "shall not be used as a reason for postponing cost-effective measures to prevent environmental degradation", which allows policymakers to opt against such preventative action, depending on the circumstances (Hughes 2006, 450). Furthermore, there is some flexibility in the weight of the burden placed on the advocate of a technology (the lighter this weight, the weaker the principle becomes) and there is room for discussion regarding how strongly the policymakers ought to affirm (3) and (4). However much the principle might be weakened or strengthened through changes to these features, though, (5) remains a problem for reasons we will explore in the next subsection. 


\section{III.2.ii. Concerns with the Precautionary Principle}

Despite the clear advantages the precautionary principle has in practice, it remains no stranger to criticism. In this subsection, I want to discuss two more common (and closely related) objections to the precautionary principle and a third more a posteriori objection that receives less attention but, I think, remains a problem insofar as the precautionary principle maintains its distinctive allocation of the onus of proof. The interconnected objections are the so-called "precautionary paradox" and concerns about a status-quo bias at the heart of the principle and the latter less-common objection has to do with the effect the precautionary principle has on advocacy and public dialogue on contentious research and development projects (including, but not limited to, enhancement).

The precautionary paradox is the idea that the precautionary principle's attempts to mitigate risk so as to reduce the harm caused by some more dangerous technologies actually causes more harm than it prevents due to its paralyzing effect on scientific discovery (Harris and Holm 2002, 361). There are two elements here, namely, the cause of the practical "paralysis" problem that the precautionary principle poses to technological development and the objectionable effect such a paralysis might have. The related concerns about a status-quo bias are concerns about identifying these objectionable effects - our intuitive preference toward the "devils we know" is not necessarily reflective of the objectively rational choice, given the potential benefits a technology promises and the possible dangers involved. In the coming paragraphs, I will discuss these elements in turn.

The problem of paralysis due to an overemphasis on precautionary risk-mitigation comes largely from the fact that the precautionary principle places the onus on the advocate of a technology to prove a technology's safety despite contravening concerns (Jordan and O'Riordan's precautionary principle feature (5)). As Harris and Holm rightly point out, expecting a technology's advocates to prove general statements about the safety of a technology risks making an impossible task necessary for the 
justification of research projects. Just as proving all ravens are black would require an inspection of all individual ravens, proving that a technology is and will continue to be safe would require empirical proof about future instances of that technology's use and activity, which simply cannot be done (especially if the research is prohibited!) (Harris and Holm 2002, 361). Stronger versions of the precautionary principle, especially ones that impose an obligation to act on risk mitigation even without conclusive evidence of the risk, would obligate policymakers to work against many research and development projects in response to the specter of possible negative future consequences. Weaker versions that do not employ such obligatory language will still regard the expectations of (5) as legitimate, despite the overly high expectations placed on technology proponents to meet the impossible task of proving their project safe against the unsubstantiated worries about future consequences.

Another avenue that is available to proponents of the precautionary principle is to weaken the burden of proof that is imposed on the advocates of a technology. One way that this is done is to incorporate the different worries into the cost/benefit analysis and artificially adding greater weight to the dangers (especially environmental dangers) in an attempt to rig the cost/benefit analysis such that it errs on the side of caution (John 2007, 221). This does, unfortunately, add yet another level of vagueness to an already vague principle and threatens to undervalue the benefits technological developments have to offer. While Glannon might object to germ-line genetic interventions for the treatment of sickle cell disease due to (unknown) potential consequences for future generations, Harris and Holm can point to real-world empirically verifiable benefits for the millions burdened with this disease and this alteration to the precautionary principle would, as a matter of principle and method, still emphasize Glannon's concerns. Such a move might be hasty, then, for if there is room for evaluating the weight of the different concerns, surely that takes place within the analysis and not prior to it, which would permit epistemological questions about the certainty with which opponents assert different worries, discussion about the values threatened by the technological development, 
attentiveness to the risks involved with not developing the technology, etc. Otherwise, the presupposition that the harms caused by the development of the technology in question are, as a matter of principle, to be weighed more heavily than both the benefits of its development and the dangers of not developing it causes the worry of paralysis to return and risks affirming a bias toward the status-quo, which will be addressed below.

First, however, something should be said about the secondary element of the precautionary paradox, namely, the "objectionable effect" that the paralysis might have when it comes to scientific discovery. The prolonging of suffering and harm which would otherwise have been mitigated were researchers permitted to go forward with their research is the most obvious of these negative effects. It is a difficult balance to strike; on one hand one surely wishes to reduce the possible ill-effects a technology might have to the environment, society and individuals, while on the other it must be recognized that there is already great harm underway, and downplaying the urgency of meeting these harms borders on complacency. I think there are especially interesting questions here regarding the commensurability of risks caused by human technological projects and the risks posed by nature; certainly harm caused by, say, a dangerous pharmaceutical seems straightforwardly worse than the harm caused by a natural pathogen, but I suspect that has largely to do with there being a bearer of blame in the first case as it is indicative of a systemic failure, malevolence, etc. rather than the harm itself being actually worse. If the harm caused by human development projects and harm caused by natural mechanisms are commensurable to some degree, then the precautionary paradox maintains its bite. This is even more unsettling when one considers the effects of the so-called "status-quo bias", to which we now turn our attention.

The status quo bias identified by Bostrom and Ord has been used extensively to point at problems in the bioconservative positions on human enhancement (Agar 2010, 134). The core of the 
bias comes down to a general human predisposition to prefer the current state of affairs over change an empirically demonstrable and allegedly unjustified preference. An example of this is the case of the Californian power consumers who, after being asked about their preferences with respect to the tradeoffs between service reliability and rates and were given the choice between different plans that combined different degrees of reliability and rates with one plan designed to reflect the status-quo, "a strong bias to the status quo was observed" (Agar 2010,135). This bias is problematic in the context of the precautionary principle for two reasons: firstly, it obfuscates the objectionable effects that paralyzing the development of a technology might have and, secondly, it risks overemphasizing the future uncertain risks. The obfuscation of the objectionable effects occurs because the paralysis of the technology preserves the status-quo, which is intuitively preferred due to the status-quo bias rather than for any principled or justified reason. The status-quo is often objectionable, especially when one regards the suffering and hindrances to autonomy that are observable in the world today, and yet if the precautionary principle is employed, the suffering and hindrances to autonomy that might result from the development of enhancement research are given the presumption of priority. Further, it risks overemphasizing future risks since those risks represent departures from the preferred status-quo, making them seem more objectionable than they might otherwise be. This objection highlights how difficult it is to assess the risks involved in maintaining the status-quo, which is necessary to achieve a publicly justifiable assessment of the risks that a new technology brings to the table, and erring on the side of caution no longer seems as safe a move as before.

The last concern I want to consider here has to do with the effects advocacy groups that wield a strong version of the precautionary principle have on the public dialogue concerning contentious and risky research and development and is not entirely unrelated to the concerns above. Public dialogue concerning different technological developments is important, not only because public funds are being used at many stages in the development process, but also because the risks and benefits involved in 
such projects often accrue to the public specifically. At the same time, however, the debate in the public sphere is precarious, as members of the public, when considering contrasting views regarding something as important and personal as food safety "place great emphasis on negative information" (Comstock 2010, 58). That is, the possible negative implications a technology might have in the future are typically given greater weight than the foreseeable positive implications - and this might well be the rational thing to do in the case of GMOs and plentiful food, since the surplus of nutrition found in the developed world allows the individual to avoid suspicious foods without compromising their food supply (ibid.). To make this point clear, Comstock presents an interesting thought experiment wherein the individual is presented with an array of doughnuts to choose from and, in the middle of their deliberations, a naked man with wild hair runs into the room, picks out a particular doughnut and declares that "this doughnut will cause cancer! Avoid it at all costs or die!" (ibid.). The naked man is far from a credible source, but given the multiplicity of other options, one might be excused for not choosing the purportedly tainted doughnut ${ }^{52}$.

But how does this bear on our discussion of the precautionary principle? The concern is this: a worry about the negative consequences a technology might have, when expressed, is given more weight by the general public than a positive view, and there isn't much by way of a principled reason why this should be the case (indeed, much of this predisposition can likely be attributed to the status-quo bias at work). Furthermore, due to the precautionary principle's locating the onus of proof on the proponent of a new technology rather than the opponent, the worries about negative consequences do not even need to be substantiated to have purchase in the policy debate and the public dialogue, where they will be given greater emphasis despite the lack of evidence ${ }^{53}$. This puts the advocates of a technology at a

\footnotetext{
${ }^{52}$ To the risk-takers who are inclined to answer that they would take the purportedly tainted doughnut, Comstock suggests a slight modification of the thought experiment where the individual is choosing a doughnut to give to his or her 2-year-old daughter, which, I suspect, is enough to dampen such inclinations (Comstock 2010, 58).

${ }^{53}$ An example of this might be found in the debates regarding geoengineering as a way to mitigate the effects of climate change. The kinds of global engineering projects that involve direct intervention in the climate systems of
} 
significant disadvantage in the public sphere especially, and again the paralysis of scientific discovery that lies at the heart of the precautionary paradox is evident.

As such, while the precautionary principle seems intuitively pleasing, there is reason to worry that some of its appeal is due to it having a very human and yet unjustified bias built into it. It allows for the paralysis of a technological development based on little or no evidence (even if it does not obligate it) and leaves the proponents of a technology at either a distinct disadvantage or with the impossible task of proving their technology safe. Risk in the development of new technologies is unavoidable, but overemphasizing that risk threatens to understate the risks involved with not developing the technology (more clearly, the harms that would be perpetuated by the status-quo) and the benefits that can come from its development. Despite the precautionary principle's advantages, there is good reason to be suspicious of its influence in our policy discussions.

\section{III.2.iii. An Alternative to the Precautionary Principle}

The "Proactionary ${ }^{54}$ Principle" is a rather strong principle developed in response to the precautionary principle that takes as its mandate the promotion of technological development despite the safety concerns that accompany such projects. Originally proposed by the technoprogressive commentator Max More and his Extropy Institute in 2004, the proactionary principle begins with the idea that scientists and researchers have some kind of right to innovate and impositions on that right amount to undermining their freedom to do so (More 2005). Importantly, a key feature of the proactionary principle is its relocation of the onus of proof regarding the safety of the technology onto the opponent of its development, meaning any attempt to block the development of a technology will

the earth come up against an array of worries and concerns, which need no evidence to sway the public while the evidence needed to prove the safety of geoengineering is exceedingly difficult to gather (due to either the impossibility of gathering evidence about future events or due to the sheer size and complexity of the experiment needed to show its impact on global climate and the environment).

54 "Proactionary" here is not to be confused with the proactionary feature of the precautionary principle as identified by Jordan and O'Riordan. 
have to be supported with strong evidence. This is advantageous in the sense that the threats of paralysis posed by unsubstantiated worries in the precautionary principle are significantly reduced and technological development can progress unimpeded by under-justified concerns. Further, built into the principle is the imperative to treat natural and technological threats "symmetrically" such that technological threats are not given higher priority merely due to their being "unnatural". As briefly stated above, I find this move especially appealing, since there appears to be so little distinguishing natural and technological dangers when considering policies to reduce suffering.

Straightforwardly, in More's view, a better approach to evaluating the risks involved in research that avoids the paralysis problem would be this proactionary approach that highlights the following principles:

(1) Freedom to Innovate

(2) Objectivity

(3) Comprehensiveness

(4) Openness/Transparency

(5) Simplicity

(6) Triage

(7) Symmetrical Treatment

(8) Proportionality

(9) Prioritize (prioritization)

(10) Renew and Refresh (More 2005).

Many of these features are shared with the precautionary principle (albeit with differences in language), but key differences are to be found in (1) and (10), while the explicit endorsement contained in (7) is worth noting ${ }^{55}$. (1) proposes a shifting of the onus of proof away from the advocate of a novel technology and onto those who would support measures to restrict its development, claiming that the

\footnotetext{
${ }^{55}$ The Symmetrical Treatment principle makes a case for treating harms originating from nature and technology alike. Of course, I would think that it has to admit that intentional harms brought about by the use of technology would be exempt from this symmetrical treatment as they are clearly worse than unintended and unforeseen harms, but the point is that technological harms should not be taken to be worse than natural harms merely due to their origin. This is a point to which we will return in Section IV.2.iii. in our discussion of the natural harms and limitations imposed by the human condition and the technological attempt to overcome them.
} 
importance of scientific research to humanity means that we should be wary about the use of unproven concerns to motivate limitations on its development (More 2005). Whereas the precautionary paradox is problematic for proving a novel technology's safety in the face of unproven future concerns, the proactionary principle's shifting of the onus of proof minimizes the chances of unacceptable paralysis by ensuring that restrictive policies are to be motivated by concerns that are well-supported by evidence. If we hold true to the research/practice distinction as discussed in Section II.1., then such research projects are also not to be motivated by appeal to the speculative future benefits that might arise from its proliferation, ensuring that the deliberation about novel research avenues is based on available evidence and debate over the kinds of capacities that society should be seeking to expand.

The last of the principles in the proactionary principle, (10), proposes that an ongoing evaluation of a technology's safety is to be preferred over a presumption of precaution so that we might take action where research becomes problematic. More proposes here that we ought to establish a "trigger" within research projects that prompts a reevaluation of its safety and potential when conditions have changed enough to warrant such a re-examination (More 2005). Presumably, this trigger would include new evidence of danger in a research project, the discovery of mechanisms by which such research could become dangerous, developments in other research projects that call the value of the research into question, etc. and, in More's view, would be sufficient for ensuring that research does not impose too great a burden of risk while still avoiding the pitfalls of a presumption of precaution.

Of course, the proactionary principle is not without problems of its own. Most notable of these issues is its attitude toward the dangers posed by certain kinds of technological development. By cashing out the foundation of the principle in terms of the "freedom to innovate", the principle promotes research and development projects with little regard for the risks involved and permits research and development projects to be pursued until evidence can be provided regarding its dangers. 
The kinds of safety studies that are being proposed here would be taking place during the development and proliferation of the technology, a kind of "ongoing" process that intertwines research and development with safety testing (as indicated by principle (10)). This has the potential to be exceedingly risky, especially given the kinds of research being done today where error means significant danger to the environment and human health, and the conclusions regarding the dangers posed by a technological development that are gleaned from the real-world effects of its proliferation will be of little comfort to those whose lives were negatively affected by overzealous research projects that went forward in the face of uncertainty.

Furthermore, the proactionary principle in this particularly strong form sacrifices what is perhaps the main advantage of the precautionary principle, namely, its capacity to hamstring corporate attempts to force research projects through regulatory agencies on the basis of a lack of evidence pointing to its dangers. Worse still, there exists a multitude of examples of corporations striving to suppress evidence that threatens their products (and profits), from the tobacco industry fighting reports linking their products to cancer to the oil industry attempts to undermine research on global climate change (Milberger, et al. 2006, 19). Without some kind of criterion that properly incorporates legitimate worries about possible negative consequences, the proactionary principle risks offering a carte blanche to research institutions to engage in whichever project they desire, and those tasked with protecting the public from the very real dangers posed by certain kinds of technological developments are simply asked to keep up or stand aside. Furthermore, if the regulatory agencies and advocacy groups lack the resources to carry out the safety studies and gather evidence of threats, then the projects that are neglected for resource reasons become significantly riskier as they are allowed to develop without oversight and without proper attention to their dangers. As such, the proactionary principle is burdened with problems and its main proponents, being quite adamantly on the technoprogressive side of the spectrum, have shown little motivation to weaken its mandate. 


\section{III.2.iv. Weakening the Proactionary Principle}

If we want to preserve the distinctive advantages of the precautionary principle while avoiding its potentially paralyzing effect, we have good reason to seek a weaker proactionary principle that does not fall into the significant problems expressed above. To do this, it must at first be recognized that cashing out the researchers' freedom to innovate in liberty rights terms is dangerous - doing so guarantees that the researcher can pursue experiments that are very likely to be harmful when insufficient time has been given to actually gather the evidence of their dangers. This does not mean, of course, that it is perfectly just to interfere with researchers arbitrarily, but rather that research endeavours that impose risks on the general public and trial participants are not protected by some liberty right and thereby made unassailable to regulators. As Nicholas Agar puts it "I am skeptical of the general idea that the 'uncertainty of the ultimate consequences' of an action is ground for support rather than for opposition" (Agar 2010, 138); it does not follow from the lack of certainty regarding a technology's dangers that we ought to pursue it wholeheartedly. Furthermore, even in the absence of scientific certainty regarding the potential dangers of a technological development, not all empirically unsubstantiated worries are created equal. Concerns that rely on imagined or unknown physical mechanisms are substantially different from concerns that identify known mechanisms within, say, an ecosystem, that can play a causal role in the emergence of negative consequences and, as such, merit different degrees of credence.

A weaker version of the proactionary principle would, then, retain the distinctive location of the onus of proof while taking some measures to ensure that proper safety measures can be taken prior to the development of a technology. It is difficult to see how this can be done without some sort of trial period in which the regulatory agencies and advocacy groups (on whom the burden of proof is placed) have a chance to actually gather the evidence of its danger. Lack of scientific evidence regarding the 
dangers posed by a particular technology has little weight when there has not been sufficient time to gather this evidence - it is this trial period that might offer a route to preserve the precautionary principle's distinct advantage, namely, its capacity to hamstring attempts to push potentially harmful technologies through regulatory bodies citing lack of scientific certainty regarding its dangers. Furthermore, the length of the trial period can be made relative to the foreseeable risk of a particular research avenue, which can be identified using clear benchmarks such as: recall potential, direct threats to participant health, indirect threats to health factors, threats to the environment, etc. Positive factors can be incorporated into the determining of the length of this trial period as well, including: risk due to inaction, social value, scientific value, etc. Such an approach can give clear benchmarks (as opposed to the often-vague criteria that motivate the precautionary principle) while placing a burden of proof that can be plausibly met by those who oppose the new technologies.

A weaker proactionary principle that includes this kind of trial period might offer a route to a more methodologically sound approach to dealing with uncertainty in the development of risky technologies. Admittedly, however, it does not solve the practical problem in the proactionary principle related to the financial burden that would be placed on regulators and advocacy groups by substantially increasing the role that they are to play in the development of a new technology. As things currently stand, it is unlikely that regulatory agencies will be in a position to shoulder the cost, so the implementation of this proactionary principle will have to be accompanied by changes in the way that the regulators are funded.

While this relocation of financial burden seems at first objectionable, I would like to suggest a few reasons why this change might nonetheless be warranted. Firstly, governments and the public that they represent have a legitimate interest in ensuring that the research and development projects that take place under their purview are safe and there is, therefore, good reason to pursue evidence and take 
action against projects that can be proven to be harmful. Secondly, the current state of affairs where the methodologically problematic precautionary principle places the burden on researchers to provide evidence of their activity's safety is unacceptable and risks perpetuating the status-quo. Thirdly, funding regulatory agencies such that they might pursue concrete evidence of a technology's danger and take action against that technology gives the regulators the power they need to prevent the research of a verifiably dangerous technology, and to do so on sound scientific grounds. If the ongoing investigation into the dangers of a particular technology does uncover some serious, verifiable concerns about the technology's impact once proliferated, regulators are empowered when it comes to regulating their proliferation as well. Lastly, it is certainly possible to have the proponents of a particular research avenue shoulder some (if not all) of the costs of independent review, insofar as measures are taken to ensure that their financial contributions do not unduly influence the investigation. They, too, have good reason to ensure that their research does not impose excessive risks, and such independent investigations can pursue evidence of the dangers of their proposed research before they commit themselves (and, indeed, their brand) to research that may end up imposing unacceptable harms.

Finally, something should be said about the effects a weaker proactionary principle would have on the public dialogue surrounding contentious scientific research projects. A strong feature of the proactionary principle is its capacity to highlight unsubstantiated concerns and explicitly identify them as illegitimate grounds to motivate a ban on a particular technology. While it is doubtful this will have the profound effect of mitigating the overemphasis members of the public often place on the possible negative effects of a technology, it does not encourage such speculation in the way that the precautionary principle does and it does not bring such questionable predispositions to bear on policymaking. Evaluating the length of the trial period might involve such speculation, but the trial period is to be used to gather evidence about whether there are legitimate grounds for banning a technology, rather than directly banning or imposing excessive restrictions on the technology itself. This 
distinction will likely not satisfy the Extropians who formulated the proactionary principle, since this trial period will, in their view, hinder the liberties of researchers to innovate (a right of which I think we have good reason to be suspicious), but it does capture some of the more appealing aspects of the precautionary principle while admitting of some caution in development.

This proactionary approach to research does, I think, ultimately rule in favour of pursuing enhancement research, and, insofar as adequate time is given to assess and provide evidence of possible risks that may arise in the trials, it is less vulnerable to the serious drawbacks that come with giving a carte blanche to enhancement researchers. The precautionary principle's automatic privileging of the status-quo would be a reason to seriously restrict such research in the face of unsubstantiated concerns, but the problems in the status-quo are not to be underestimated. A proactionary approach has a better chance of appreciating these problems and the substantial role that scientific research plays in mitigating them through ingenuity in scientific development. Furthermore, the novel nature of these developments is not sufficient reason to endorse precaution prior to the actual analysis of the risks and benefits that may come from the research - such analysis should be done within the ethical analysis itself and the conclusion that the research is too risky even given the problems in the status-quo that it endeavours to solve should be well-supported by evidence. The proactionary principle's relocation of the burden of proof onto those who would restrict the research ensures that the status-quo is not unjustifiably preferred, but rather appreciates the importance of scientific development while maintaining the benchmarks for ethical research that endeavour to minimize risks and protect trial participants overall.

\section{III.3. Trial Participants and Enhancement Research}

The final set of concerns we will be examining with respect to the ethics of researching biomedical enhancements are those that come specifically from research ethics and focus on 
enhancement research trial design and the protection of trial participants. Historically, trial participants have been offered few protections, often resulting in egregious harms in the name of scientific research - a scenario that we must strive to avoid going forward. Trial participants are rightly regarded as an especially vulnerable group (and when those participants come from a vulnerable social group, even more so) (Jonsen and Miller 2008, 481). The main sources of this vulnerability are found in the knowledge differential between trial participant and researcher, common misconceptions such as the therapeutic misconception, the potential for exploitation, and the health risks that participants incur for the purposes of developing interventions that benefit society as a whole. The eight benchmarks mentioned in Section I.3. are designed to protect participants within the context of these trials, so arguments that intend to show that biomedical enhancement research is impermissible tend to appeal to these benchmarks and attempt to show that such research cannot possibly meet them all. First we shall examine an argument from Norman Daniels that points to the difficulties that enhancement research encounters with respect to (5), the Risk-Benefit criterion for ethically sound research. Section III.3.ii will focus on the concerns that surround biomedical enhancement research in the global context.

\section{III.3.i. Challenges from the Risk-Benefit Criterion}

In Can Anyone Really Be Talking About Ethically Modifying Human Nature?, Norman Daniels argues that research trials that seek to improve on "an otherwise normal trait" would fail to meet the risk-benefit criterion almost by necessity (Daniels 2010, 38). The central issue of this argument (dubbed "you can't get there from here") is that the trial participant incurs health risks by participating in the research trial but any benefits that might be gleaned from the trial would not be directed at health or treatment. Insofar as we treat health risks with special consideration (as we very likely should), that special consideration would, in Daniels' view, outweigh any enhancement-oriented benefits and as a result, "a careful research protocol would most likely stop this experiment in its tracks" (Daniels 2010, 
39). The incommensurability of health risks and enhancement benefits would make (5) "Favourable

Risk-Benefit Ratio" of the benchmarks for ethically sound biomedical research impossible to meet, which is sufficient to motivate prohibitions on such research.

That trial participants are exposed to health risks as part of the process of generating information and products that are of general social value is not to be taken lightly. The protection and promotion of individual autonomy is a crucial element of modern moral theory and has been extremely important to protecting trial participants from the kinds of abuses that plagued scientific research especially before the relatively recent developments in research ethics and human rights (E. J. Emanuel, et al. 2008, 129). The core of the Risk/Benefit benchmark for ethically sound biomedical research is the expectation that those risks can be weighed against the benefits that we can reasonably expect the trial to produce, and the ethical soundness of the trial can be preserved to the extent that the expected social benefits can outweigh those individual risks. Treatment-related benefits are particularly wellsuited to this analysis; research trials that aim to develop novel or improved treatment interventions will also expose the participants to health risks, but the product of that research trial may benefit them in the long run $^{56}$ as their condition is made more easily treatable through such research.

Health risks and treatment-related benefits are, then, of a special nature in Daniels' view, because of their relationship with health itself, which is of "special moral importance" for a number of reasons (Daniels, Just Health 2008, 29). The reason that is most relevant to our discussion is the considerable limitations that ill health imposes on the range of life path options available to individuals and the serious hindrances that it poses to their autonomy (which is, in part, their capacity to actually

\footnotetext{
${ }^{56}$ Importantly, to avoid the therapeutic misconception, the risk/benefit criterion is not supposed to weigh the possible benefits that trial participants might receive within the trial should the experimental intervention prove successful. The benefit is social in nature - the health benefit that the trial participant might gain would be due to the improvement of the society's capacity to meet their health needs in the long run. For this reason, we must be careful when assessing what Daniels means by enhancement benefits being outweighed by health-risks; the health risks accrue to the individual trial participant within the trial, but the treatment and contentious enhancement benefits are set within the context of society as a whole.
} 
pursue the life path that they choose). III health cannot be adequately planned for ; it often comes about through no fault of the individual, and its imposition on the individual often means that they must re-evaluate their ambitions, put their life on hold, suffer financial and social burdens, and endure the physical and emotional toll of having one's own body undermining their agency. Given the liberal state's commitments to the autonomy and opportunity range of its members, the significance of their health has implications for the identification of which institutions ought to be promoted by the state and the scope of their purview. From this foundation, Daniels argues (I think convincingly) that the state ought to be in the business of redistributing wealth such that it may offer health services to its citizens ${ }^{57}$.

By contrast, enhancement-related interventions target otherwise "normal" human characteristics and seek to improve on characteristics in a way that is not health-related in the way Daniels means. A health-related intervention, in Daniels' view, is a medical intervention that targets conditions that cause someone to fall short of what he calls "Normal Species Functioning", which is meant to be an objective baseline of human health ${ }^{58}$. Insofar as an individual falls short of this NSF standard (through illness or bad luck in the natural lottery), they are disadvantaged in the special moral sense exposited above, and a just society's commitments to the autonomy and opportunity range of its citizens means that some of the claims of individuals to provide needed medical resources will be legitimate. Enhancement technologies do not target failures to meet NSF and the entailed disadvantages, but rather aim to bring an individual above the NSF threshold. For example, cognitive enhancement seeks to take an otherwise normal trait (say, average human intelligence) and improve it

\footnotetext{
57 "Citizens" is likely too narrow a term here, given that the state likely has obligations to refugees, undocumented immigrants, and individuals disadvantaged by the global economic system. I simply mean to refer to the set of individuals for which the state has responsibilities, while the scope and extent of those responsibilities is a matter of debate.

${ }^{58}$ The objectivity of "Normal Species Functioning" (NSF) is, however, difficult to establish as there are doubts as to whether this can be done without committing to normatively loaded presuppositions (Daniels 2008, 34). That said, I find this project plausible, even if there remain problems in establishing an objective function for some human characteristics (the brain is particularly problematic here).
} 
beyond what might be considered as falling within the range of NSF. The basis of an individual's claim to medical resources for enhancement purposes is not, then, health-related in Daniels' sense of the term.

We may look to Lev et al. again for a health-related justification based on the dual-use nature of enhancements, as certain kinds of cognitive enhancement will undoubtedly contribute to the development of treatment interventions, but we should be wary of attempting to justify enhancement research based on possible ancillary benefits (Lev, Miller and Emanuel 2010, 109). Such justifications are always vulnerable to the strong objection that, should enhancement research be justified by appeal to the treatment-related benefits it might provide, then perhaps the time and research funds would be better spent on that treatment research itself. Straightforwardly, while treatment-related benefits arising from enhancement research might add to the value of that enhancement research, it is unlikely that such benefits can stand as a sufficient justification for enhancement research.

So I do think that Daniels' point is a good one, but the conclusion to be drawn is not that enhancement research ought to face prohibitive restrictions from research ethics boards as a matter of course, but that the risk/benefit criterion for ethical research demands a positive argument for the value of enhancement research that is sensitive to the purported incommensurability of health risks and enhancement-related benefits. Furthermore, if the research/practice distinction makes the more typical and speculative practice or proliferation-based Transhumanist arguments ineffective in the realm of research ethics, then we require an argument for the research specifically. As such, Section IV. of this thesis will examine possible justificatory routes for enhancement research that, hopefully, can meet this challenge.

\section{III.3.ii. Exploitation of the Developing World}


An important ethical concern relevant to biomedical research in general has to do with the exploitation of the developing world in the pursuit of biomedical advancements that are developed primarily for the benefit of the global north. While the Transhumanists clearly state that they would be unhappy with a world in which the technologies for which they advocate were distributed in such a way that they only favoured the rich ${ }^{59}$, it is nonetheless clear that the initial research and development of enhancement technology is motivated by the prospect of offering it to the developed world, or those who can afford it. Early adopters of emerging technologies tend to be the privileged elite from the global north, and in today's globalized world, those who bear the health burdens associated with trial participation tend to be those who are disadvantaged by their bad luck in the social lottery and left desperate by grossly unjust global resource distribution. This seems particularly unfair as it is the current unjust distribution of resources that leads to an unfair distribution of the risks and benefits of biomedical research where the benefits accrue to the developed world and the health risks (which, again, are of special moral importance) are shouldered by those already disadvantaged by the global economic system (Pogge, Testing our Drugs on the Poor Abroad 2008, 115).

This problem is certainly not unique to enhancement research, as treatment research is also typically oriented toward health concerns that are most prevalent in the developed world and the products of such research are often prohibitively expensive to the communities in which the trials take place. This issue is often referred to as the "90/10 gap" which alleges that 90 percent of biomedical research is done on medical conditions that "afflict the world's wealthiest 10 percent" (Bennett and Tomossy 2006, 55). It might be said that this “90/10 gap" misses its target however, as the medical problems that afflict those in the developing world are generally well-understood and the relevant treatment interventions already developed, which would indicate that this gap should be expected and the moral outrage should be directed at the distribution of treatment interventions, rather than their

\footnotetext{
${ }^{59}$ See: Bostrom, Transhumanist FAQ, 20-1.
} 
research. This response is not so readily available to advocates of human enhancement, however, as enhancement research targets human characteristics that are rather universal ${ }^{60}$ and yet the benefits and burdens of the research are unlikely to be shouldered equally among those for whom it is relevant. Most biomedical research is most relevant to conditions that afflict the developed world, but enhancement research targets otherwise normal human characteristics and the developed enhancement interventions would be relevant to anyone who shares in these characteristics, which would include the developed and developing world equally. Ultimately, the concern has to do with the parasitic nature of performing research on individuals who are unlikely to have access to its benefits.

Importantly, given the discussion from II.1., we must distinguish between the distributive concern that these technologies will be disproportionately proliferated among richer countries and the concern that the trials unfairly allocate the benefits and burdens of enhancement research. The former concern here is contingent on the distributive practices that are applied to enhancement technologyinsofar as the enhancement interventions are characterized as being medical resources, the common call for improved redistributive practices toward the developing world will apply.

There are a number of things to be said about the latter concern, as different approaches to ensuring that trial participants are fairly compensated for the risks they incur have been advocated in research ethics for some time. The ethical principles of Fair Benefits (FB) and Reasonable Availability (RA) are both designed to ensure that trial participants are sufficiently compensated for their contribution to biomedical research done primarily for the benefit of the developed world (Emanuel, Grady and Higgs 2004, 17). FB is designed to obligate researchers to adequately compensate trial participants through monetary or otherwise material means; however some have doubts as to the adequacy of monetary compensation in this context. For example, one could imagine a case in which a

\footnotetext{
${ }^{60}$ This is, of course, a controversial claim that will require argument in Section IV.1.i.
} 
trial successfully produces an intervention for treating HIV while exposing its participants to rather significant health risks in the process. After the trial is complete, the participants might receive monetary compensation for their contributions that were necessary for the successful development of the intervention, but the monetary compensation does not change the fact that they will be unable to actually acquire the intervention due to the inadequate medical infrastructure in their community (E. Emanuel 2008, 290). This strikes many as profoundly unfair because the individuals who were necessary for the development of the intervention are likely to lack access to that intervention once the trial is complete.

To avoid this concern, RA targets the distribution of the product of the research trial specifically by obligating researchers to compensate the health risks incurred by trial participants by ensuring that the products of the research trial are made available to them (and possibly their communities) (Lavery $2010,699)$. If individuals participate in the hopes of advancing the development of interventions that could one day be used to treat their own conditions, then it would seem that offering the developed interventions to these individuals would be particularly relevant and possibly adequate compensation for their participation. Furthermore, this approach would not be subject to possible objections that take issue with financial incentivization and the potentially cheapening or degrading effect of monetary reward by opting for in-kind compensation with health risks with health benefits intertwined ${ }^{61}$. That said, RA appears to be rather limiting and it must be questioned what happens when a research trial is unsuccessful in developing an intervention that can be provided to participants - the risks they incurred from participation in the trial require compensation, but RA proposes that such compensation should come in the form of the products of that trial. In such a case, the advocate of RA could maintain that compensation should be health-related so as to avoid monetary reward, but insofar as the central

\footnotetext{
${ }^{61}$ I am sceptical, however, of the claim that monetary compensation undermines consent in a way that is unlike other forms of compensation (infrastructure improvements, access to medication and medical services, etc.).
} 
concern is that the products of the research in which the individuals participated should be available to those individuals, the need for health-related compensation doesn't seem strictly necessary.

This debate is particularly relevant to enhancement research because the benefits produced by enhancement-related research trials would be particularly relevant to individuals from both the developed and developing world. The $90 / 10$ gap makes it clear that many treatment interventions are developed principally for conditions that afflict the developed world, but enhancements target otherwise normal human characteristics that are largely universal among humans in general, whatever their socioeconomic status or nationality happens to be. The current distribution of wealth and resources in the world indicates that the enhancement interventions (which are very likely to be expensive) would be disproportionately allocated to the developed world while the burdens would fall to the developing world, all while the products of that research would presumably be beneficial to all. To emphasize: the claim here is not that the interventions would only be relevant to the developed world, but rather that they are produced with exclusive distribution to the global north in mind.

While this concern highlights the problems with the allocation of benefits and burdens in enhancement research, there are a number of mitigating factors to consider. Firstly, emerging technologies are often prohibitively expensive to the vast majority of the world's population in the first years of their proliferation and rapidly become less expensive and more accessible as further developments are made. To take one of many examples, in the early 1990's, cell phones were little more than a toy for the rich, and today they are ubiquitous in the developing world and have greatly expanded communication there (Kurzweil, Google's Ray Kurzweil on the Quest to Live Forever 2013). Enhancement research might be primarily carried out for those who can pay, but it's likely that after the early adoption period, the set of individuals that will have access to it will expand considerably. Secondly, while biomedical research conducted in the developing world risks unacceptable exploitation, 
it also plays a beneficial role in the redistribution of medical resources (Pogge, Medicine for the 99 Percent 2011). Enhancement research involves a wide range of health-related resources, from genetic testing and perinatal care to improved medical infrastructure, and many of these resources would otherwise be out of the reach of the vulnerable communities in which such research is conducted. While it would be too hasty to reduce the goals of biomedical research in general to the redistribution of resources to compensate for injustices in their distribution, more research opportunities means more opportunities to bring about this ancillary benefit, and this is a side-effect that should be welcomed.

Finally, the principles of Fair Benefit and Reasonable Availability are both designed to compensate individuals for the risks they incur within the trials. While the health risks are very real, I do not believe them to be beyond adequate compensation, even if health risks threaten something of special moral importance. The special moral importance of health, in Daniels' view, is in large part due to the disadvantages that ill health imposes on individuals with respect to their range of opportunity, and that we should be particularly concerned about such disadvantages, but trial participants in the developing world are disadvantaged not only by ill health but also as a result of their socioeconomic status and a lack of access to resources (Daniels 2008, 57-8). These compensatory principles mitigate such disadvantages by redistributing resources to those that need them, and enhancement research provides more chances to redistribute resources for this purpose. Of course the current state of global resource inequality is unjust and the resulting distribution of burdens for biomedical research is objectionable in this broader context, but it is not the role of biomedical research to repair the entirety of the global economic system in which it operates - instead we should be looking for ways to ensure that such research brings about both social good through its products and through the compensation and redistribution of resources that is involved. 


\section{III.4. Concluding Bioconservative Worries}

To conclude this section, it is worth looking at what this means for the positive project that is called for when it comes to motivating enhancement research. When it comes to the permissibility of biomedical enhancement research, I have expressed my doubts about arguments that rely on some inherent wrongness when it comes to intervening in the human genome or human condition. Whether this wrongness is based on some commitments we have toward nature, human heritage or cultural values, it is difficult to go so far as to argue that these enhancements are something that society should not develop. At most, many of them make a case for individuals within certain social groups to avoid engaging in enhancement due to commitments they have toward certain cultural values, but the broader case that they should be prohibited by all of society is a far more demanding argument for which the support is underwhelming. If the concern is with the possibility of creating a novel species and its implications for human rights, I have argued that it should be recognized that the characteristics that ground personhood should also be sufficient for granting these novel individuals moral consideration and protection from the kinds of abuses that human rights theory seeks to mitigate. Arguments from the precautionary principle are as problematic as the principle itself - it overemphasizes the risks involved and understates the problems with the status-quo, playing into the common status-quo bias, which is problematic if we are to have a fruitful public debate.

When it comes to the protection of trial participants, there are very real concerns about the adequacy of the benefits of enhancement research in ensuring that the risk/benefit ratio is favourable and the possibility of the developed nations preying on poorer nations for the development of their enhancement technologies. Protecting vulnerable individuals in the developing world from exploitative biomedical research is a prerogative for REBs whether the research is treatment or enhancementoriented, and I do believe that determining adequate compensation for the risk and effort involved is 
not insurmountable. When it comes to Daniels' "you can't get there from here" argument, it is clear that a case must be made for the social value of enhancements, and if it is to be sufficient for meeting the risk/benefit criterion for enhancement research, then it must acknowledge the distinction between research and practice. This means it should not rely on the speculative benefits that might come from the widespread proliferation of enhancement interventions, just as arguments against enhancement research should not rely on appeals to possible social impacts that might eventually result from its proliferation. As such, the following section will focus on the social value of expanding society's capacities through enhancement research, as well as identify the kinds of enhancements that should not be developed.

\section{The Positive Case for Enhancement Research and Development}

Most of our discussion thus far has focused on the arguments presented by bioconservatives and those opposed to enhancement research, specifically those that argue from its inherent wrongness and the problems specific to the trials themselves. While I expressed doubts about the plausibility and applicability of the arguments from its inherent wrongness, I do think that some of the objections regarding the risk to trial participants and the social value of enhancement research are quite legitimate. Their strength does not, however, make enhancement trials off-limits by necessity, but rather call for plausible restrictions on enhancement research as well as a positive case to be made in their favour. This section will focus on the positive case for enhancement research, starting from the values needed to ensure its permissibility, then moving into the prioritization problem expressed in Section I.2. Once the case is made for its permissibility and the prioritization problem is addressed, then I will look to argue for a plausible set of limitations on enhancement research based on the values that enhancement advocates look to promote and, finally, state briefly what relationship the just state has to such activities. 
Transhumanists and enhancement advocates affirm a range of values that would be promoted through human enhancement, but research ethics demands a more specific set of values - those that are not necessarily dependent on the proliferation of these technologies and those that are not tied to the individual benefits that might result from their use. The main reason for these limitations, as I argued in Section II.1., is that the longer-term impacts of enhancement technologies are difficult to identify and that the research of a given technology is not an endorsement of its proliferation or use proliferation concerns come in at another stage in the analysis. On one hand, Transhumanists like David Pearce and Ray Kurzweil argue that such enhancements are likely to bring about some utopian vision of lives free of suffering and individuals capable of achieving their wildest ambitions and on the other George Annas and Margaret Somerville argue for the likelihood of war, discrimination and the destruction of important human values as the likely consequences. When it comes to the analysis of the ethics of researching enhancement technology, these speculative arguments are more of a distraction than they are constructive.

Furthermore, as I argued with regards to the social benefit-oriented justification of research trials, while many state activities might be judged by appeal to the benefits they will have for individuals, the justification of research trials will rely more on the relationship between the product that the research seeks to develop and the capacities of society. The relevant question here is whether the research is directed toward a permissible and well-motivated expansion of the society's capacities. Going forward, I shall propose that certain enhancements can be motivated by the neutrally ${ }^{62}$ valuable benefits that they offer as society expands its capacity to offer these enhancements to promote individuals with respect to their opportunity range and the adaptability that comes with a greater degree of control over nature. If it can be shown that certain enhancements can have neutral value in a

\footnotetext{
${ }^{62}$ I am tempted to call these "objectively" valuable, but neutral value is more obviously relevant to state funding and obligations for the state to remain neutral with respect to different conceptions of the good, and it also eschews the possibility of metaphysical commitments that might come with claims concerning objective value.
} 
way that is similar to treatment research, then we can make a case for the value of these enhancements that is not subject to concerns surrounding expensive tastes and show why even a liberal state that is supposed to remain neutral concerning the different life paths that individuals take can contribute to this research. We can also show why these enhancements have value for society more generally.

A better understanding of the values pursued through enhancement research can permit us to better evaluate the prioritization problem in more depth, as the problem originates from the automatic priority granted to treatment research. Treatment research is certainly valuable, but given the values promoted by enhancement research, it might be too hasty to grant it automatic priority and it might be understood that enhancement research ought to be pursued in parallel. This might be achievable by pointing to the ancillary benefits that come from enhancement research, as it does have positive effects for the development of treatment interventions as well, but we will concern ourselves mostly with the justification of enhancement research for its own sake. As such, I will propose a further nuancing of the social value benchmark for ethical research which can serve to more clearly show the different ways in which research can be valuable to individuals and society and can offer an explicit avenue for the justification of enhancement research that does not incentivise researchers to characterize their enhancement work as treatment.

\section{IV.1. The Permissibility of Enhancement and the Risk/Benefit Criterion IV.1.i. Health Risks and Enhancement-Related Benefits}

As discussed in Section III.3.i., Daniels' challenge from the risk/benefit criterion is that enhancement research will almost always fail the risk/benefit criterion because the benefits that might result from its development will almost certainly fail to outweigh the very serious health risks undertaken by trial participants ${ }^{63}$ (even when those health risks have been minimized to the extent

\footnotetext{
${ }^{63}$ It might be pointed out that research that is routinely carried out on plastic surgery techniques would be an example of trial participants being subjected to health risks for the development of purely subjective, desireoriented interventions and, contra Daniels, that such research is typically considered acceptable. Daniels agrees
} 
possible, insofar as they remain non-negligible) (Daniels 2010, 39). While this might be motivated by pessimism about the potential of these new technologies, it is more likely that the argument rests on the alleged incommensurability of enhancement-related benefits and health risks since the former foundation risks straying into the long-term speculative arguments that we seek to avoid in this discussion. Importantly, if such a strong distinction divides treatment and enhancement research based on the objectively ascribable health risks imposed on trial participants in the pursuit of quite different products, then this would motivate Daniels' "you can't get there from here" view that would render enhancement research impermissible. For this reason, it must be examined whether the benefits of enhancement technologies are so incommensurable with the health risks involved in developing them, and whether the value of enhancements can indeed outweigh those risks.

One reason why health risks and enhancement benefits might be incommensurable in research is that health risks are "objectively ascribable" while enhancement benefits are primarily beneficial with respect to subjective preference satisfaction (Daniels, Just Health 2008, 43). At first glance, then, enhancements appear to fall within the realm of "health wants" whereas deviations from Normal Species Functioning that impair the individual's capacity to compete for positions they value are characterized as "health needs", and this difference has significant implications for our analysis here. Individuals appear to desire enhancements for this reason, not because they are needed if they are to compete at all in the market, but because they are wanted so as to improve someone's ability to compete for the particular position or goal that interests them. When it comes to the research of enhancement interventions, the case is slightly different. We are not taking about distributing medical resource to meet any health want and to satisfy the ambitions of certain individuals, but rather we are

that this is an example of a research trial that fails to meet the standards he sets out for acceptable risk in research, but rather than attempt to justify these trials through some other means, he argues that "our incomplete adherence to appropriate patient-protection concerns should not count as an argument in favour of ignoring them in the case of [enhancement interventions]" (Daniels, Can Anyone Really be Talking About Ethically Modifying Human Nature? 2010, 38). 
talking about researching interventions that, if developed and made available through some kind of distributive practice, could expand the options of individuals that are looking to compete for that position that interests them. Cognitive enhancements, behavioural enhancements, aesthetic enhancements, etc. are all particularly useful to positions that seek out individuals that excel in these capacities, and those who are disadvantaged in the competition over these positions due to their natural talents are asked by the traditional view ${ }^{64}$ to work to develop these capacities or alter their life plans accordingly.

Arguably, the key difference is that enhancements might be necessary to certain individuals if they are to compete for particular positions, whereas treatments might be necessary if those individuals are to compete at all. Similarly, the health risks involved in enhancement research threaten individuals with respect to their membership in NSF while the enhancements promise benefits with respect to subjective life goals, but can it be said that these two are so incommensurable that the health risks might prohibit enhancement research ${ }^{65}$ ? Recall that the main reason for Daniels' view of the real difference between health risks and enhancement-related benefits lies in the special concern that the state and society have for the health of its citizens. Failure to meet his standard of health is such a hindrance to an individual's ability to compete and pursue their chosen life path that the obligations of the state with respect to the promotion of equality of opportunity are sufficient for motivating healthcare expenditure. That said, there are two plausible responses to this problem, (1) that health risks are tolerable even when it comes to researching certain health wants, or (2) that there are

\footnotetext{
${ }^{64}$ We will return to this Rawlsian "Traditional View" in more depth in Section IV.2.i. For now it is enough to say that the Traditional View regards the limitations imposed on individuals through the natural lottery to be beyond the purview of justice, and something that the individual has a responsibility to accept and adapt their life path decisions in accordance with (Buchanan, et al. 2000, 63-4).

${ }^{65}$ Again, this appears to be Daniels' claim in his "you can't get there from here" argument when he says that: "if we are trying to improve on an otherwise normal trait, the risks of a bad outcome, even if small, outweigh the acceptable outcome of normality. So we cannot ethically get there from here." (Daniels 2010, 38).
} 
neutrally ascribable benefits to enhancement research that, when society is able to offer them to individuals, are comparable to those produced through treatment research.

Lev et. al take the route described in (1) when they question why biomedical research must be restricted to benefits that are specifically health-related (Lev, Miller and Emanuel 2010, 104). While health risks are obviously threats to individuals with respect to NSF, it doesn't follow from this that the benefits gleaned from the research must be health-related specifically. It could be said that individuals take on calculated health risks in the pursuit of subjective benefits all the time, as everything from extreme sports to dangerous careers carry with them non-negligible health risks and are pursued out of personal desire. Many are willing to make health sacrifices for the sake of their ambitions, and it is arguable whether this is as ill-advised as it might seem, since mere survival (or "mere" health) is typically regarded as being insufficient for the good life that individuals pursue. It would follow from this line of reasoning that trial participants willingly taking on health risks as part of an enhancement-related research trial might not be as dubious as it first seems, as it would represent a similar life choice based on a legitimate, personal risk assessment.

That said, the risk/benefit criterion demands more from us than an appeal to the personal benefits that individuals might hope for when engaging in a research trial when justifying the risk undertaken, lest we make an error similar to that described by the therapeutic misconception. Mehlman's description of the "Melioristic Misconception" is relevant here, as, like the therapeutic misconception, it is the misguided attempt to justify the research by appeal to the benefits that individual trial participants might glean from the trial (Mehlman 33). Justifying the personal health risks that trial participants incur as a part of the trial by appealing to individuals' tendencies to take on risks in the name of personal gain comes perilously close to this error. Avoiding this misconception involves examining the benefits that are gleaned from the enhancement research trial through a social lens - 
that is, are the social benefits that might be gleaned from research trials of the sort that risks might be legitimately shouldered by trial participants? Can the capacities of society that are promoted through enhancement research be sufficient to outweigh the threats to participant health?

It must be noted that society does, on occasion, ask its members to shoulder some personal health risk for broader social benefit. An example of this is the employment of soldiers by the state for the purposes of defending and promoting the interests of the society. Unquestionably, there are health risks involved, but insofar as individuals accept these risks when they join the military ${ }^{66}$, they are generally seen as acceptable as the social benefits involved might outweigh them, even if they are not specifically health-related. Indeed, health risks are involved in a wide range of activities that are of social value, including activities that are in pursuit of scientific knowledge and technological progress. If Daniels is to claim that REBs should be stopping enhancement research based on this distinction between health risks and enhancement-related benefits, then some distinction must be made between human enhancement and other kinds of activities that involve health risks accruing to consenting participants, such as space exploration or military endeavours. I doubt this further distinction is possible, and, furthermore, if the second route concerning the possibility of neutrally ascribable health wants is possible, human enhancement research might be even more strongly justified than some of these other scientific pursuits.

One possibility for distinguishing human enhancements and other kinds of technological development is to define biomedical research with exclusively treatment-related aims. It might be claimed that the goal of biomedical research is to develop treatment interventions in an attempt to guarantee some level of normal species functioning to individuals such that they might be able to compete in the market alongside their fellow citizens without the hindrances of disease and illness. We

\footnotetext{
${ }^{66}$ Assuming, of course, that they do so willingly based in part on their personal risk assessment. Conscription would make for a stronger case here, but it is also a rather dubious foundation within a liberal context.
} 
might recall Leon Kass' worry about the rise of physician-assisted death in the field of medicine when he says that the "very soul of medicine is on trial", implying that the field is to be limited to the treatment of patients, rather than catering to their personal decisions concerning life paths (Somerville 2004, 148). If biomedical research, like Kass' view of medicine, is to be limited to treatments in particular, then it would be quite unlike the technological development that takes place in other fields and enhancement research might have no place in its mandate.

Ultimately, however, it is difficult to see what would motivate this distinction without begging the question. Insofar as research is about expanding the capacities of society to engage in novel activities and promote the interests of its members, researching interventions that promote subjective preferences seems like a perfectly acceptable part of its mandate - even if that research involves personal health risks to the voluntary participants. Furthermore, if risky careers directed at the promotion of social good are any indication, it seems plausible that these health risks can be compensated through other means, including monetary reward. Health risks are certainly something to be taking seriously, but they do not preclude participation in research trials aimed at enhancement interventions; rather they highlight the obligatory nature of fair compensation and the need for social value in the research.

When it comes to (2), the possibility of neutrally ascribable benefits comparable to the neutrally ascribable health needs of those who fall short of NSF, we must look more closely at the specific capacities being targeted by human enhancements ${ }^{67}$. Another point of agreement between the Transhumanists and the bioconservatives lies in the characteristics they find praiseworthy, from cognitive ability to motivation and concentration; they celebrate those features that contribute

\footnotetext{
${ }^{67}$ Importantly, the claim here is not that these benefits would be intrinsically valuable, since they are most certainly instrumental for achieving other things of value, but rather that they are neutrally valuable in the sense that they would be valuable whatever one's subjective preferences might be.
} 
positively to human achievement and the pursuit of one's ambitions. Again, the bioconservatives attach the need for struggle and self-development as part of the praiseworthiness of these features, but as I said above, while enhancements might promote these capacities, they certainly do not remove the prospect of developing and nurturing these natural talents, not to mention actually employing them effectively in one's life. The relevant question here is whether we might say that there are neutrally valuable enhancement benefits that would justify the imposition of health risks through research trials.

Concerning this question of neutrally valuable enhancement benefits, Christine Overall makes an important point; namely, that the capacities that we identify as being worth enhancing through some appeal to their value are only valuable insofar as certain social groups bestow value upon them (Overall 2009, 327). As far as Overall is concerned, "the existence of 'raw' natural abilities [is] an illusion" due to the substantial role that social groups play in selecting those that are valuable (ibid.). This is important to the question of neutrally valuable enhancement benefits because their value would be found in the human capacities they promote, and if it were the case that these capacities were simply determined by subjective social attributions of value, then it is doubtful that any enhancement could have this kind of neutral value.

Fortunately, Overall does not make this step and, in the end, argues largely in favour of life extension as being worth developing and distributing for the purposes of promoting equality (Overall $2009,338)$. While it is certainly the case that some capacities and the value of some enhancements are entirely socially determined, some may have value beyond that social attribution of value. Humans live in particularly social environments (and, perhaps, all human environments are social to some extent); the question is whether there are enhancements that would be of value whatever one's social environment (Overall 2009, 327). Positional or relational goods such as height, aesthetic appeal, and 
power $^{68}$ are certainly determined socially, as they have relatively little value when taken out of the social context that values them. But, as Overall argues, life extension in particular represents the kind of good that goes beyond this, serving as a "precondition for any other good" (Overall 2009, 338, emphasis mine). In the coming sections, I will be arguing that this evaluation is not to be limited to life extension (even if it is most easily made in the case of life extension) and that this has value that can motivate enhancement research on a wider range of human capacities as well as give us tools for dealing with the prioritization problems that come with competing enhancement and treatment research.

As such, even if we accept NSF as a sufficient standard for human health due to the neutrally ascribable disadvantages that come from falling below the baseline it sets, certain enhancements are likely to bring about benefits that entail neutrally ascribable benefits. These neutrally ascribable enhancement-related benefits would be beneficial whatever life path one happens to choose, which would mean that the health risks involved in the research trial are not necessarily imposed for the sake of subjective benefits. Daniels' argument concerning the distribution of enhancements in Just Health takes as its primary example the case of cosmetic enhancements such as plastic surgery, but surely not all enhancements are so dubious (Daniels 2008, 151).

If we apply Daniels' analysis of the justification of treatments and treatment research, we see that the underlying value that is doing the work here has to do with the commitments that society has to the opportunity range of its citizens. Precisely how this will be cashed out will have to do with which kinds of impositions on individual opportunity range are to be treated as unjust and worthy of state intervention, but ultimately the social value of a research avenue will rest principally on what the research represents for the life options available to individuals. Treatment research responds to neutrally ascribable health benefits, and enhancement research can be a response to the neutrally

\footnotetext{
${ }^{68}$ This is, of course, a very loaded term. Power can mean bargaining power and capacity for self-determination despite the goals and wishes of others, but it can also mean power over others. The latter, I take it, is a strong example of a positional or relational good.
} 
ascribable benefits that it offers to individuals with respect to their opportunity range. From this, we may formulate the following broad principle, (I), for the social value justification of biomedical research:

(I) Biomedical research has social value insofar as it contributes to the capacities of society to promote, protect and preserve the fair opportunity range of individuals.

Importantly, given what we said in Section II.1. with regards to the research/practice distinction, the point of research is to expand the capacities of society with respect to meeting what particular demands might arise. This distinguishes the justification of research from questions concerning the distribution of the products of that research and focuses instead on the role that scientific progress plays in expanding the society's capacities for meeting different obligations and demands. The way in which these demands might be met stands as a separate question to be addressed in political philosophy, as they may be distributed through public or private means and with different distributive principles in mind, but the actual development of the biomedical interventions is motivated by the society's obligations to promote, protect and preserve the opportunity range of individuals. The focus on the opportunity range, rather than the specific opportunities and life path decisions of individuals, preserves the spirit of the justificatory route (1) above, namely, that certain enhancement interventions might confer neutrally ascribable benefits similar to those promoted through treatment research. The degree to which research into different enhancement interventions will be motivated by this principle will depend on the intervention in question, so it is worth examining a few examples of enhancements in more depth.

\section{IV.1.i.a. Life Extension}

Perhaps the strongest case for neutrally beneficial enhancements is the case of life extension and radical life extension ${ }^{69}$. To understate, there are few things that hinder one's ability to compete in

\footnotetext{
${ }^{69}$ I have my doubts as to whether the degree of life extension is a salient difference here at all, but the two are often distinguished in the literature with the view that radical life extension is the harder case to make.
} 
the market, deliberate about and pursue chosen life paths, and develop one's natural talents more than death. Treatments are often justified by appeal to their effect on the patient's life expectancy, and the expected increase in life years that the product of a research trial might offer is certainly an aspect of its social value. As noted above, life serves as a precondition for any other good in the sense that whatever one's life path, it benefits from being longer. A longer life means more chances at opportunities, realizing ambitions, trying different life paths, realizing the equality to which one is entitled ${ }^{70}$, as well as more time to enjoy one's achievements, and experience a broader range of that which society has to offer. None of these benefits that come with life extension are contingent on the particular life paths chosen by those who would benefit from them, but rather are valuable whatever one's life path happens to be.

That said, there are three very distinct objections that might be mounted against the claim that lifespan enhancement is valuable in the sense required to motivate research despite the health risks involved. These objections are: (A) there are life paths that preclude enhancement interventions, (B) that the "full human life" has no need for life extension and society has only commitments to ensuring that its members enjoy a full human life, and (C) that life extension is not an enhancement at all and thus serves as a poor example for justified enhancement research.

With regards to $(A)$, it must be admitted that there are life paths that one can freely (and justifiably) choose that preclude enhancement interventions, which brings up important questions regarding enhancement of children who have not yet committed to a particular life path or consented to having certain life paths restricted from them. This contests the idea that life extension would be neutrally valuable, since it would not be so easily applied to any life path that one happens to choose,

\footnotetext{
${ }^{70}$ Overall argues strongly from this benefit in particular. She argues in favour of distributing life extension technologies to those who are disadvantaged so that there might be a better chance of them receiving the resources necessary for equality (Overall 2009, 336).
} 
and opens up the possibility of applying the "hyperparenting" arguments from Sandel and Kass to even life extension. The hyperparenting concern has to do with parents imposing enhancement interventions on their children that force them into the particular life path that the parents desire while failing to appreciate the child's agency and the potential for them to develop different preferences (Sandel 2007, 52). For example, a parent might be inclined to enhance their child with respect to physical ability with the expectation that they will pursue some sport with little regard for the child's actual desire to pursue that sport. Extending this concern to enhancements such as life extension involves noting that there are available life paths that would be hindered by it - in this case, the strongest examples are found in life paths that are religious in nature, such as Jehovah's Witnesses who object to a wide range of medical interventions, including treatments.

This is not a trivial point; JWs represent a life path that an child may grow up to freely choose that would be hindered by even those enhancements that we are claiming to be beneficial to all life paths. Unless a case can be made that includes such life decisions, then it would seem at first glance that the enhancement research still risks the health of individuals for purely subjective benefits that are comparable to the aesthetic enhancements from which we seek to distinguish them. At the same time, however, we appear willing to impose treatment interventions on children of JWs despite the parents' wishes (and for good reason), even though the intervention is precluded by the life path that they may eventually choose. Worse still, there is good reason to think that the children of JWs are likely ${ }^{71}$ to choose the same religious path as their parents. And yet, for the sake of the neutrally valuable treatment benefits, such potential life paths are overridden. My suspicion is that those that support the imposition of treatment interventions on children despite the religious views of the parents can at the very least appeal to the fact that the child was not responsible for the treatment that violates what

\footnotetext{
${ }^{71}$ This shouldn't be a controversial claim as individuals who grow up in a particular religious context tend to favour that religion at least more than those who grow up in different contexts.
} 
would become their faith, since it was imposed on them before they even chose that life path. Just as this route is available to treatment interventions, it would be available to enhancement interventions insofar as they are similarly valuable.

In his book False Hopes: Why America's Quest for Perfect Health is a Recipe for Failure, Daniel Callahan argues along the lines of (B) when he claims that "the average life expectancy that is now achieved in developed nations is sufficient to constitute a full life" (quoted in Overall 2009, 333). If it is truly the case that the full human life can be achieved within the roughly 80 years that can reasonably be expected in the developed world, then the benefits that would come from life extension would, in some sense, be supererogatory and a matter of personal taste. From this view, it could be claimed that one has enough time to experience a full life, and wanting more time would be a personal choice similar to the decision to purchase a Ferrari - subjectively beneficial, perhaps, but certainly not the kind of benefit that society has a responsibility to provide.

Overall is right to pick up on the suspicious use of the "full life" here, pointing out that Callahan describes it as being a life in which "one's life possibilities have on the whole been accomplished" (ibid.). First of all, it simply cannot be as clear-cut as this definition suggests, since much must be packed into precisely what constitutes a "possibility" as well as this qualifier "on the whole". What is a possibility for Callahan in this sense? If he thinks that 80 years is sufficient for the full life, then one's possibilities cannot simply be the product of an individual's ambitions, since plenty of individuals die (even of old age) well before they have achieved their life's ambitions ${ }^{72}$. If one takes into account what an individual can reasonably expect given their luck in the natural lottery as well as the technological and historical development of their society (the same constraints that Daniels places on NSF), then that still tells us nothing about whether someone has experienced a full life or not. It could be that all humans are falling

\footnotetext{
${ }^{72}$ I suspect, also, that many who say otherwise have merely tailored their ambitions to their life expectancy later in life, which would further indicate that their life expectancy is limiting their ambitions.
} 
short of a full life due to lifespan limitations, even if they can only reasonably expect so much given their society's technological development. Worse still, Callahan wants to claim that expected lifespans in the developed world are sufficient for living a full life while maintaining that the lifespans available to those in the developing world are insufficient, so his conception of the full life must be more than what one can expect given their society, otherwise the expected lifespans of those in the developing world would be similarly sufficient ${ }^{73}$. Built into his conception of the full life, there must be some range of possibilities to which individuals ought to be privy and whether they achieve the full life must be dependent on the degree to which they actually achieve these possibilities within their life.

This is an important distinction, both for the Transhumanist and pro-enhancement position to consider and for what we will say in Sections IV.2 and IV.3., namely, there is a very real difference between what an individual can expect given their society's capacities and what might be considered a "full life". It is certainly common to look at the lives of those who have died and say that they lived a "full life", and yet it would be reasonable to say that the deceased would have benefitted from a life that was extended by ten or twenty healthy ${ }^{74}$ years. Again, this benefit would be applicable to whatever life path they choose given those extra years, since there are no life path decisions to be made in death.

(C) makes a rather different case that makes no attempt to preclude life enhancement research, but rather claims that life extension is not a good example to be using in this debate. The contention here is that life extension research is treatment research and is to be justified along those lines, contrary to the enhancement designation it is normally given in the human enhancement debate. The

\footnotetext{
${ }^{73}$ To be fair, like Overall, Callahan's ultimate concern is with the distributive problem of social stratification resulting from the upper class enjoying life extension benefits while the poor languish without them. But part of his case involves these claims concerning the full life that implies, in his view, that individuals in the developed world should be happy with the life expectancy they already enjoy.

${ }^{74}$ The insertion of "healthy" here is not a sleight-of-hand, when we are talking about lifespan enhancement, we are specifically talking about extending a life in terms of healthy years. Extending unhealthy years through lifesupport technologies is a different matter entirely.
} 
Transhumanist gerontologist Aubrey de Grey forcefully argues this point, forwarding the position that aging itself, due to the degeneration of cells and bodily functions, is more properly characterised as a disease in need of treatment (de Grey 2013,69). The central point is that we should not be distinguishing between age-related diseases and aging itself, since the latter is quite clearly what brings about the former and the absence of age-related diseases among the young is merely an indication that these diseases "take a long time to develop" the point where they hinder one's opportunity range (ibid.). Just as we see the provision of treatments to the elderly as justified (at the very least, and more likely obligatory), we should also see life extension as pre-emptive treatments for the age-related diseases that are sure to impose themselves on the individual given enough time.

John Harris makes a rather similar point to de Grey by way of analogy, albeit with some key differences. Harris takes issue with Daniels' view that vaccines are to be justified in treatment terms and neatly incorporated into his Rawlsian view of healthcare provision. Daniels' view of vaccines is, roughly, that they are best considered "preventative treatments" due to the role that they play in preventing possible deviations from NSF (Harris 2009, 152). Defined as such, the state's research and provision of vaccines would be obligatory due to the commitments that the state has with regards to the NSF of its citizens. There is good reason to doubt this designation, however, as Harris points out, the contention is "whether making a normal immune system do something it normally doesn't do constitutes 'normal functioning'" (ibid.). In Harris' view, vaccines are a strong example of an enhancement that has treatment benefits, which demonstrates that blurriness of the bright line that Daniels wishes to draw. Life enhancement interventions are remarkably similar, they are an enhancement for a feature included in NSF that have treatment-oriented benefits, since, ultimately, they fend off the deviations from NSF that come with aging. 
If we wish to maintain the treatment/enhancement distinction here, then it seems exceedingly difficult to have it both ways - if vaccines are preventative treatments, then life extension is as well, and if life extension is an enhancement because it improves on a particular aspect of NSF, then vaccines are as well. We need not go so far as de Grey in classifying aging as a disease so as to justify life extension research, but rather can appeal to the treatment-oriented role that it plays in maintaining NSF and obligate society to take steps to promote this kind of research. When this is established, the research ethics point is relatively straightforward - just as the health risks involved in vaccine research are justified by appeal to the neutrally valuable benefits that are tied to maintaining NSF, life extension benefits are valuable for the very same reasons and justified (and likely even obligatory, under Daniels' framework) even if characterized as enhancements. As far as I can tell, the only possible avenue for Daniels to maintain that life extension is an enhancement unworthy of the same justification as vaccinations is to strongly privilege the current expected lifespan as a part of NSF and maintain that the disadvantages that come from aging are a part of the human condition that does not warrant intervention. Similarly, Callahan's view that 80 years is sufficient for living the full life appears to have a lot packed into it, including normative claims about the range of possibilities that should be available to humans in general. As such, the role of aging in the human condition is worth examining given the typical prioritization of vaccine research over life extension research, the privileged place that the current human lifespan has enjoyed in the debate, and the value Transhumanists place on researching interventions that improve on the human condition, so we shall return to these points in Section IV.1.iii.

\section{IV.1.i.b. Cognitive Enhancement}

The more difficult case for the neutral value of particular enhancement benefits is found in the debate concerning cognitive enhancement. Cognitive enhancements are a rather broad category that

includes interventions that target everything from cognitive capacity and memory to characteristics such 
as attention span, awareness and resistance to fatigue. Such enhancements do not enjoy the same justificatory route as life extension or treatment research, since they are specifically targeting a human characteristic for enhancement in a way that cannot be characterized as treatment or preventative treatment. Unlike treatment and preventative treatment research, cognitive enhancement is not about protecting individuals from possible deviations from NSF, but rather intends to make a characteristic better than normal.

Again, some might be tempted to take the line that Lev et al. (2010) take by pointing out the treatment-oriented benefits that come with cognitive enhancement, especially with respect to mitigating the effects of dementia and Alzheimer's. This does not escape the contention that if the ultimate justification of the enhancement research depends on its contribution to treatment interventions, then the research funds should be directed at the treatment research directly. Furthermore, it could be said that certain careers and life paths would benefit from the use of cognitive enhancement interventions, but the health risks incurred by trial participants remain problematic and Daniels' 'you can't get there from here' argument remains quite strong. It is for this reason that we are seeking a justification of cognitive enhancement research that does not rely on treatment-oriented benefits or the benefits to particular life paths that might come about through the practice of enhancement, but rather an examination of what the capacity to cognitively enhance individuals offers and why this might be sufficient to justify health risks to trial participants.

Firstly, cognitive capacity is a characteristic that is typically lauded by everyone from staunch bioconservatives to eugenicists and advocates of human enhancement and its role in human life is difficult to understate (Buchanan, et al. 2000, 49). It is held up to be a distinguishing feature between human persons and non-human animals that plays some role in determining personhood and grounding rights. The reason for this is partially obvious - everything from choosing between life paths to moral 
responsibility rely on cognition to a large degree and often the wrongs done to humans are seen as more grievous than those done to animals due (rightly or wrongly ${ }^{75}$ ) to the greater capacity of humans to suffer not only from physical abuse but also the injustices that they are capable of understanding. Furthermore, even rather rough measures of intelligence such as IQ are positively correlated with success and reward in contemporary society and standards such as literacy and numeracy serve as important benchmarks for evaluating and comparing different societies (Bostrom and Sandberg 2009, 388).

Indeed, as Bostrom points out, modern society has come to expect much of the cognitive capacities of its members, as everything from government and medical consent forms have become increasingly complicated and education inflation indicates an increasing demand for employees with higher cognitive abilities in positions that once demanded less (ibid.). Greater technical proficiency is an asset in almost all lines of work, including careers that were once considered "low skill" such as agriculture and manufacturing as the methods increasingly take advantage of technological advancements and as complex regulations are applied to the activities. Of course, at this stage, this is merely an argument for the expansion of education and the provision of resources to promote an understanding of these developments or simplifying the demands of society in general. To make the case for cognitive enhancement research despite the health risks endured during trials, something must be said about the intentional enhancement of cognitive capacities beyond what is possible through education.

A normally functioning member of the human species certainly has the capacity to take substantial advantage of educational resources to improve their grasp of the complexities entailed by

\footnotetext{
${ }^{75}$ Accusations of speciesism would be relevant here if the relevant moral concern is merely capacity to suffer, but I have my doubts that a case could be plausibly made that non-human animals and human persons are equal in their capacity to suffer. Regardless, suffering imposed on both could be seen as egregious while admitting the greater capacity among human persons to suffer.
} 
their chosen life path and by modern society in general. One does not have to be exceptionally lucky in the natural lottery to achieve success in even the more intellectually demanding fields, since the NSF standard is designed to include the range of intellectual capacity required for achievement should one put in the time and effort to cultivate their natural talent. That being said, however, technological development brings with it greater complexity and takes us further from the environment for which our brains and bodies evolved. As Bostrom argues, the environment for which we are evolutionary adapted is the pre-civilized plains of Africa where the successful traits were not necessarily the same as those that are successful today ${ }^{76}$ (Bostrom and Sandberg, The Wisdom of Nature: An Evolutionary Heuristic for Human Enhancement 2009, 381). More powerful technology, more complex systems and more technical professions mean that the cognitive capacity that comes with NSF might not be sufficient for living in contemporary society. This is especially true for those who fall within the normal range of human cognition, yet perhaps closer to the lower-end of that range, and given that the technological development shows little signs of slowing.

In this sense, we might say that cognitive enhancement has neutral value in the sense that whatever the life path that one chooses, enhanced cognition would be useful for its pursuit and for operating within society. This is not to deny that it is also advantageous as a positional good, but its value to individuals is broader than that - it is valuable to individuals' lives in general and is becoming more important as society develops and its demands on individual cognitive capacity differ more and more from those of the environment that produced them. Again, Sandel's "hyperparenting" concern is that enhancements might be used to force individuals into particular life paths (especially those life paths chosen by their parents), but cognitive enhancement is not vulnerable to this concern - whether the individual chooses to be a scholar or a custodian, enhanced cognition will be valuable to them,

\footnotetext{
${ }^{76}$ We will return to this concept of the 'environment of evolutionary adaptedness' (EEA) in more depth in Section IV.2.iii.
} 
whether in their career or in their life in general. This is quite distinct from Sandel's concerns about the use of enhancements to create "perfect" athletes or pianists, where the enhancements are designed with a particular life path in mind; these enhancements are broadly valuable to individuals and thereby promote them with regards to life path options in general.

\section{IV.1.i.c. Cosmetic Enhancements}

In the debate concerning the development of human enhancements, the conversation often turns to enhancements that target positional goods, including cosmetic enhancements such as plastic surgery and the use of growth hormones for height. Research trials for these kinds of enhancements are, of course, already underway in many cases, and there is good reason to worry about the kinds of risks imposed on trial participants for the sake of these relatively dubious benefits.

Undoubtedly, aesthetics is valued by many social groups - being tall is positively correlated with success in the market and social influence, and, furthermore, certain careers are only open to individuals who were lucky enough in the natural lottery to have desirable cosmetic traits (Bostrom 2003). Physical attractiveness is simply advantageous to individuals, but as Bostrom points out, it offers little social benefit: "[i]f everybody grew two inches, nobody would be better off than they were before", the money spent on such enhancements, from a social perspective, is largely wasted. So this questionable social benefit leads Daniels to conclude that research that involves non-negligible ${ }^{77}$ health risks for the purposes of developing cosmetic enhancements is unjustified, and the existence of these trials today in no way supports their ethical soundness (Daniels 2010, 38). Even if there is some positional advantage to be gained through cosmetic enhancements and therefore there exists some economic demand as

\footnotetext{
${ }^{77}$ Of course, there might be cosmetic enhancements that can be researched without imposing health risks on participants, whereas other enhancements (such as cognitive enhancements) would likely come with a far greater degree of health risk. We are concerned here primarily with those trials that do impose risk, and in such a case the standard benchmarks for ethical research certainly apply. Among these benchmarks is the obligation to minimize risk as much as possible, but the point is that in these risks can be justified for certain kinds of enhancement research and not just treatment.
} 
individuals seek positional advantages, it certainly does not follow from this that they are something that research should be concerning itself with. The proper conclusion to be gleaned from the advantages that certain individuals gain due to good luck in the natural lottery with respect to their physical features is that positive changes need to happen in the social groups that place so much emphasis on such features. If research really is about expanding the capacities of society to meet particular needs and wants, then we seek a more social justification of the values that it promotes, and mere positional advantages with respect to catering to the prejudices of certain social groups simply do not stand up to this standard.

All too often this criticism of cosmetic enhancements is extended to enhancements meant to target non-positional benefits. Daniels himself argues in Just Health against the distribution of nearly all enhancement interventions on the basis that they represent such purely subjective benefits for individuals, which distinguishes them from the neutrally valuable health benefits promoted through treatment research (Daniels, Just Health 2008, 151). The desire to be "better than normal" is seen as a subjective, personal pursuit that lacks the force required to produce a favourable risk-benefit ratio within research trials.

This overextension of the criticism from positional advantages is seen most clearly in the enhancement arguments concerning sport. Numerous commentators have dedicated substantial effort to the discussion of whether enhancements should be permitted in the realm of sports, and those who conclude that they should not be permitted for reasons related to the undermining of the goal of sports or the undermining of personal achievement within that realm (as argued by Kass and Sandel) tend to extend this criticism to cognitive enhancements as well (The President's Council on Bioethics 2003) ${ }^{78}$. Extending such criticisms beyond sport is inappropriate for two reasons, the first of which being that

\footnotetext{
${ }^{78}$ I do not mean here to denigrate the very interesting debate concerning human enhancements and sport, but rather to point out the limits of its scope.
} 
personal achievement is not simply handed to individuals through enhancement, as time and effort are still necessary to actually cultivate those talents (as we discussed in Section IV.2.iii.), and the second has to do with the disanalogy between the ultimate goals of sport and human society.

The second reason to doubt the plausibility of the extension of the argument from personal achievement in sport to enhancements like cognitive enhancement is that the argument finds its foundation on some conception of the meaning and purpose of sport in general. If sports are meant to showcase human achievement within a set of rules that are meant to ensure fair competition and to highlight particular talents and effort, then applying the argument to non-positional goods within the context of human society appears to be entirely inappropriate. Human society is simply not constrained by a set of artificial goals in the same way that sports might be. Sports have arbitrary rules in order to constrain the possible set of strategies such that the only viable strategies for achieving victory involve cultivating the particular talents that the sport seeks to promote. Chess players are not allowed to covertly consult with coaches during a game and it would be against the rules of hockey to pay an audience member to flash a light in the opposing goalie's eyes because both would represent strategies that seek to dodge the mental and physical effort that the sports are meant to highlight. But life is not sport, we do not impose artificial constraints on individuals so as to highlight their effort and natural talents, but rather seek to promote effort and natural talent for the benefit of society and its worst-off members. The overall goal involves human achievement in general, not human achievement within an arbitrary set of rules designed to identify the "best". Just as human enhancement does not undermine the praiseworthiness of achievement, it does not undermine this general goal of human achievement within the context of society. 
Despite the somewhat dubious commensurability of positional goods such as cosmetic enhancements $^{79}$ and health risks incurred in trials, there may be good reasons to research certain enhancements even if they are directed at positional goods. Once again, the valuable work of Lev et al. (2010) demonstrates that the research/practice distinction leads to a view that can endorse some research directed at subjective benefits by appealing to other factors that are not strictly centered on the potential benefits that might eventually accrue to individuals through proliferation. A safety study that focuses on assessing the safety of particular techniques used in cosmetic enhancement procedures does not endorse the practice of cosmetic enhancement and only seeks to ensure that procedures that are already being done (legally or illegally) are not imposing undue risk on those who engage in the practice (Lev, Miller and Emanuel 2010, 107). That being said, it is unlikely that this could be applied more broadly to cosmetic enhancement research in general, since it would fall short of justifying the development of novel cosmetic enhancements that impose risks on trial participants, but it shows that there is more leeway when it comes to the development of positional enhancements than it first seems.

\section{IV.2. Motivating Enhancement Research IV.2.i. Adaptability and Meeting the Competing Claims of Justice}

Perhaps the main capacity that is implicit in the Transhumanist values promoted through enhancement research is the capacity for society to mitigate certain disadvantages due to the natural lottery. As Buchanan et al. (2000) point out, egalitarians who argue for a distributive mechanism by which resources are to be distributed equally between individuals might also be committed to extensive interventions in the natural lottery (Buchanan, et al. 2000, 76, 82). Roemer's call for resource egalitarians to develop a mechanism for mitigating natural disadvantages through the reallocation of

\footnotetext{
${ }^{79}$ It might, however, be inappropriate to apply this criticism to positional goods in general, since disadvantaged members of society might benefit from others being advantaged with respect to these positional goods. For example, certain careers might be closed to individuals who are not advantaged with respect to certain positional goods, but the careers themselves might be valuable to society in a way that benefits all of its members, the disadvantaged included. For this reason, in Section IV.3.i., I intend to include this possibility while also admitting that priority should go to biomedical research that promises more direct benefits.
} 
social resources appears to be arbitrarily limited when the society is also capable of allocating enhancement resources for mitigating these natural disadvantages directly (ibid.). These are, of course, not arguing specifically for enhancement research but rather the distribution of the products of enhancement research, but there is something to be said for developing the capacity to meet different demands of justice. We must be careful here to recognize the difference between motivating particular kinds of enhancement research so as to expand the capacities of society and the state's obligations to distribute enhancement interventions as a matter of justice.

It is clear that the demands of justice with regards to resource distribution are still a matter of legitimate debate. The "Equality of What?" debate of the early 2000's was fruitful in that it carved out a number of competing positions and identified the points of contention between them, but legitimate disagreements persist. As I have claimed, enhancement research does not implicitly or explicitly endorse any of these distributive principles, but rather expands the range of options available to societies and states with respect to these different distributive principles. If it is eventually decided that, say, the state should distribute resources in accordance with the principles espoused by luck egalitarians, then enhancement interventions would expand the state's power to mitigate the effects of brute luck in the natural lottery and would allow it to carry out its obligations to a greater degree than what is currently available. If, at the other extreme, some brand of libertarian justice ends up being favoured, then the development of enhancement interventions would still expand the options available to citizens within that society, even if the distributive mechanism by which these enhancements are proliferated is particularly capitalistic and market-based in nature. Either way, enhancement interventions expand the society's capacity to meet particular health wants and needs, and the disagreements with regards to distributive justice simply determine the way in which such capacities should be put into practice when it comes to their proliferation. 
Until recently, the options available to the state in the mitigation of things like disadvantage, bad brute luck, and the effects of limitations on individuals' range of life options were limited to social and systemic changes. What Buchanan et al. call the "Traditional View" is that the natural lottery lies beyond the purview of state authority, standing as a "given" status quo that, at times, brings about problems for individuals that are to be mitigated indirectly (Buchanan, et al. 2000,63-4). In the Rawlsian picture, for example, the state's responsibilities end where these differences in natural talents and deficiencies begin and the individual must base their decisions about their life paths on what they can reasonably expect out of the natural capacities they possess. In this case, the state maintains its responsibility to ensure that the life options of individuals are not unfairly limited by the impact of unfair policy, but the restrictions on life options that come from simple differences in natural capabilities are not described as unfair but merely unfortunate and are not considered an example of injustice (ibid.). At the same time, Daniels' attempts at broadening the Rawlsian model to include health services relies principally on the effects of ill health and the idea that such effects might fall within the domain of justice.

We discussed Daniels' view on the special moral importance of health in Section III.3.i. but mentioned only briefly its connection to positive social policy. Insofar as the state has responsibilities to protect and promote the strategically important fair opportunities that individuals have when it comes to competing over jobs and life paths, such responsibilities will mandate positive measures (such as education) over and above negative measures (such as the elimination of systemic barriers to employment) (Daniels 2008, 58). All else being equal, an individual that falls within the range of normal species functioning would be unhindered by ill health and poor natural talents to the degree that they have the opportunity to achieve their ambitions in the market. In his view, the ambitions of individuals are legitimately restricted by their natural talents (Daniels 2008,45 ) and their society's material wealth, historical and technological development (Daniels 2008, 43). The main reason that this view regards the 
natural distribution of talents as legitimate is that it is more concerned with the disadvantages imposed on individuals by unjust institutions and compensating individuals for the injustices they face due to the structure of society (Buchanan, et al. 2000, 74). Enhancement interventions would, then, belong to a set of resources that are not to be subjected to redistributive principles and individuals whose natural talents do not match their life path aspirations are asked to make use of educational opportunities to develop their talents or, otherwise, revise their life plans accordingly.

Of course, the "Traditional View" does not stand uncontested. Shlomi Segall's work on luck egalitarianism and the provision of healthcare calls for a more expansive view on the state's role in distributing biomedical enhancements by emphasizing the importance of mitigating "all preventable disadvantageous conditions that are unchosen" (Segall 2010, 121). Whereas the Traditional View draws the line at interventions in the natural lottery and focuses solely on the redistribution of social resources for the mitigation of disadvantages, Segall's luck egalitarianism looks at disadvantages in general and sees them as falling within the purview of the state. Segall argues powerfully for the distribution of biomedical enhancements for the sake of mitigating the disadvantages that individuals are subject to due to bad luck in the natural lottery.

The reason why Segall's position ultimately must endorse the distribution of enhancements has to do with his views concerning bad brute luck and his solution to the so-called "abandonment of the imprudent" objection to luck egalitarianism. The luck egalitarian position ultimately seeks to compensate individuals for the effect that bad brute luck has on their lives, for it can certainly disadvantage individuals with respect to their chosen life paths and ambitions and, by definition, does so through no fault of their own (Segall 2010,1). The driving intuition here is that luck is "morally arbitrary" and yet it has a profound effect on people's lives, disadvantaging some while giving way to advantages in others, especially given the fact that two individuals can make the same decision and 
differ significantly in the outcomes of their decisions due to sheer luck (Segall 2010,47). It seems profoundly unfair that an individual can be disadvantaged due to circumstances that are completely beyond their control, so Segall's luck egalitarian attempts to mitigate such disadvantages through the redistribution of resources.

This does call into question what we are to do with individuals who are disadvantaged due to their own bad choices - are we to abandon them for their imprudence? It would seem that the implication that we ought to leave an imprudent driver to die on the side of the road because their calculated risk did not pay off would be a devastating blow to the luck egalitarian position as a moral theory. Yet the theory declares compensation obligatory in the case where someone is disadvantaged by circumstances beyond their control, and the imprudent individual is disadvantaged due to circumstances that were clearly within their control. Furthermore, if the luck egalitarian overcompensates to deal with this problem and argues that the luck egalitarian state should mitigate all disadvantages that come about through bad luck, then this might overburden the state with the task of mitigating disadvantages that come about through, say, gambling. The so-called "All Luck Egalitarianism" that would seek to equalize the effects of all luck quickly ends up in a position where they saddle the state with equalizing the outcomes of even the calculated risks that individuals undertake (Segall 2010, 49). It would require pooling the risks that gamblers take on and equalizing the outcomes in a way that undermines the very concept of gambling, and, worse still, this would be applied to all calculated risks.

Fortunately, Segall's commendable work identifies a plausible escape from this implication, namely, that luck egalitarians may stipulate that the effects of bad option luck ought to be mitigated by the state insofar as they are a consequence of a decision that would be "unreasonable to expect them to avoid" (Segall 2010, 13). Thus, the state can reasonably expect individuals to avoid certain risks, and in 
the case where they fail to do so, they may be subject to state-imposed risk-pooling (though taxation, for example) to mitigate the effects of this kind of option luck.

In this sense, the natural lottery imposes disadvantages on individuals that they could not reasonably avoid, and so Segall sees the distribution of enhancement interventions as being obligatory insofar as they are effective at mitigating the disadvantage; the disadvantage is a result of such bad luck (Segall 2010, 127). Due to Segall's focus on disadvantage in general rather than on disadvantage that comes from deviations from NSF, his theory is able to justify compensation to individuals who fall within the range of normal functioning but are nonetheless disadvantaged due to aspects of species functioning or the human condition itself (such as pregnancy or labour ${ }^{80}$ ). The research and development of enhancement interventions would expand the society's capacity to employ state redistributive mechanisms to meet the demands of this kind of luck egalitarian justice, even compensating for disadvantages that come as part of the human condition and NSF, as Segall's theory demands.

The natural baseline taken as a given by the traditional view is meant to be sufficient for competition on the market and whatever personal development is needed for the achievement of one's goals. Distributive practices that cater to the enhancement of characteristics that are otherwise sufficient for fair opportunity might indeed represent the state overstepping legitimate limits on its authority to redistribute wealth. That said, the research and development of enhancement interventions might not be so limited, since research is meant, at least in part, to develop novel capacities for society and options for individuals to consider in their selection of life paths, which does not necessarily require positive distributive practices by the state.

\footnotetext{
${ }^{80}$ As these are part of normal functioning and come with disadvantages (such as the pain of labour or the physical burdens of pregnancy), Daniels' theory does not directly endorse the public allocation of medical resources to mitigate their effects. He instead appeals to other principles of justice to make up for this seeming oversight, while Segall's view that does not privilege NSF as a baseline for the allocation of resources can easily justify public healthcare for such conditions (Segall 2010, 128).
} 
The distinction here is subtle but important; the research and development of enhancement technologies expands the society's capacities when it comes to meeting a range of wants and needs. Just as scientific research does not implicitly endorse its eventual use, it also does not endorse any particular distributive method ${ }^{81}$. This difference calls for different justificatory routes; whereas distributive arguments will contend with the state's concrete responsibilities toward mitigating things like brute luck and natural disadvantage, an argument for expanding the society's capacities relies on the benefits of a society that has greater control over the human condition and the state's obligations here will have to appeal to its role in developing technologically and expanding the range of life paths that are available to its citizens. It can be freely admitted that some natural disadvantages are not unjust in the strictest sense, but maintain that the state should play a role in the promotion of enhancement research ${ }^{82}$. Fortunately for the advocate of human enhancement research, then, I would think that the burden of proof that they face is lighter than those who are arguing for particular distributive principles that ought to guide the proliferation of developed enhancements.

This capacity to meet different, competing demands of justice is valuable in that it might serve to counteract the concern that enhancements will only serve the interests of the rich. If the situation arises that only the most affluent members of society are capable of affording enhancement interventions, even once the typically expensive early adopter phase has concluded, and if this situation is deemed profoundly unfair for any particular reason, there are distributive principles available to govern the mitigation of this concern. This responsiveness to different justice concerns is an advantage of the research/practice distinction, since most of the most pressing concerns of political philosophers concerning the unjust distribution of enhancement-related benefits fail to "bridge the gap" and limit the

\footnotetext{
${ }^{81}$ This is part of the reason why I have been distinguishing between the "state's capacities" and "society's capacities".

82 This will be the subject of Section IV.3.i.
} 
initial research. The research simply does not commit to any of these distributive methods ${ }^{83}$, but rather expands society's capacity to mitigate whatever disadvantages that are found to be problematic.

There is another sense in which the adaptability entailed by enhancement research is valuable that is related to the well-justified nature of preventative treatments. Not only can a society with expanded human enhancement capabilities better adapt to developments in political philosophy and distributive justice, but it can also better adapt to the changing external conditions that threaten its members. As Bostrom has argued at length, it is not merely the case that we are becoming more aware of threats to continued human existence (dubbed 'existential risks'), but they are actually becoming more plentiful due in large part to technological development (Bostrom 2002). From climate change and the evolution of viruses to nuclear weapons and so-called 'gray goo' ${ }^{84}$ scenarios, existential threats are not to be neglected, especially considering that human activity may be increasing their probability.

Importantly, because many of these existential risks are driven by human technological development rather than natural changes to external conditions, and the fact that human technological development greatly outpaces evolution and natural adaptation, it may eventually become necessary to intervene in the human condition in response to these external pressures. A similar case is often made in favour of space colonization - the existence of existential threats that have global reach means that we should not be keeping all of our civilization's eggs in one celestial basket. We would be ill-advised to count on nature to save the day in the face of problems generated by increasingly powerful and rapidly developing technologies, and the greater control over the important characteristics of the human condition would be a substantial advantage given these existential risks.

\section{IV.2.ii. Obligations to Enhance}

\footnotetext{
${ }^{83}$ As I said in Section IV.1.i., it does, however, commit to state responsibilities with respect to the promotion of individuals' opportunity range, but it does not commit to any one method for achieving this.

${ }^{84}$ Popularized by Eric Drexler, 'gray goo' scenarios were originally meant to describe runaway replicating nanotechnology that reprocesses the matter on earth to fuel its replication (Anissimov 2004).
} 
The social value of enhancements does not have to be limited to the expansion of the society's capacity to meet contentious distributive obligations. Indeed, some advocates of human enhancement, such as John Harris, David Pearce and Nick Bostrom, do not premise their arguments on distributive justice at all, appealing instead to the promotion of individuals with respect to their potential and life path options. In Harris' view, for example, enhancements are obviously beneficial for individuals, as if they weren't, they "wouldn't be enhancements" in the first place (Harris 2009, 132). Enhancements improve on certain aspects of the human condition to which individuals are bound, and as such, the capacity for intervention in the natural lottery might itself be of social value, due in part to moral reasons for the enhancement of individuals, the unacceptability of the status-quo and the importance of expanding the possibility of exerting human influence over what has normally been left up to chance. I have my doubts about the applicability of arguments from the moral imperative to enhance to the ethics of researching enhancement interventions, but, as we shall see, I do think the latter two values are important to the enhancement debate.

Harris' claim that there exist moral obligations to make use of enhancement interventions for the creation of "healthier, longer lived and altogether 'better' individuals" is, unsurprisingly, contentious (Harris 2009, 131). His argument rests in large part on the claim that the central moral imperative here is to "prevent harm and confer benefit" ${ }^{\prime 5}$, and insofar as the enhancement interventions are obviously beneficial to the enhanced, there is strong moral reason to engage in human enhancement, and Harris contends that this would include strong reasons to actually develop the enhancements so that they might be put to use by those that desire them (Harris 2009, 154). Harris uses this largely utilitarian principle to criticize Daniels' "you can't get there from here" argument from research ethics, as in his

\footnotetext{
${ }^{85}$ Harris is not the only advocate of biomedical enhancement who takes this route, but I take his argument here as being representative of those who attempt to justify enhancement research based on the possible benefits that might arise through the proliferation of the technology. David Pearce and Ray Kurzweil both make a similar move - in the most general sense, they are similarly committed to the claim that the research can be motivated through an appeal to the benefits individuals might gain once they engage in the developed intervention.
} 
view these enhancements are obviously beneficial and "[w]here the risk is only to the individual she surely should decide for herself" about the extent to which she participates in the research and practice of the enhancement intervention (Harris 2009, 150-1).

While this kind of argument from the personal benefits people might gain through enhancement might give strong reasons for individuals to engage with enhancement interventions, I do think that it overlooks the crucial role that the risk/benefit criterion should be playing in their development. When it comes to personal risk assessment on the part of trial participants and their hope that they may benefit from the research trial, it must be emphasized that the benefits are on a social level and are not to be characterized in individualistic terms. The point is that the trial participants are taking on personal health risks for benefit of society, and so society ${ }^{86}$ surely plays some role in determining which trials have the potential to produce benefits that might outweigh the risks that are imposed on its members during their development. Harris says that he fails to see why Daniels considers his argument from research ethics as being strong, but I suspect that this has to do with Harris' neglect of this role that the principles of ethically sound scientific research play in the development of enhancements (Harris 2009, 150).

If it comes down to the personal risk assessment of potential trial participants, as Harris seems to indicate, then it is entirely up to the individual participants whether the product of that research trial would be a beneficial addition to their society's capacities and whether their own health is worth risking for this purpose. This seems plainly insufficient when it comes to the ethical assessment of a research trial; the willingness of individuals to participate in the trial is not necessarily an indication of its ethical soundness (although their willingness is, of course, necessary). It certainly seems possible that

\footnotetext{
${ }^{86}$ I don't mean to use "society" here vaguely, as if there is some collectivist method by which society may make decisions about research trials. Rather, there is a set of institutions (REBs especially) that are committed to ensuring that research trials are carried out ethically, and that the assessment of the value of a given research trial will very much depend on the value that the product may have for the capacities of the society.
} 
individuals might be willing to participate in research trials that are clearly unacceptable on risk/benefit grounds, even if their personal assessment ends up being in favour of participating in the trial for reasons due to their personal risk tolerance, and not for illegitimate reasons such as the melioristic misconception. The social value of a given research trial is extremely difficult to assess, which is why the burden of its assessment falls on experts and REBs, rather than on the participants alone.

\section{IV.2.iii. Improving on the Human Condition}

In "Human Genetic Enhancements: A Transhumanist Perspective", Nick Bostrom argues that one of the core values of Transhumanists that is meant to motivate the development of human enhancement interventions is the overcoming of limitations imposed by the human condition and the exploration of what he calls the "post-human realm" (Bostrom 2003). While the bioconservatives that we covered in Section III.1.ii. view the limitations imposed by nature on human ambition as legitimate and the human drive to overcome these limitations as a prime example of Promethean hubris, the Transhumanists celebrate the prospect of defeating nature's impositions on human ambition. The natural limitations in question here are not those that hinder an individual with respect to their membership in normal species functioning, which are almost undeniably cause for intervention if we are to ensure that individuals are capable of deliberating between and pursuing life paths, but rather the limitations that come with normal species functioning. The basis of disagreement between the two groups comes down to how we view the human condition - whether it is a gift that ought to respected and appreciated for what it is, or whether it is a condition that should be subjected to human intervention.

It is helpful here to recall the status-quo bias that we covered in Section III.2.2., where there appears to be an automatic and under-justified favouring of the "devils we know" that risks privileging the current state of human evolution and the present state of the human condition over future 
potentialities. The reason this was a problem for the precautionary principle is that the bias tends to overemphasize the risks involved in scientific research while understating the negativity of preserving the status-quo, which can motivate overly risk-averse practices and paralyze discovery. But the Transhumanists clearly object to a preservation of the status-quo for its own sake and find value in overcoming the limitations that it imposes on individuals - so the question here is, simply, what is so wrong about the human condition as we experience it today and why should we take risks in the name of developing methods for overcoming certain features of the human condition?

Firstly, it is important to keep in mind that many of the central characteristics of the human condition were forged on the rather cruel mantle of 'survival of the fittest', where the fitness of particular characteristics were graded on their ability to ensure individual survival and reproduction in the pre-civilized age of humankind. In this pre-civilized age, the standards for fitness revolved around the ability to acquire resources, the efficient use of energy and the acquired resources, and other characteristics that were important to surviving on the African savannah (Bostrom and Sandberg 2009, 381). Evolution is blind to the preferences and desires of the individuals who are subject to it and its main tool for selection involves the death and extinction of those who, for one reason or another, are deemed unfit. Of course, there is little doubt as to its effectiveness, as it brought about remarkably complex creatures from the most humble of beginnings, and the characteristics that we value in creatures were a direct result of evolution's machinations. In this sense, we were indeed fortunate to be "gifted" with the characteristics that it brought about, which brings us back to one of the questions I posed in Section III.1.ii., namely: whether the limitations that are set by nature are really so deserving of our respect and admiration.

Advocates of human enhancement, for the most part, answer this question with a resounding 'no'. One can appreciate the valuable characteristics that were brought about through evolution while 
maintaining that other characteristics lost much of their value once humanity became civilized.

Evolution is an incredibly slow process that spans eons while the progress made by the intentional, concentrated, and collective effort of persons is relatively rapid and easily outpaces the trudging of natural selection. Not only are some characteristics of the human condition arguably obsolete, but we find that there may be a need for new characteristics that wouldn't necessarily be selected for outside of a technologically advanced civilization. The current state of human evolution, as Harris points out, is not unambiguously good or optimal, but rather the accidental state that happened to come about through evolutionary processes (Harris 2009, 133). Furthermore, many of these less-desirable characteristics stand as a rare point of convergence between bioconservatives and Transhumanists who tend to agree that things like aggression, poor impulse control and even the manner in which the body stores fat and nutrition are regarded as problematic given the context of modern society. The main difference is that Transhumanists argue for biomedical enhancement research to bolster individuals' capacities to overcome these obstacles, whereas bioconservatives limit the tools with which we may counteract these characteristics to those involved in character development and virtue.

It is not altogether surprising that character development and virtue have been so thoroughly advocated for throughout the history of ethics, as before the prospect of human enhancement became a reality, they were the only methods available to individuals who sought to overcome their evolutionary baggage so as to be moral. Developing a good, virtuous character is a challenging and character-building exercise that puts one's moral sense and conscience up against base instinct and animalistic urges. This striving to improve oneself is regarded as essential to the human experience and, in the bioconservative view, important for the self-image and personal achievement of individuals. This sentiment is expressed by Sandel when he states: "If bioengineering made the secular version of the 'self-made man' come true, it would be difficult to view our talents as gifts for which we are indebted, rather than achievements for which we are responsible" (Sandel 2004). This is also the reason why 
human enhancement debates tend to gravitate toward conversations about enhancements in sports, because just as the effort involved in developing one's talents with respect to a sport appears to be necessary for the praiseworthiness of achievement in that sport; it is claimed that the effort involved in developing oneself into a virtuous person is necessary for achieving virtuousness. In the view of the President's Council on Bioethics, these shortcuts to human achievement undermine the "dignity of human achievement", which involves the struggle and hardships that come with the development of one's character (The President's Council on Bioethics 2003)

This is where I think a lot of the shorthand language used to describe human enhancement is doing us a great disservice in the debate concerning the development of the capacity to enhance certain aspects of the human condition. Arguments concerning the design of "perfect" human beings seem to understate the fact that even enhanced individuals do not spring from the womb as fully-developed, virtuous individuals. Enhancements improve the functioning of certain human characteristics, but do little to help those who, through laziness, disinterest or some other reason, neglect the development of these characteristics. Natural talents, whether gained through luck in the natural lottery or through enhancement interventions, count for very little unless one actually puts in the effort required to cultivate and make use of them. This means that the effort and struggle involved in pursuing one's ambitions is unlikely to be divorced from the human (or post-human) condition anytime soon - the praiseworthiness of one's achievement is not undermined by one's natural talents.

As far as the Transhumanists are concerned, then, interventions in the natural lottery for the purposes of enhancing certain aspects of human nature are valuable for the promotion of individuals living within our era with respect to the range of life choices available to them. They offer the possibility of improving on certain characteristics, but an enhanced characteristic is by no means a substitute for actually putting in the effort to cultivate one's talents. Modern society is no longer about hunting prey 
for nutrition, withstanding the elements, brute strength, tribal warfare and the basic survival and reproduction that were of prime importance for our environment of evolutionary adaptedness. A different set of natural talents has emerged as the more important to the information era, and normally functioning members of the species might be ill-equipped for their ambitions and the needs of society. The bioconservative idea that we ought to respect these characteristics as gifts and take them for what they are or that enhanced individuals are in some way barred from achievement appears to be misguided - we can appreciate the role that evolution has played in getting us to the point where we can intervene and improve the human condition, and take up the task of researching enhancements to promote the characteristics that are valuable going forward.

There is also something to be said for expanding society's capacity for intentional interventions in the natural lottery that relies less on the unwanted characteristics that have come from evolutionary processes and instead focuses on the worth of choice over blind luck in the human condition. Whereas for most of human history, individual endowment through the natural lottery came down to a genetic roll of the dice, enhancement interventions offer the possibility of intentionally choosing these characteristics so as to minimize the role chance plays in such outcomes. Buchanan et al. argue in their book "From Chance to Choice" that the development of enhancement interventions entails the possibility of expanding the domain of justice - a so-called "colonization of the natural by the just" (Buchanan, et al. 2000, 82). There are two senses in which justice could be said to be "annexing" the domain of the natural here: (1) through an expansion of the so-called "Resource Compensation Principle" and (2) through a blurring of the line between the subjects and objects of justice (Buchanan, et al. 2000 , 84). Both of these expansions of the role of justice are, I think, worth pursuing.

The expansion of the Resource Compensation Principle is directed primarily at the resource egalitarians who, to varying degrees, are committed to the idea that resources should be redistributed 
to compensate those who are disadvantaged relative to others with respect to their resources

(Buchanan, et al. 2000, 76). With respect to resourcist distributive justice, insofar as the natural assets that result from the natural lottery become resources over which we have some control, Buchanan et al. see no "obvious reason to restrict the operation of the institutions of justice to the redistribution of social resources" (Buchanan, et al. 2000, 76-7). Individuals can be disadvantaged due to the inequalities in the way social resources and natural resources are distributed within a society and in both cases the egalitarian position would endorse some positive role for the state to redistribute such resources such that all individuals can expect an equal share of resources throughout their lifetimes. Furthermore, these disadvantages need not be so profound that they indicate a departure from NSF (which would call for a treatment intervention), but can be a result of the demands of social institutions that favour those who happen to possess particular assets to a high degree. As discussed in Section IV.1.i.b, this is especially true as society becomes more technologically advanced and complex.

With respect to (2), individuals are typically understood as subjects who have some claims with respect to the objects of justice, whether that object is described in terms of resources, opportunity, or luck. Human enhancement makes the "identity constituting characteristics" of individuals into objects of justice subject to redistribution as disadvantages due to the natural lottery are no longer limited to being mitigated through the redistribution of social resources (Buchanan, et al. 2000, 85). This breakdown of the distinction between the subject and object of justice would mean that we must revise the way in which we examine individuals with respect to justice, as the identity-constituting characteristics of individuals become something that we cannot simply take for granted.

I think that Transhumanists and proponents of human enhancement argue convincingly for at least making natural assets something that we can bring under our control as objects of justice (and possibly going further to actually apply redistributive principles to them as a matter of justice). One's 
natural assets play an extremely important role in the life path options that are available to them and enhancing them can mean opening doors to novel life paths worthy of exploration. Arguably, they are the most significant preconditions for the possibilities that we might have in life and one's prospects for achieving their ambitions. Due to this substantial role they play in the lives of individuals, there is good reason to worry about leaving their distribution to mere chance - it would at least be very unlike how we treat most important aspects of our lives. Indeed, many of the redistributive principles of political philosophy are motivated by this core idea that relying on mere chance to determine the important factors in peoples' lives is a questionable strategy. While chance itself might arguably be morally neutral, the disadvantages imposed by chance are in part due to the way in which society is set up as some features will be favoured and others disfavoured and individuals cannot be faulted for failing to be lucky enough to end up with the more advantageous characteristics. We should demand more certainty than a dice roll when it comes to the natural characteristics that play such a significant role in our lives, and if biomedical enhancement offers a strategy for broadening our control over these characteristics, then I would think this to be of significant social benefit.

\section{IV.3. Priority, Proaction and State Responsibilities in Enhancement Research IV.3.i. The Prioritization Problem and Treatment Research}

In Section I.3., I briefly expressed a problem when it comes to the prioritization of treatment research over enhancement research. This problem, again, is that the standard assessments of the value of biomedical research automatically favour treatment research over enhancement, which leads to an incentivization problem that should be cause for concern. If funding and REB approval automatically favours treatment, then there is some risk that enhancement researchers will look to describe their research in treatment terms, and even deceive REBs with regards to the nature and goals of their studies. As University of Michigan gerontologist Richard Miller notes: "[w]hen people apply for funding to the National Institute on Aging, they are exceptionally careful not to bring up life-span 
extension... It is forbidden. They talk about specific diseases and preserving health and 'successful aging.' That's politically clever." (Alexander 2004). Such an attitude should be cause for concern, not only because we have cause for worrying about such an antagonistic division between researcher and REB, but also because the prioritization problem wouldn't exist if the values promoted by enhancement research were more formally recognized and factored into the evaluation of what research should be pursued. The automatic priority given to treatment research should not be set in stone, and this section will reflect on how it might be prevented.

The central reason for the importance of treatment research (and the reason why it might be prioritized) is due to its positive impact on the health of individuals. Health, as argued convincingly by Daniels, is important due to its status as a precondition for competing for careers, pursing one's possibilities in life and, indeed, for even deliberating about which life paths one wishes to pursue (Daniels 2008, 29). As discussed earlier, however, enhancement interventions have similar potential for the promotion of individuals with respect to their opportunity range due to the increasing complexity of careers, heightened expectations of society with regards to particular natural assets (which indicates the NSF standard might not be the best standard with regards to the opportunity range of individuals), the preventative nature of certain enhancements and the ancillary benefits that enhancement research offers.

That being said, not all treatment and enhancement research projects are created equal. I argued in Section IV.1. that certain enhancements, such as cognitive enhancements and life extension, have broad, neutral value regardless of the life path chosen by individuals, whereas others (cosmetic enhancements and enhancements that target positional goods in particular) are beneficial to a very specific set of life paths and social contexts. This division is also recognizable between most treatment research and these more dubious enhancement interventions, as treatment research directly targets 
deviations from normal species functioning that typically hinder citizens with respect to their opportunity range. Furthermore, even if particular treatments and enhancements can be motivated by their more neutral value, it must be acknowledged that some will be more beneficial than others in the global context.

Due to the comparable goals of treatment and enhancement research, criteria could, I think, be established so as to nuance the second benchmark for ethical research. Nuancing the social value criterion for ethical biomedical research can formally establish justificatory routes that would apply to treatment and enhancement research such that treatment research isn't preferred simply as a matter of course and allow researchers to appeal to specific social value criteria in their pursuit for financial support for their research and an explicit recognition of its importance. Naturally, given the differences between treatment and enhancement research, these criteria would have to be relatively broad to capture both, but I think these criteria can be roughly expressed, in ranked order, as follows:

(1) Broad, neutral value to individuals.

(2) Value to society in general.

(3) Value given the historical/technological development of a particular society.

(4) Value to particular individuals and particular life paths.

As I have argued over the past few sections, treatment research will most often fall within (1) due to its role in the promotion of health, which is of special moral importance to both individuals and the society. Interventions that blur the line between preventative treatment and enhancement, too, from vaccines to life extension, would most straightforwardly fall within the scope of (1) as they protect individuals from possible future deviations from NSF in a way that would significantly impact their range of opportunity. These research avenues are the most straightforwardly justifiable and can admit of greater degrees of risk as the health risks taken on by trial participants are clearly commensurable with the neutrally valuable benefits that the research seeks to produce. 
Distinct from the broad value that certain research has for individuals, it can also be beneficial for society in general and fall within (2). As I argued in Section IV.1.i.b., cognitive enhancement could very well be motivated by this as individuals with increased cognitive capacity would be better equipped to contribute to the solution of the complex problems and demands faced in the modern context. If the highly specialized nature of modern academia is any indication, many of the problems faced in the modern sphere require individuals to commit substantial amounts of time to study and develop their understanding of the issues. This is not inherently problematic for the individual, as the time spent developing one's understanding of particular fields of research so as to contribute positively to their chosen field is certainly beneficial, but it seems plausible to think that society has an interest in promoting those who seek to solve these complex problems, and enhancement interventions appear to be a viable route for this promotion. Beyond academia, scientific and other research institutions often dedicate significant resources and effort to expand their society's capacity to deal with particular problems, and offering certain cognitive enhancements to researchers has the potential to improve their capabilities in this regard. Again, quite unlike sports, the pursuit of solutions to society's problems is not something that should be constrained by arbitrary rules to highlight particular natural talents and personal effort - we're interested in the solutions that these researchers can develop in the face of the complex and daunting challenges that society faces.

Certain behavioural enhancements could fall within (2) as well, as our collective evolutionary baggage includes predispositions to violence and anger, which are contributive to antisocial behaviour. It is, of course, important to remember here the lessons learned from the egregious actions of the eugenics movement, as its proponents used a criterion similar to (2) to justify the imposition of biomedical interventions on individuals without proper regard for their consent, but such actions are specifically precluded by the other benchmarks for sound ethical research (informed consent and respect for participants in particular). 
(3) would capture adaptability especially well - enhancements meant to mitigate natural disadvantages would be specific to the historical and technological development of the society in which the disadvantages are more acute. The development of vaccinations would also satisfy this criterion as different regions in the world are in need of different vaccinations and, in some cases, cheaper vaccinations if they are to sufficiently distribute them to those in need.

Enhancements directed strictly at positional goods are particularly contentious and would fall within (4). They offer little value to society in general, but rather promote particular individuals and life paths over others, which indicates that their social value is dubious at best. Bostrom ${ }^{87}$ goes so far as to say that they are a waste of medical resources, but they may be more egregious than that as, if risks are imposed on individuals in the trials, they would almost certainly outweigh the subjective benefits that may be gleaned. A case may still be made in their favour if the risks involved are negligible and the research institutions pursuing them are privately funded, but they would certainly fail to enjoy the strong justifications that one sees in treatment research and enhancement interventions with broader social value.

This nuancing of the social value criterion is meant to clarify the priorities of society and research and allow for a plausible route for researchers to identify how their research is valuable in such a way that does not commit them to relying on treatment-based benefits. I do think we can plausibly hold this list as a way to prioritize between the different biomedical research projects available, with the projects that are justifiable through (1) being the most valuable as they can be used to promote all individuals whatever their life path or personal values happen to be. Society and the state's commitments to the promotion of individuals' opportunity range ultimately endorses (1) above all the other social value criteria. Research that falls under (2) and (3) might be important and worth pursuing

\footnotetext{
${ }^{87}$ See: Bostrom (2003).
} 
but fall short of the priority that treatment and certain kinds of enhancement interventions exemplify. Those enhancement interventions that fall under (4) are relatively dubious in the case where there are non-negligible health risks involved, and yet it must be recognized that they are not completely without value - even value that goes beyond the positional value that benefits individuals alone. Disadvantaged individuals might still have something to gain from others' positional advantages, in the case where the positional advantage brings about certain contributions to society that benefit them, but I do suspect that these benefits would be more the exception than the rule as, say, cosmetic enhancements are largely a waste of resources with little social benefit, as Bostrom contends.

Of course, with regards to the deceptive element of the prioritization problem, it is still possible that there will be researchers that attempt to deceive REBs by characterizing their enhancement research as treatment research for the purposes of falling within (1), but I do suspect that the problem would be somewhat mitigated by the formal inclusion of values that enhancement research promotes more specifically. I doubt that the issue of researchers attempting to deceive their way into greater funding can be easily solved, but the formal recognition of this more nuanced view of social value does go a long way to solving a number of factors that would incentivize researchers to take this rather heinous route. Firstly, as the arguments that rely on expanding the contentions with positional goods show, enhancement research is often relegated to (4) as critics of enhancement research attempt to argue that enhancements promote some individuals over others with respect to particular life paths. It would be entirely inappropriate to lump cognitive enhancement and life extension into the same category as plastic surgery or stature, as the former have the broad value for a range of life paths that would identify them as falling within (1).

\section{IV.3.ii. State Responsibilities and the Promotion of Enhancement Research}


When it comes to research in general, the state has well-defined responsibilities with respect to ensuring the safety of trial participants and society at large, and enhancement research clearly falls within that purview. While private investment can play a significant role in the promotion of this kind of research, it is far more difficult to employ private means to protect the health and wellbeing of citizens who participate in research trials and those who may be affected by its implications. As the protection of individuals is valuable to society and private means tend to fall short in this endeavour, the state appears to be in an excellent position to make use of its institutions to ensure that enhancement trials are carried out in accordance with the standards described in Section I.3.

Part of this obligation to ensure that research sufficiently meets those benchmarks is to ensure that proper consent is achieved. As pointed out in IV.1.i., Mehlman et al. identify a possible misconception in enhancement research that is similar to what is found in treatment research, referring to it as the "Melioristic Misconception" (Mehlman, et al. 2011, 33). This misconception is the mistaken assumption on the part of trial participants that the ultimate goal of the trial involves their personal enhancement, and that researchers therefore have a commitment to ensuring that they benefit from the enhancement. This risks undermining consent in much the same way that the therapeutic misconception does, but might even represent a bigger problem for enhancement trials. As the therapeutic misconception has to deal with the desperate "last chance" mentality that, when combined with the therapeutic misconception, undermines participants' understanding of the trial's purpose, enhancement research involves largely healthy participants and its benefits are, in large part, meant to be applicable to any and all individuals. That is to say, anyone could enter an enhancement-related trial in the hopes of achieving personal benefit, and can make the mistaken assumption that this is the purpose of the trial. The larger set of potential participants taking on health risks for mistaken reasons might make it easier to find sufficient participation, even in the less-popular early phases, so the conflict of interest problem that results needs explicit recognition and positive measures to ensure that 
participants are properly informed. Similar to the therapeutic misconception, strong steps need to be taken to ensure that this does not happen, and it is up to the state, in its commitment to the protection of individuals, to ensure that researchers are sufficiently informing participants about the ultimate goal of the trial.

Furthermore, in the Rawlsian conception of justice and Daniels' view of justice in healthcare, individuals are expected to constrain their ambitions and life path decisions in accordance with their natural talents and the historical and technological development of their particular society. We have discussed at length the problems with the first of these expectations, due to the possibility of making natural talents into objects of justice, the unjustified privileging of the human condition (and its chancebased distribution) and the unequal distribution of natural assets that pays little heed to the actual wants and ambitions of individuals. Up until now, however, we have said relatively little about what might be expected of the state with regards to the second expectation and its responsibilities to develop enhancement technologies as a matter of historical and technological development. This section will examine briefly the role that the state plays in technological development and what the nuances we have proposed for the social value criterion mean for the state's contribution to enhancement research.

Generally speaking, it is rather difficult to argue against technological development due to its positive contribution to the lives of so many; global communication and mobility have promoted individual possibilities and expression; medical technology has overcome terrible impositions on NSF; computing and more advanced scientific methods have contributed to our understanding of the universe, etc. More specifically, state funding and research has made strides in fields that were deemed too risky for private investment and ensured a higher degree of safety in the development of products than would have been possible without that oversight. 
The state's role in confronting and addressing collective action problems can necessitate technological innovation, since many of the collective action problems today persist due to an inadequate understanding of the problem and the lack of wherewithal to solve it. While it would be too far to claim that technology can solve all of these collective action problems, it certainly offers options for more brute-force methods of combatting the issues that threaten individuals. Military technology (when used properly) increases the state's capacity to protect its sovereignty and its citizens from international threats; geoengineering has the potential to combat some of the serious consequences of global climate change; GMOs have the potential to mitigate food security problems; biomedical treatment research can prevent serious medical threats and pandemics; and, indeed, enhancement research has the potential to promote citizens with respect to their life plans and ensure that the unequal distribution of natural assets does not unfairly disadvantage particular citizens. Many see statesponsored scientific research as important, and given the role that it plays in improving the lives of individuals, this sentiment seems correct.

A state that is in a position ${ }^{88}$ to contribute to technological development and expand its capacity to protect, promote and preserve its citizens and yet fails to do so seems worthy of some admonishment. We see the state as having responsibilities to its citizens to provide things like education because of the importance of promoting individuals equally with respect to their opportunities, and failing to take advantage of possible avenues for accomplishing this through the promotion of technological development represents a failure to live up to that mandate. While we may expect citizens to constrain their ambitions to what is possible given the technological capacities of their society, it seems reasonable for them to expect developments with respect to those technological capabilities such that a wider range of options is made available to them.

\footnotetext{
${ }^{88}$ Of course, not all states are in a position to accomplish this on their own, given that in some regions even basic needs are not met. The global community's commitments to contributing to the development of these regions do, however, include improvements to their technological capabilities that may mitigate this disparity.
} 
There is good reason to worry, however, about the extent to which individual demands can burden state resources with respect to technological development and enhancement research. If individuals can reasonably expect the state to contribute positively to technological development, the so-called "expensive tastes" problem reaches beyond distributive justice and becomes an issue for the ethics of research and prioritization. The liberal state has obligations with respect to maintaining a degree of neutrality with respect to the different life paths available, given the possibility of reasonable pluralism here, so as John Basl notes: "the state may not justify a policy decision by appeal to reasons that only some constituent groups of a society would endorse as justification of that policy" (Basl 2010, 43). The central thought here is that there are many reasonable life paths available and the state should not be in the business of constructing policy that favours a particular set of reasonable life paths over others, and the concern regarding expensive tastes is that the expectation of individuals that the state should pursue particular forms of enhancement research would do just that.

The nuances of the social value benchmark described in the previous section can help us here somewhat, as the purely individualistic positional goods expressed in (4) represent precisely the kind of violation of liberal neutrality that we seek to avoid. That being said, the point of (1) especially is to identify enhancement interventions that would be beneficial to all life paths, and the development of enhancements that meet (1) would not represent a failure to meet this neutrality requirement. Furthermore, enhancements that benefit society in general, (2), could very well be seen as beneficial to all individuals, even those who are not enhanced, as a society's prospering should be beneficial to its members, and, as the Rawlsian would contend, perhaps should be beneficial to the worst off in particular. That is to say, enhancements can be developed without violating this neutrality and the state can be justified in pursuing them for the benefit of all its members.

\section{Conclusion}


Much of the discussion concerning biomedical enhancement has focused primarily on the issues surrounding enhancement distribution and the possible consequences that the proliferation of enhancement technologies may eventually have on society. These proliferation-based arguments are surely important, but they are contingent upon the actual development of these new interventions, which is contentious in itself. In Section II.1 I argued that there are salient differences between research and practice in large part due to the role that research plays in expanding the capacities of society, rather than endorsing a particular practice, which indicates that the purely practice-based arguments are something to address separately from an analysis of the ethics of a particular research avenue. The purely proliferation-based arguments such as the risk of social stratification, the "disenhancement" of particular individuals, and the potential for war between the enhanced and unenhanced are not good reason to preclude enhancement research unless their supporters can show either a necessary connection between the research and these proliferation problems or supply substantial evidence of this issue - neither of these requirements have been met, and I think it is rather unlikely that they will be. Instead, research ethics ought to be concerning itself primarily with problems that come from within trials themselves, as well as the relatively few practice-based concerns that "bridge the gap" and can be applied to research as well.

Among the proliferation-based arguments that might plausibly be applied to research ethics, I included a number of arguments from inherent wrongness as well as arguments based on a principle of precaution that seeks to, in part, undermine the gap between research and practice such that practicebased concerns can preclude initial research. Ultimately, however, I concluded that many of the bioconservative critiques from inherent wrongness fail due to problems with their foundation, the shaky relationship between that foundation and the desired conclusion, or some combination of the two. The precautionary approach has problems of its own that should be recognized, and given the potential value of enhancement research, I suggested that a more proactionary approach might be called for. 
When it comes to the research trials themselves, there are a number of concerns related to the imposition of health risks on healthy individuals and the potential for exploitation of the developing world. While these are certainly cause for concern, then, I do not believe them to be insurmountable so long as trial participants are sufficiently compensated and informed, and if the research trial in question has sufficient social value to justify the health risks. The alleged incommensurability of neutrally ascribable health risks and subjective benefits applies primarily to those enhancement interventions that target mere positional goods, but this does not apply to all enhancement research as there are enhancements that are valuable to individuals whatever their chosen life path happens to be. Furthermore, some enhancements will be valuable to society as a whole, and, as such, valuable to its members, and this is not a value that is to be neglected due to the risks involved. Insofar as treatment research is justified due to the positive benefits it confers upon individuals with respect to their opportunity range, some enhancements will be justified through the role they play in the promotion of the opportunities available to individuals within that society. Globalized research is not exempt from this, but it must be recognized that the participants might not benefit personally from the products of the research trial directly, but rather through the compensatory principles established for treatment research in the developed world. Of course, to meet the benchmarks for ethically sound research involving human subjects, the risks involved must be minimized as much as possible, but the substantial social value that enhancement research offers does mean that these research projects are worth pursuing and the effort and costs involved in meeting these benchmarks are called for.

While private entities are pursuing numerous avenues of human enhancement research, these efforts are not going unhindered as bioconservative commentators and some philosophers are resisting such investigations. These arguments are ultimately attempting to hinder research that has substantial social value for individuals as well as society as a whole, as enhancements offer serious advantages 
when it comes to the society's capacity to expand the opportunity range of individuals and to meet different demands of justice and mitigate certain risks that come with the status-quo.

Given the valuable role that enhancements and enhancement research may play in the historical and technological development of society, I do believe that they deserve investigation despite the very real problems that society constantly faces. Of course we should not neglect the problems of poverty, hunger, illness, etc. but we also should not put scientific progress on hold in the hopes of solving only them - we do not expect this of space exploration or investigations in theoretical physics, and we should not expect this of scientific projects involving human enhancement. The explicit recognition of the nuancing of the social value criterion in ethical research would clarify the place that enhancement research occupies in our scientific endeavours and would serve to counteract the current state of affairs in which researchers are incentivized to mischaracterize their research so as to secure funding and regulatory approval. While I doubt this latter possibility can be eliminated entirely, if legitimate justificatory routes can be offered for enhancement research, researchers will least not be forced to choose between being truthful in their aims and finding success in their proposed projects, which is an improvement that should not be underestimated.

I have, then, attempted to present a case for enhancement research for its own sake, rather than appeal to the ancillary benefits that might come from it or the treatment-based obligations that the state has with respect to particular products. These avenues might be viable to a degree, but they are insufficient when one considers resource limitations, the objectives of enhancement researchers and the role that the state might play in the promotion of enhancement research more generally. One would be ill-advised to neglect the risks involved in such, often ambitious, projects, but the human condition has certainly saddled humanity with a host of traits that are disadvantageous given the modern context and wholly undesirable given the ethical standards to which we hold humanity. 
Enhancement research offers the possibility of overcoming the limitations imposed upon humanity by the happenstance of natural evolution and the expansion of justice to aspects of human life that were once inaccessible due to technological limitations. 


\section{Works Cited}

Agar, Nicholas. Humanity's End: Why We Should Reject Radical Enhancement. Cambridge: The MIT Press, 2010.

Alcor Life Extension Foundation. Alcor's Mission Statement. 2014.

http://www.alcor.org/AboutAlcor/mission.htm (accessed April 2014).

Alexander, Brian. "Don't Die, Stay Pretty." Wired. 2004.

http://www.wired.com/wired/archive/8.01/forever_pr.html (accessed March 14, 2014).

Anissimov, Michael. "More Dangers from Nanotechnology." Accelerating Future. June 2004.

http://www.acceleratingfuture.com/michael/works/nanotechdangers.htm (accessed March 15, 2014).

Annas, George, Lori B. Andrews, and Rosario M. Isasi. "Protecting the Endangered Human: Toward an International Treaty Prohibiting Cloning and Inheritable Alterations." American Journal of Law and Medicine, 2002: 151-178.

Appelbaum, Paul S., and Charles W. Lidz. "The Therapeutic Misconception." In The Oxford Textbook of Clinical Research Ethics, by Ezekiel Emanuel and et al., 633-644. New York: Oxford University Press, 2008.

Appelbaum, Paul S., Charles W. Lidz, and Thomas Grisso. "Therapeutic Misconception in Clinical Research: Frequency and Risk Factors." IRB: Ethics and Human Research, 2004: 1-8.

Basl, John. "State Neutrality and the Ethics of Human Enhancement Technologies." AJOB Neuroscience, 2010: 41-48.

Beloin, Valérie. Public Policies Guided by the Precautionary Principle. Institut National de Santé Publique, 2009.

Bennett, Belinda, and George F. Tomossy. Globalization and Health: Challenges for Law and Bioethics. Springer, 2006.

Bostrom, Nick. "A History of Transhumanist Thought." Journal of Evolution and Technology, 2005.

Bostrom, Nick. "Existential Risks: Analyzing Human Extinction Scenarios and Related Hazards." Journal of Evolution and Technology, 2002.

Bostrom, Nick. "Human Genetic Enhancements: A Transhumanist Perspective." Journal of Value Inquiry, 2003: 493-506.

Bostrom, Nick. "In Defense of Posthuman Dignity." Bioethics, 2005: 202-214.

—. "The Transhumanist FAQ." World Transhumanist Association. 2003.

http://www.transhumanism.org/resources/FAQv21.pdf.

Bostrom, Nick, and Anders Sandberg. "Brain Boosters." In Unnatural Selection: The Challenges of Engineering Tomorrow's People, by Peter Healey and Steve Rayner, 130-141. London: Earthscan, 2009.

Bostrom, Nick, and Anders Sandberg. "The Wisdom of Nature: An Evolutionary Heuristic for Human Enhancement." In Human Enhancement, by Julian Savulescu and Nick Bostrom, 375-416. Oxford: Oxford University Press, 2009. 
Brey, Philip A. E. "Anticipatory Ethics for Emerging Technologies." NanoEthics, 2012: 1-13.

Buchanan, Allen, Dan W. Brock, Norman Daniels, and Daniel Winkler. From Chance to Choice: Genetics and Justice. Cambridge: Cambridge University Press, 2000.

Clarke, Steve. "Future technologies, dystopic futures and the precautionary principle." Ethics and Information Technology, 2005: 121-126.

Comstock, G. "Ethics and Genetically Modified Foods." In Food Ethics, by F. Gottwald and et al., 49-66. New York: Springer Science+ Business Media, 2010.

Dabrock, Peter. "Playing God? Synthetic Biology as a Theological and Ethical Challenge." Systems and Synthetic Biology, 2009: 47-54.

Daniels, Norman. "Can Anyone Really be Talking About Ethically Modifying Human Nature?" In Human Enhancement, by Julian Savulescu and Nick Bostrom, 25-42. Oxford: Oxford University Press, 2010.

—. Just Health: Meeting Health Needs Fairly. New York: Cambridge University Press, 2008.

de Grey, Aubrey. "The Undoing of Aging: Can Regenerative Medicine Become the Route to Eternal Youth?" SENS.org. 2013. http://www.sens.org/sites/srf.org/files/tpj_ed.pdf (accessed March 03, 2014).

de Grey, Aubrey, and Michael Rae. Ending Aging: The Rejuvination Breakthroughs That Could Reverse Human Aging in Our Lifetime. New York: St. Martin's Press, 2007.

Dworkin, Ronald. Sovereign Virtue: The Theory and Practice of Equality. Cambridge: Harvard University Press, 2000.

Emanuel, Ezekiel. "Addressing Exploitation: Reasonable Availability versus Fair Benefits." In Exploitation and Developing Countries, by Jennifer Hawkins and Ezekiel J. Emanuel, 286-313. Princeton: Princeton University Press, 2008.

Emanuel, Ezekiel J., Christine Grady, Robert A. Crouch, Reidar K. Lie, Franklin G. Miller, and David Wendler. The Oxford Textbook of Clinical Research Ethics. New York: Oxford University Press, 2008.

Emanuel, Ezekiel, Christine Grady, and Elizabeth Higgs. "Moral Standards for Research in Developing Countries: From Reasonable Availability to Fair Benefits." Hastings Center Report, 2004: 17-27.

Frazer, Jennifer. "Swapping Young Blood for Old Reverses Aging." National Geographic. May 4, 2014.

Fukuyama, Francis. Our Posthuman Future. New York: Farrar, Straus and Giroux, 2002.

Garreau, Joel. "Radical Evolution: An Overview of the Near Future." In Unnatural Selection: The Challenges of Engineering Tomorrow's People, by Peter Healey and Steve Rayner, 11-24. London: Earthscan, 2009.

Gould, Benjamin. "Cognitive Enhancement on Campus: Taking Competition Seriously." The Hastings Center Report Bioethics Forum. 01 21, 2009.

http://www.thehastingscenter.org/Bioethicsforum/Post.aspx?id=3142 (accessed 2 2014, February).

Harris, John. "Enhancements are a Moral Obligation." In Human Enhancement, by Julian Savulescu and Nick Bostrom, 131-154. New York: Oxford University Press, 2009. 
Harris, John, and Soren Holm. "Extending Human Lifespan and the Precautionary Paradox." Journal of Medicine and Philosophy, 2002: 355-368.

Healey, Peter, and Steve Rayner. Unnatural Selection: The Challenges of Engineering Tomorrow's People. London: Earthscan, 2009.

Hinsch, Kathryn. "Bioethics: The New Conservative Crusade." In Progress in Bioethics, by Jonathan D. Moreno and Sam Berger, 67-90. Cambridge: The MIT Press, 2010.

Hughes, J. "How Not to Criticize the Precautionary Principle." Journal of Medicine and Philosophy, 2006: 447-64.

John, S. D. "How to take deontological concerns seriously in risk-cost-benefit analysis: a re-interpretation of the precautionary principle." Journal of Medical Ethics, 2007: 221-224.

Jones, James H. "The Tuskegee Syphilis Experiment." In The Oxford Textbook of Clinical Research Ethics, by Ezekiel Emanuel, Christine Grady, Robert A. Crouch, Lie K. Reidar, Franklin G. Miller and David Wendler, 86-96. New York: Oxford University Press, 2008.

Jonsen, Albert R., and Franklin G. Miller. "Research With Healthy Volunteers." In The Oxford Textbook of Clinical Research Ethics, by Ezekiel J. Emanuel, Christine Grady, Robert A. Crouch, Lie K. Reidar, Franklin G. Miller and David Wendler, 481-487. Oxford: Oxford University Press, 2008.

Jordan, A., and T. O'Riordan. "The Precautionary Principle in Contemporary Environmental Policy and Politics." In Protecting Public Health and the Environment: Implementing the Precautionary Principle, by C. Raffensperger and J. A. Tickner, 15-35. Washington, DC: Island Press, 1999.

Juengst, Eric T. "The Human Genome Project and Bioethics." Kennedy Institute of Ethics Journal, 1992: 71-74.

Kass, Leon. "The Wisdom of Repugnance." New Republic, 1997: 17-26.

Kelly, Kevin. Technology's Epic Story. Amsterdam: Ted.com, November 2009.

King, Nancy M. P., and Larry R. Churchill. "Assessing and Comparing Potential Benefits and Risks of Harm." In The Oxford Textbook of Clinical Research Ethics, by Ezekiel J. Emanuel, Christine Grady, Robert A. Crouch, Lie K. Reidar, Franklin G. Miller and David Wendler, 514-526. Oxford University Press, 2008.

Kurzweil, Ray, interview by Kate Lunau. Google's Ray Kurzweil on the Quest to Live Forever (October 14, 2013).

—. The Singularity is Near. London: Penguin Books, 2006.

Kymlicka, Will. "Liberal Individualism and Liberal Neutrality." Ethics, 1989.

Lavery, James V. "The Obligation to Ensure Access to Beneficial Treatments for Research Participants at the Conclusion of Clinical Trials." In The Oxford Textbook of Clinical Research Ethics, by J. Ezekiel Emanuel, Christine Grady, Robert A. Crouch, Lie K. Reidar, Franklin G. Miller and David Wendler, 697708. New York: Oxford University Press, 2010.

Lev, Ori, Franklin Miller, and Ezekiel Emanuel. "The Ethics of Research on Enhancement Interventions." Kennedy Institute of Ethics Journal, 2010: 101-113. 
Levine, Robert J. "The Nature, Scope, and Justification of Clinical Research: What is Research? Who is a Subject?" In The Oxford Textbook of Clinical Research Ethics, by Ezekiel Emanuel, Christine Grady, Robert A. Crouch, Lie K. Reidar, Franklin G. Miller and David Wendler, 211-221. New York: Oxford University Press, 2008.

Mehlman, Maxwell J., Jessica W. Berg, Eric T. Juengst, and Eric Kodish. "Ethical and Legal Issues in Enhancement Research on Human Subjects." Cambridge Quarterly of Healthcare Ethics, 2011: 30-45.

Milberger, S., et al. "Tobacco manufacturers' defence against plaintiffs' claims of cancer causation: throwing mud at the wall and hoping some of it will stick." Tob Control, 2006: 17-26.

Miller, Franklin G., and Steven Joffe. "Evaluating the Therapeutic Misconception." Kennedy Institute of Ethics Journal, 2006: 353-366.

More, Max. "The Proactionary Principle." The Extropy Institute. July 29, 2005. (accessed April 4, 2013).

O’Mathúna, Dónal P. "Decision-Making and Health Research: Ethics and the 10/90 Gap." Research Practitioner, 2007: 164-172.

Overall, Christine. "Life Enhancement Technologies: The Significance of Social Category Membership." In Human Enhancement, by Julian Savulescu and Nick Bostrom, 327-340. Oxford: Oxford University Press, 2009.

Pearce, David. "The Hedonistic Imperative." 2007.

Peters, Ted. "'Playing God' and Germline Intervention." The Journal of Medicine and Philosophy, 1995: 365-386.

Pogge, Thomas. Medicine for the 99 Percent. Canberra, September 2011.

Pogge, Thomas. "Testing our Drugs on the Poor Abroad." In Exploitation and Developing Countries: The Ethics of Clinical Research, by Jennifer S. Hawkins and Ezekiel Emanuel, 105-141. Princeton: Princeton University Press, 2008.

Robert, Jason Scott, and Francoise Baylis. "Crossing Species Boundaries." The American Journal of Bioethics, 2003: 1-13.

Sandel, Michael J. The Case against Perfection. Cambridge: Harvard University Press, 2007.

Sandel, Michael J. "The Case Against Perfection." Atlantic Monthly, 2004: 51-62.

Savulescu, Julian. "The Human Prejudice and the Moral Status of Enhanced Beings: What Do We Owe the Gods?" In Human Enhancement, by Julian Savulescu and Nick Bostrom, 211-250. Oxford: Oxfored University Press, 2011.

Segall, Shlomi. Health Luck and Justice. Princeton: Princeton University Press, 2010.

Shaw, David. "Cryoethics: Seeking Life after Death." Bioethics, 2009: 515-521.

Somerville, Margaret A. The Ethical Canary: Science, Society and the Human Spirit. McGill-Queen's University Press, 2004. 
The President's Council on Bioethics. Beyond Therapy: Biotechnology and the Pursuit of Happiness. AEI Press, 2003.

Turner, Bryan S. Vulnerability and Human Rights. Pennsylvania State University Press, 2006.

Wiesenthal, David, and Neil I. Wiener. "Privacy and the Human Genome Project." Ethics and Behaviour, 1996: 189-202. 